\title{
IDENTIFICATION OF A NOVEL \\ EXTRACELLULAR ADENOSINE 5'-TRIPHOSPHATE \\ RECEPTOR IN ARABIDOPSIS THALIANA
}

\begin{abstract}
A Dissertation
Presented to

The Faculty of the Graduate School

At the University of Missouri - Columbia

In Partial Fulfillment

Of the Requirements for the Degree

Doctor of Philosophy

\author{
By \\ An Quoc Pham
}

Dr. Gary Stacey, Dissertation Supervisor

December, 2019 
The undersigned, appointed by the Dean of the Graduate School, have examined the Dissertation entitled:

\title{
IDENTIFICATION OF A NOVEL EXTRACELLULAR ADENOSINE 5'-TRIPHOSPHATE RECEPTOR IN ARABIDOPSIS THALIANA
}

\author{
Presented by \\ An Quoc Pham
}

A candidate for the degree of

Doctor of Philosophy

And hereby certify that, in their opinion, it is worthy of acceptance.

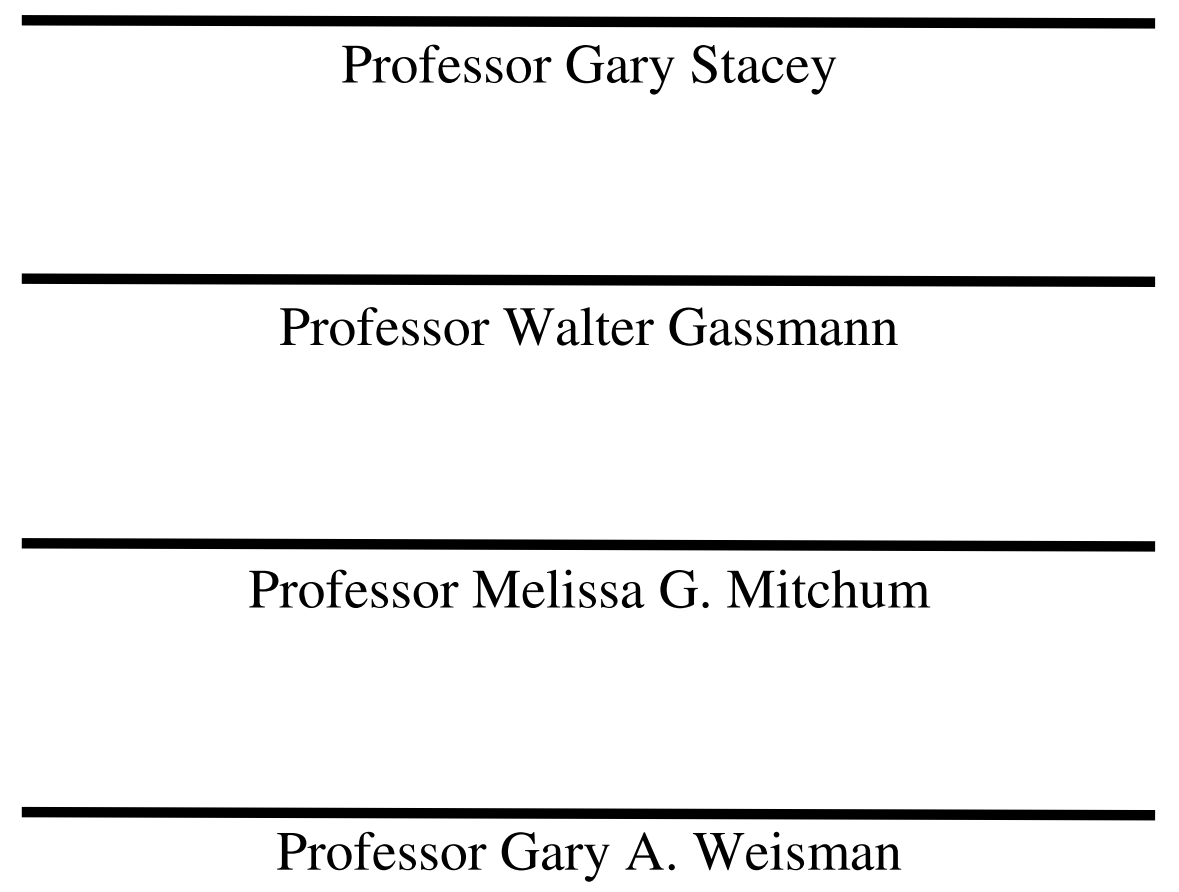

Professor Gary A. Weisman 


\section{ACKNOWLEDGEMENTS}

I would like to thank my advisor, Prof. Gary Stacey, for giving me an excellent opportunity to work in his lab; thank you for your patience, understanding, encouragement, and guidance in research, career, and life. My sincere thanks to my advisory committee members, Prof. Walter Gassmann, Prof. Melissa G. Mitchum and Prof. Gary A. Weisman for their constructive advice and supportive encouragement. I appreciate Dr. Yangrong Cao and Dr. Kiwamu Tanaka, who guided me in the first two years. Also, I warmly thank Dr. Sung-Hwan Cho, Dr. Deawon Kim and Dr. Dongqin Chen for guiding me to complete my thesis. I want to thank Dr. Cuong T. Nguyen, my lab member, who not only contributed to this study but also supported me a lot in my student life. I am grateful to Prof. Bing Stacey, Dr. Phat Do and Dr. Katalin Tóth for their wonderful advice. I also want to thank Cuong X. Nguyen, Nhung T. H. Hoang, Ha N. Duong and other members of the Stacey lab for their joyful, happy and meaningful moments shared with me. I appreciate Dr. Hoang H. Nguyen, who encouraged me to study abroad and supported my career.

Most of all, I would like to thank my family, my parents, Phuong K. T. Doan and Manh V. Pham for their unconditional love, my older brother, Binh T. Pham for his support and my wife, Phuc H. Vo for her endless love.

My work was supported by the Vietnam Education Foundation (VEF), the US National Institutes of Health, and the Systems and Synthetic Agrobiotech Center of Korea. 
Acknowledgment ....................................................................................................................................... ii

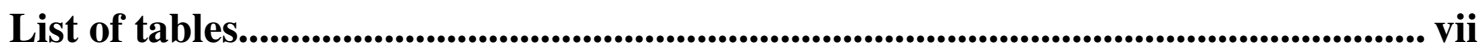

List of figures........................................................................................................ viii

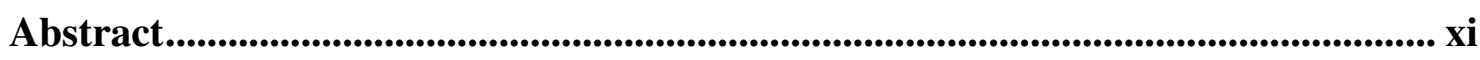

Chapter I: Introduction........................................................................................................1

I.1. ATP, a signaling molecule in plant cells .....................................................3

ATP can be released to the extracellular matrix...............................................5

Homeostatic control of extracellular ATP concentration in plants...........6

eATP can trigger an increase in cytosolic calcium concentration ..............8

I.2. P2K1 (DORN1), the first eATP receptor identified in plants ......................10

Nucleotides are P2K1's ligands......................................................................11

P2K1 can phosphorylate downstream proteins ............................................12

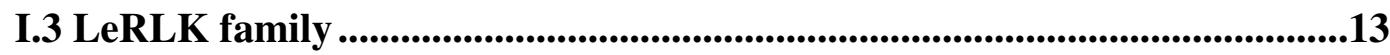

Diversity of LecRLKs in plants ..............................................................................16

LecRLK proteins play essential roles in plant immunity ............................16

LecRLK perception. ..................................................................................19

I.4 The rationale of the thesis............................................................................................20

Chapter II: Material and methods ...........................................................................................24

II.1. Phylogenetic tree analysis ...........................................................................25

II.2. Plant materials ...............................................................................................................26

II.3. Seed sterilization ..........................................................................................................27 
II.4. Molecular complementation and ectopic expression

II.5 Cytoplasmic calcium assay

II.6 Plasmid construction for protein purification.......................................30

II.7 Protein purification.......................................................................................................31

II.8 Arabidopsis protoplast preparation and transformation .........................32

II.9 In vitro ATP binding assay (Performed by Dr. Cho Sung-Hwan) ............33

II.10 Computational analysis of putative 3D protein structure (Performed by

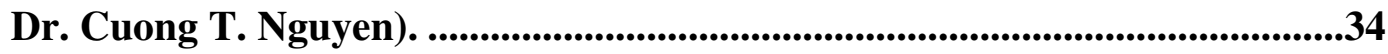

II.11 Identification of putative ATP-binding sites of P2K2 (Performed by Dr.

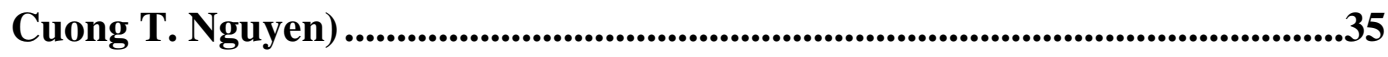

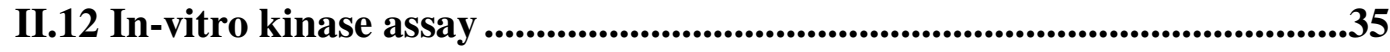

II.13 Detection of promoter-GUS fusion expression................................................36

II.14 Bimolecular fluorescence complementation (BiFC) ....................................36

II.15 Split-luciferase complementation assay ......................................................37

II.16 Coimmunoprecipitation and immunoblot analysis ..............................37

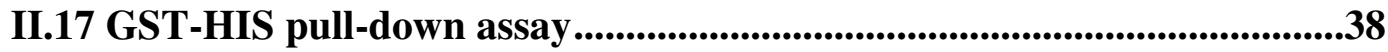

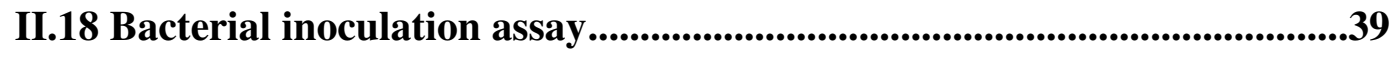

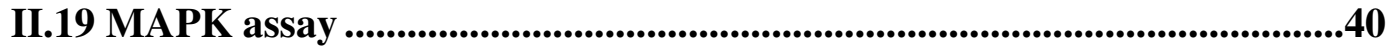

II.20 qRT-PCR assay ..............................................................................40

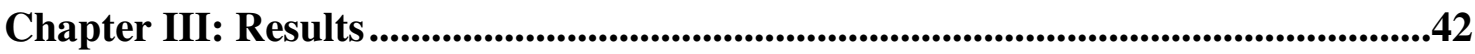

III.1 Screening for the second extracellular ATP receptor in Arabidopsis

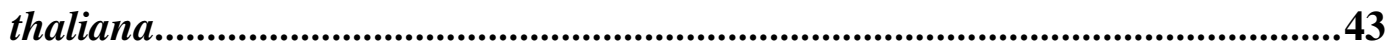

III.1.1 P2K1, DORN1 belongs to group I of the AtLecRLK family ........43 
III.1.2 LecRLK I.5 can partially reverse the p2k1-3 mutant in response to eATP addition. .45

III.1.3 Plants ectopically expressing LecRLK I.5 (P2K2) showed an increased calcium response to nucleotides.....................................................48

III.1.4 Protein domain map of P2K2 ....................................................51

III.2 P2K2 extracellular domain .................................................................52

III.2.1 P2K2 shows high ATP binding affinity (experiment performed Dr. Cho Sung-Hwan) .52

III.2.2 P2K2 specifically binds to ATP and ADP (experiment performed

Dr. Cho Sung-Hwan) .53

III.2.3 Computational analysis of P2K2 structure (experiment performed by Dr. Cuong T. Nguyen) .54

III.2.4 Identification of putative ATP-binding sites (experiment performed by Dr. Cuong T. Nguyen) .56

III.2.5 Mutations at critical binding residues reduce the ATP binding affinity of P2K2 (experiment performed by Dr. Cho Sung-Hwan)........61

III.3 P2K2 intracellular domain.................................................................63

III.3.1 The intracellular domain of $\mathrm{P} 2 \mathrm{~K} 2$ is an active kinase .63 III.3.2 p $2 k 2$ intracellular domain mutations disrupt kinase activity. ....65 III.3.3 Mutations in the kinase domain abolish kinase activity leading to the loss of $\mathrm{P} 2 \mathrm{~K} 2$ receptor function .68

III.4 P2K2 localizes to the plasma membrane ...............................................70

III.5 P2K2 directly interacts with P2K1 in the plasma membrane ..................72 
III.5.1 P2K2 interacts with P2K1 and itself in the plasma membrane in the BiFC assay .72

III.5.2 P2K2 directly interacts with P2K1 in an in vitro pull-down assay .74

III.5.3 ATP enhances P2K1-P2K2 interaction ..........................................76

III.5.4 P2K1 can phosphorylate P2K2 but not vice versa ........................78 III.6 P2K2 plays an essential role in eATP-triggered plant defense signaling .81

III.6.1 P2K2 plays a role in plant resistance to Pseudomonas syringae DC3000 infection .81

III.6.2 2 2k2 T-DNA mutant plants failed to induce downstream defense signaling in response to ATP........................................................................84

Chapter IV: Discussion........................................................................................................91

P2K2's eATP perception .....................................................................................93

Other extracellular ATP receptors in the LecRLK family ............................95

P2K2 may function as a co-receptor of P2K1. ..............................................97

Roles of P2K2 in eATP-triggered plant defense................................................101

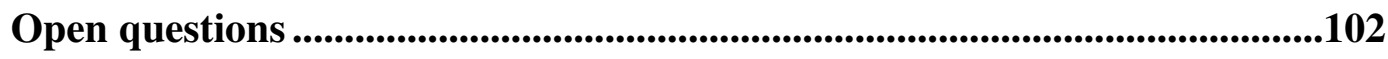

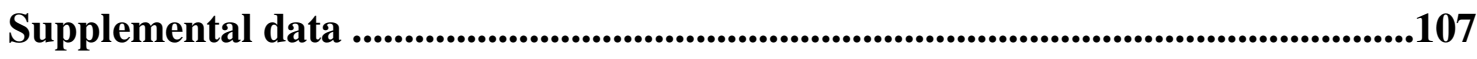

BIBLIOGRAPHY .................................................................................................110

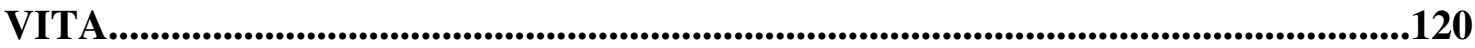




\section{LIST OF TABLES}

Table I.1 Known related biological functions of LecRLK members.

Table II.1 Primers used for T-DNA homozygosity confirmation. .26

Table II.2 Primers for full-length $A t$ LecRLK clade I member cloning. ....................28

Table II.3 Primers for P2K2 kinase domain and extracellular domain cloning. ...31

Table II.4. Primers for qRT-PCR.

Table III.1: List of predicted P2K2 interacting residues with ATP ligand obtained from different prediction tools. .57

Table III.2. List of P2K2 interacting residues with the ATP ligand obtained from target docking. . .60

Table IV.1: LecRLK members, not belong to clade I that have a conserved $H 99$ and a predicted active kinase domain.

Table IV.2: Candidate proteins predicted to interact with P2K2. 100 


\section{LIST OF FIGURES}

Figure I.1 Phylogenetic tree of $A t$ LecRLK family. .15

Figure I.2 Overview of ATP release, recognition, signal transduction and homeostatic control.

Figure III.1: Relative gene expression levels of clade I LecRLK members in comparison to P2K1 (LecRLK I.9).

Figure III.2: Ectopic expression of P2K2 (p35S:LecRLK-I.5) in p2k1-3 mutant plants confers partial complementation of the ATP-triggered cytosolic calcium response

phenotype. .46

Figure III.3: The kinetics of the calcium responses of $p 35 S: P 2 K 2 / p 2 k 1-3$. .47

Figure III.4: eATP-triggered calcium response of $p 2 k 2$ T-DNA mutant and two independent $P 2 K 2$ overexpression lines.

Figure III.5: The kinetics of the calcium responses of $p 35 S: P 2 K 2 /$ wild-type and p2k2.

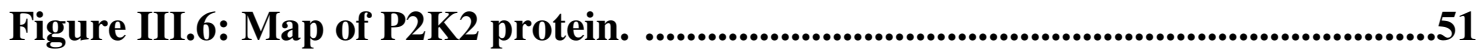

Figure III.7: ATP-P2K2 in vitro binding assay. . ..........................................................52

Figure III.8: Competitive binding assay for P2K2 . . ..........................................53

Figure III.9: P2K2 extracellular domain 3D structure. .........................................55

Figure III.10: ATP-P2K2 free docking. .........................................................................58

Figure III.11: Putative ATP-binding site of P2K2 in target docking. ......................59

Figure III.12: In vitro binding assay of ATP binding to P2K2 wild-type and mutant versions. 
Figure III.13: Kinase activities of the P2K2 kinase domain. .64

Figure III.14: Kinase activity of mutation versions of P2K2. .66

Figure III.15: P2K2 kinase domains, wild-type and mutant versions, were treated with Lambda protein phosphatase (PPase). .67

Figure III.16: Ectopic expression of kinase-dead mutant P2K2 in p2k1-3 mutant line failed to complement the eATP-triggered cytosolic calcium response phenotype..69 Figure III.17: Subcellular localization of P2K2 fused to YFP in Arabidopsis protoplasts. .71

Figure III.18: P2K2 localized to the plasma membrane in the root. . .71

Figure III.19: P2K2 can form homomer and heteromer complexes with P2K1 in the protoplast plasma membrane. .73

Figure III.20: P2K2 can directly interact with P2K1 in vitro. 75

Figure III.21: Luciferase complementation imaging assay showing that ATP can enhance P2K2-P2K1 interactions in tobacco leaves. .77

Figure III.22: P2K1 and P2K2 can phosphorylate a kinase dead version of P2K2. .79

Figure III.23: P2K1 and P2K2 cannot trans-phosphorylate P2K1. .80

Figure III.24: Susceptibility of various Arabidopsis lines to flood-inoculation with Pseudomonas syringae DC3000 LUX. . .83

Figure III.25: $P 2 K 2$ promoter activity in roots. .87

Figure III.26: Expression of $P 2 K 1$ and $P 2 K 2$ in mutant lines. .86

Figure III.27: MAPK signaling is impaired in $p 2 k 2$ single and $p 2 k 1 p 2 k 2$ double mutants upon ATP treatment. .88 
Figure III.28: qRT-PCR expression analysis of $P 2 K 2, M Y C 2$ and $Z A T 10$ after treatment with ATP $200 \mu M$.

Figure III.29: Co-immunoprecipitation assay of P2K2 with P2K1, FLS2 and

CERK1.

Figure IV.1: Multiple sequence alignment of the P2K2 and P2K1 extracellular domain comparing to four crystalized lectin proteins.

Figure IV.1: Model of P2K2 function, as a potential co-receptor of P2K1, in eATP perception, triggering a plant defense response.

Supplemental Figure S1: Gus staining assay showed $P 2 K 2$ promoter activity in

whole plants.

Supplemental Figure S2: P2K2 promoter activity in pollen. 108

Supplemental Figure S3: Susceptibility of $p 2 k 1-3, p 2 k 2$ and $p 2 k 1 p 2 k 2$ to $P$. syringae in bacterial leaf infitration assay. 109 


\begin{abstract}
In animals, extracellular adenosine 5'-triphosphate (eATP) is a well-studied signaling molecule that is recognized by plasma membrane-localized, P2-type purinergic receptors. In contrast to animals, much less is known about purinergic signaling in plants. In 2014, our laboratory identified the first plant purinoreceptor, P2K1 (DORN1), which is a member of the L-type lectin receptor-like kinase (LecRLK) family. P2K1 is comprised of an extracellular lectin domain, a transmembrane domain and an intracellular kinase domain. In order to identify other plant purinoreceptors, we tested a number of LecRK genes for their ability to complement the inability of $p 2 k 1$ mutants to induce an elevation in the intracellular calcium concentration upon ATP addition. One such gene, termed $P 2 K 2$, was found to partially complement the ATP-induced cytosolic calcium response of the $p 2 k 1$ mutant. Subsequently, we found that the extracellular lectin domain of P2K2 binds to ATP with high affinity $\left(\mathrm{K}_{\mathrm{d}}=40.2 \pm 4.5\right.$ nanomolar). Interestingly, $p 2 k 1, p 2 k 2$, and $p 2 k 1 p 2 k 2$ mutant lines are more susceptible to Pseudomonas syringae compared to wild-type. P2K1 and P2K2 interact other and cross-phosphorylate each other during eATP treatment. These data suggest that $\mathrm{P} 2 \mathrm{~K} 2$ is the second purinergic receptor found in plants and plays an important role in plant immunity.
\end{abstract}




\title{
Chapter I:
}

\author{
Introduction
}


Following on Darwin's theory of evolution, living organisms on earth originated from the last universal common ancestor (Theobald, 2010). During evolution, plants and animals have maintained similar biological processes. For example, both plant and animal cells are regulated by intracellular and extracellular signals, including hormones, elicitors, or molecular patterns. These signals are recognized by plant and animal proteins called receptors. After signals or ligands bind to their receptors, second messengers are produced for signal amplification. Commonly in both animal and plant cells, second messengers including cytosolic calcium $\left(\mathrm{Ca}^{2+}{ }_{\text {cyt }}\right)$, nitric oxide (NO), reactive oxygen species (ROS) and cyclic nucleotides (Tanaka et al., 2010). Due to their crucial shared signaling characteristics, essential signaling molecules found in animal cells also play essential roles in plant cells. For example, glutamate is well-known as a neurotransmitter in animals. The first ionotropic glutamate receptor was cloned in 1989 (Hollmann et al., 1989; Hollmann and Heinemann, 1994). Interestingly, glutamate also can trigger cytosolic calcium increase in Arabidopsis (Dennison and Spalding, 2000). In 2001, A glutamate receptor family in plants was identified (Lacombe et al., 2001), and now, they are called glutamate receptor-like channels (GLRs) (Forde and Roberts, 2014).

In this chapter, I will tell a story about another well-known animal signaling molecule that is becoming more recognized for its importance in plant physiology and development; that is extracellular adenosine 5'-triphosphate (eATP). I will provide an explanation of why we now generally accept that ATP is a signaling molecule in plant cells similar to animal cells. Next, I will discuss the first eATP receptor identified in plants. We also provide an overview of the LecRLK family, in which the first plant eATP receptor belongs. Finally, I will explain the rationale for this project. 


\section{I.1. ATP, a signaling molecule in plant cells}

ATP, discovered in 1929, is well-known as the source of cellular energy for all organisms. This molecule is composed of three components, including a ribose, adenine base and three phosphates. With high energy stored in phosphate bonds, intracellular ATP (iATP) provides energy for many anabolic and catabolic cellular processes. For over 30 years, no one considered that ATP could serve as an extracellular signaling molecule. However, in 1962, Burnstock found that ATP could be responsible for signaling between motor nerves and muscle. However, it took ten years for Burnstock to confidently publish his findings that extracellular ATP plays an essential role as a neurotransmitter (Burnstock, 1972; Khakh and Burnstock, 2009).

Interestingly, under normal conditions, cells maintain a high concentration of intracellular ATP ( $\sim \mathrm{mM}$ level) but a very low extracellular concentration $(\sim \mathrm{nM}$ level$)$. Upon the appropriate stimulus, ATP is released from the cytosol into the extracellular matrix and regulate growth (Di Virgilio and Adinolfi, 2017), development (Burnstock and Dale, 2015) and stress responses (Eltzschig et al., 2012; Tanaka et al., 2014). Given that eATP is acting as a signaling molecule from outside the cell, it was logical to postulate that plasma membrane receptors existed to bind and be activated by eATP.

In animals, $\mathrm{P} 2 \mathrm{X}$ and $\mathrm{P} 2 \mathrm{Y}$ receptors have been well characterized as plasma membrane purinoreceptors that bind eATP, as well as other nucleotides to trigger various downstream signaling cascades (Burnstock, 2018). The binding of eATP to P2X receptors (P2XRs) activates ATP-gated ion channels that are permeable to calcium, sodium and potassium (Bjorkgren and Lishko, 2016), whereas the activation of P2Y 
receptors (P2YRs) recruits heterotrimeric G proteins that regulate secondary intracellular signaling molecules (i.e., Inositol phosphate, cytosolic calcium and cyclic AMP) (Erb and Weisman, 2012). The activation of P2XRs and P2YRs explains the critical roles of eATP in various biological animal processes such as inflammation, neurotransmission, cell proliferation, cell differentiation and cell death (Burnstock and Verkhratsky, 2010; Eltzschig et al., 2013).

In plants, the first evidence of extracellular ATP acting as a signaling molecule was from the study of Jaffe 1973 in which exogenous ATP increased the closure of Venus flytraps. However, the authors did not suggest ATP was acting as a signaling molecule. Instead, they reasoned that ATP was providing energy for the flytrap's midrib contraction or perhaps by elevating the cytoplasmic ATP concentration (Jaffe, 1973). Also, in 1973, Udvardy and Farkas found that ATP strongly stimulated the formation of nucleases (Udvardy and Farkas, 1973). In the following year, eATP was shown to activate ion uptake into leaf cells (Luttge et al., 1974). However, these authors also thought that the eATP was serving as an energy source for this process. In 2000, extracellular ATP and ADP were shown to cause membrane depolarization of growing Arabidopsis root hairs. In these experiments, nucleotide hydrolysis and phosphate uptake were excluded from the mechanism of action (Lew and Dearnaley, 2000). ATP $\gamma \mathrm{S}$, a poorly-hydrolyzable ATP analogue, was used to show that ATP and not a hydrolytic product served as the signaling molecule that regulates pollen germination and pollen tube growth in Arabidopsis (Reichler et al., 2009). In general, it is now widely accepted that eATP acts as a signaling molecule in plants. However, the underlying molecular mechanisms for eATP action in plants remain largely unknown. 


\section{ATP can be released to the extracellular matrix}

As mentioned above, cells maintain a high level of iATP for energy and intracellular signaling but a much lower level of eATP $\left(\sim 1 \times 10^{6}\right.$ times lower $)$ under normal conditions. However, the majority of published work has used a high concentration of external ATP for their experiments ( $\mu \mathrm{M}$ to $\mathrm{mM})$. Animal cells are known to release ATP via vesicular fusion with the plasma membrane (e.g., at the nerve synapse) or as a consequence of wounding (Fitz, 2007; Khakh and Burnstock, 2009). There is some support for all three mechanisms in plants.

Using luciferase as an ATP sensor, it was shown that 25-45 $\mu \mathrm{M}$ ATP was released after leaf wounding (Song et al., 2006). Although wounding is an extreme case of stress, a variety of other biotic and abiotic stresses were shown to cause the release of ATP. For example, treatment of plants with yeast extract increases eATP concentration up to 70 times while touching increases it 3.5 fold (Jeter et al., 2004; Wu et al., 2008). Slight touching of Arabidopsis roots was shown to induce the release of nM ATP (Weerasinghe et al., 2009). Release of eATP was visualized in the roots of Medicago truncatula at sites of cellular expansion, consistent with ATP release via vesicular fusion (Kim et al., 2006). However, the vesicular nucleotide transporter (VNUT), like SLC17A9 in animals, has not been identified in plants (Sawada et al., 2008). Although plants also express the anion transporter 1 (ANTR1), a homolog of animal SLC17, it functions as an inorganic phosphate transporter (Ruiz-Pavon et al., 2010; Reimer, 2013). Evidence for direct transport of ATP in plants comes from studies of transporters, such as the MDRI homolog PGP1, a member of the ATP binding cassette superfamily (Thomas et al., 2000) or PM-ANT1, a member of the mitochondrial carrier family (MCF) that localizes to the 
plasma membrane (Rieder and Neuhaus, 2011). In short, more information is needed to understand the mechanism of ATP export in plants, but in general, it is accepted that ATP can be released in to the extracellular matrix by cells under certain circumstances and may function as a signaling molecule in plant cells.

\section{Homeostatic control of extracellular ATP concentration in plants}

If eATP is an important signaling molecule that can stimulate various plant cell responses, then one would expect that plant cells should have mechanisms to control the eATP concentration. These mechanisms could explain how plant cells maintain low eATP concentrations as well as switch cell status from stress conditions to normal conditions after danger signals are gone. Apyrase (APY) proteins were shown to be important in homostatic control of eATP. From 1999, APYs were proposed to be enzymes that hydrolyze eATP at both the $\gamma$ - and $\beta$-phosphate positions (Thomas et al., 1999). During that period, the function of APYs was interpreted within the context of eATP hydrolysis releasing inorganic phosphate $\left(\mathrm{P}_{\mathrm{i}}\right)$. However, using pollen as a model, Steinebrunner et al. showed that: (1) the apylapy2 double mutant in Arabidopsis had reduced pollen germination; (2) addition of high concentrations of ATP inhibited pollen germination; and (3) additional of phosphate did not induce germination in apylapy2 mutant pollen (Steinebrunner et al., 2003). These data were interpreted to indicate that APY1 and APY2 function to maintain a low level of eATP during pollen germination, without the need to provide $\mathrm{P}_{\mathrm{i}}$ via ATP hydrolysis. A puzzling aspect of these studies of both AtAPY1 and AtAPY2 is that these apyrases were primarily localized to Golgi complex, a location inconsistent with a role in eATP homeostasis at the plasma membrane (Chiu et al., 2012). An explanation for this contradictory finding has not been 
provided. It is possible that, although primarily found in the Golgi, some APY1 and APY2 proteins find their way to the plasma membrane to play a role in purinergic signaling. However, it is also possible that yet undiscovered mechanisms maintain a low level of eATP in plants.

Another protein that can hydrolyzes eATP in plants is purple acid phosphatase (PAP). In common bean, PvPAP3 localized to the plasma membrane was found to hydrolyze eATP (Liang et al., 2010). However, like the earlier conclusions related to APY function, the authors proposed that PAP hydrolyzed eATP primarily to provide $\mathrm{P}_{\mathrm{i}}$ for root hair development. In the same year, Clark et al. (2010) also published evidence that eATP can regulate root hair development (Clark et al., 2010). This could be similar to the case of APYs by which PAPs could play critical roles in eATP homeostatic control.

The product of eATP hydrolysis by APYs and PAPs, eAMP, can be further hydrolyzed by ecto-5'-nucleotidases. Although the enzymes that carry out this reaction have not been identified in plants, Riewe et al. (2008) showed that cell wall-bound proteins generate adenosine and adenine from eAMP (Riewe et al., 2008). Several plant nucleoside hydrolase (NSH) proteins have been identified. While NSH1 and NSH2 work as intracellular nucleoside hydrolases, NSH3 plays a similar function in the apoplast. NSH4 and NSH5 have not been assigned specific functions beyond their catalytic capability (Jung et al., 2009; Jung et al., 2011).

After hydrolysis of AMP, adenosine and adenine are transported into plant cells. Equilibrative nucleoside transporter 3 (ENT3) is a pyrimidine nucleoside 
transporter that mediates adenosine uptake (Traub et al., 2007). Adenine was proposed to be transported into the plant cells along an $\mathrm{H}^{+}$gradient by purine permease (PUP) proteins (Gillissen et al., 2000; Burkle et al., 2003). P1 receptors for adenosine in animal have not been described in plants suggesting that the adenosine generated from eATP degradation is to be intracellularly recycled. However, Ries et al. (1993) has demonstrated that addition of exogenous adenosine triggers increase of calcium, magnesium and potassium in plants (Ries et al., 1993).

\section{eATP can trigger an increase in cytosolic calcium concentration}

As a signaling molecule, eATP is expected to trigger the production of intracellular secondary messengers. In animals, eATP binds to P2 receptors leading to an increase in

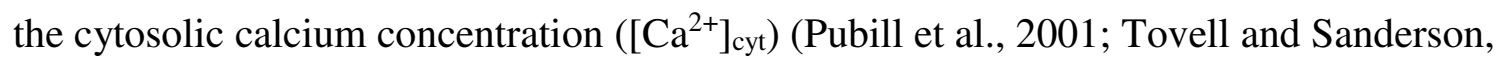
2008). In plants, many earlier studies show that eATP increases $\left[\mathrm{Ca}^{2+}\right]_{\text {cyt }}$ under a variety of biotic and abiotic stresses (Demidchik et al., 2003; Jeter et al., 2004; Demidchik et al., 2009; Tanaka et al., 2010; Tanaka et al., 2010). An increase in $\left[\mathrm{Ca}^{2+}\right]_{\text {cyt }}$ was proposed to lead to an elevation in the levels of reactive oxygen species (ROS) and nitric oxide (NO) (Wu et al., 2008; Wu and Wu, 2008; Monshausen et al., 2009; Tanaka et al., 2010).

Therefore, $\left[\mathrm{Ca}^{2+}\right]_{\mathrm{cyt}}$ seems to be an secondary messenger that activate the intracellular signaling cascades in plants to response to eATP.

In resting plant cells, the $\left[\mathrm{Ca}^{2+}\right]_{\text {cyt }}$ is usually low, around $100 \mathrm{nM}$, while the apoplastic calcium concentration can reach $1 \mathrm{mM}$ and vacuoles can contain up to $80 \mathrm{mM}$ calcium (Stael et al., 2012). In plants, ion channels mediating calcium influx can be classified as voltage-dependent, ligand-dependent and stretch-activated $\mathrm{Ca}^{2+}$ channels 
(Kudla et al., 2010). In plants, much evidence supports the existence of voltagedependent calcium channels (VDCCs) (Pei et al., 2000; Klusener et al., 2002). However, the specific VDCC that mediates calcium influx in response to stress is largely unknown, likely due to functional redundancy among the various transporters (Kudla et al., 2010; Swarbreck et al., 2013). Only the two-pore channel 1 (TPC1), localized to the tonoplast, was identified as a VDCC (Peiter et al., 2005). The ligand-dependent calcium channels (LDCCs) found in plants are cyclic nucleotide-gated channels (CNGCs) and glutamatelike receptors (GLRs) (Dietrich et al., 2010; Michard et al., 2011) A number of CNGCs have been implicated in the response of plants to a variety of stresses, but none have been directly associated with purinergic signaling. Stretch-activated calcium channels (SACCs) were proposed to be MscS-like (MSL; or mechanosensitive channel of small conductance like) and Midl-complementing activity (MCA) proteins. MSL proteins were proposed on the basis of similarity to bacterial mechanosensitive channels (Veley et al., 2012). However, plant MSL channels seem to prefer anions and may not be calcium channels (Maksaev and Haswell, 2012). On the other hand, MCA1 and MCA2 proteins localize to the plasma membrane and can mediate calcium uptake (Mori et al., 2018).

Although calcium is a significant cytosolic secondary messenger in plant cells, at present, the specific mechanism by which eATP increases $\left[\mathrm{Ca}^{2+}\right]_{\text {cyt }}$ remains unknown. Also, there has been little research to investigate how the elevation in $\left[\mathrm{Ca}^{2+}\right]$ cyt induced by eATP modulates signaling in plants. 


\section{I.2. P2K1 (DORN1), the first eATP receptor identified in plants}

P2 receptors appeared quite early in evolution. For example, P2XRs were found in Ostreococcus tauri and Dictyostelium discoideum (Fountain et al., 2007; Fountain et al., 2008). However, no homolog of an animal P2 receptor has been identified in plants. Interestingly, similar to animals, plant cells respond to eATP or other nucleotides with an increase of $\left[\mathrm{Ca}^{2+}\right]_{\text {cyt }}$ as well as NO and ROS levels (Reichler et al., 2009; Tanaka et al., 2010). These data suggest that plants might have eATP receptors that are divergent from those in animals. Choi et al. (2014) screened for Arabidopsis mutant plants that did not respond to eATP as measured by changes in $\left[\mathrm{Ca}^{2+}\right]_{\text {cyt }}$. The screening discovered the first eATP receptor in plants, named DORN1 (DOes not Respond to Nucleotides 1) (Choi et al., 2014), subsequently renamed P2K1. Currently, the P2K1 nomenclature is favored, since it is more consistent with the $\mathrm{P} 2 \mathrm{X} / \mathrm{P} 2 \mathrm{Y}$ nomenclature used in animals and the ' $\mathrm{K}$ ' designation identifies $\mathrm{P} 2 \mathrm{~K}$ receptors as kinases.

The P2K1 (DORN1) protein contains: (1) an ectodomain that can bind various nucleotides but prefers ATP; (2) a transmembrane domain that enables P2K1 to localize to the plasma membrane and (3) an intracellular domain that has an active kinase. The identification of this receptor opened new opportunities to examine the crucial roles of eATP in many biological plant processes, such as root growth (Tang et al., 2003; Weerasinghe et al., 2009; Clark et al., 2010), stress responses (Thomas et al., 2000; Song et al., 2006) or pollen germination (Reichler et al., 2009; Rieder and Neuhaus, 2011). Also, P2K1, being different from animal P2 receptors, defines a new class of purinoreceptor (Choi, Tanaka et al. 2014) and changes our thinking about how eATP signals triggers intracellular signaling in plant cells. 


\section{Nucleotides are P2K1's ligands}

Although being named as DORN1 based on the mutant phenotype or P2K1 as a purinoreceptor, the first eATP receptor in plants had previously been identified as LecRLK I.9, a member of legume type lectin receptor-like kinase (LecRLK) family (Choi et al., 2014). With an extracellular lectin-binding domain, P2K1 has a putative carbohydrate-binding site. However, work in our lab, as well as by an other group (Gouget et al., 2006) failed to find that P2K1 binds sugars. Also, specific amino acid changes in the sugar-binding domain of $\mathrm{P} 2 \mathrm{~K} 1$ make it unlikely the protein binds carbohydrates. Instead, Choi et al. (2014) demonstrated that P2K1 binds ATP with a very high affinity $(45.7 \pm 3.1 \mathrm{nM})$. Besides ATP, in vitro competition binding assays showed that with varying affinities, other nucleotides bind to P2K1 and inhibit ATP binding. In

order of affinity ADP > ITP > GTP > UTP were shown to inhibit ATP binding. In planta, experiments showed that $p 2 k 1$ mutant plants have a lower response to nucleotide addition while maintaining the ability to respond to a wide variety of other elicitors, such as flg22, chitin, elf26, pep1, $\mathrm{NaCl}, \mathrm{D}$-glucose and mannitol. The results suggest that $\mathrm{P} 2 \mathrm{~K} 1 \mathrm{can}$ specifically recognize nucleotides and acts as a specific purinergic receptor.

Li et al. (2016) tried to crystallize the extracellular domain of a P2K1 ortholog from Camelina sativa. However, the crystallization conditions were not optimized (Li et al., 2016). Unpublished data derived through collaboration with Dr. Jijie Chai (Max Planck Institude for Plant Breeding Research in Cologne) succeeded in elucidating the crystal structure of P2K1 with ADP bound. These data showed that the P2K1 crystal represents a homodimer with the ADP binding site localized at the protein interface. Concurrent with our efforts to deduce the P2K1 crystal structure, Nguyen et al. (2016) 
used a computational approach to predict the $\mathrm{P} 2 \mathrm{~K} 1$ ectodomain structure and the ATP binding site. Based on previous leguminous protein crystal structures, a 3D computational model of $\mathrm{P} 2 \mathrm{~K} 1$ was constructed. The putative 3D structure of $\mathrm{P} 2 \mathrm{~K} 1$ contains $13 \beta$-strands and five loops (loop A, B, C, D and extended loop). This model was largely consistent with the X-ray crystal structure elucidated in the Chai laboratory.

Subsequently, Nguyen et al. (2016) used their computational model of P2K1 to predict the ATP-binding domain. In vitro binding assays supported these predictions by showing that mutations in loop B or loop C significantly reduced ATP binding. Using a targeted docking method, Nguyen et al. (2016) also identified 11 putative ATP-binding residues, but none of them have been individually confirmed (Nguyen et al., 2016).

\section{P2K1 can phosphorylate downstream proteins}

$\mathrm{P} 2 \mathrm{~K} 1$ is an active kinase that can autophosphorylate as well as trans-

phosphorylate downstream proteins (Choi et al., 2014; Chen et al., 2017). Interestingly, P2K1 can directly interact and phosphorylate a NADPH oxidase, the respiration burst oxidase homolog protein D (RBOHD), a key enzyme in ROS production (Chen et al., 2017). The RBOHD was reported to be phosphorylated and activated by calcium-

dependent kinase 5 (CPK5) (Dubiella et al., 2013) demonstrating that ROS production is also responsive to increase in $\left[\mathrm{Ca}^{2+}\right]_{\text {cyt. }}$ Other work demonstrated that BIK1, a cytoplasmic kinase that is activated upon elicitor treatment, also phosphorylates and activates RBOHD (Kadota et al., 2014). However, Chen et al. (2017) showed that P2K1 phosphorylates RBOHD at specific residue, S22, which is not a target of either CPK5 or BIK1. Activation of RBOHD via P2K1 phosphorylation explains how the addition of 
ATP can regulate stomatal aperture in leaves, which is known to respond to elevated ROS levels (Chen et al., 2017). Besides RBOHD, Chen et al. (2017) also mentioned but did not identify 22 additional proteins that are potential targets of $\mathrm{P} 2 \mathrm{~K} 1$ phosphorylation. This suggests the potential for $\mathrm{P} 2 \mathrm{~K} 1$ to regulate a variety of downstream plant processes via transphosphorylation.

As mentioned above, a key unanswered question is how eATP triggers an increase in $\left[\mathrm{Ca}^{2+}\right]_{\text {cyt. }}$ Using patch-clamp methods, Wang et al. (2018) showed that $p 2 k 1-1$ mutant plant cells with a point mutation in the $\mathrm{P} 2 \mathrm{~K} 1$ kinase catalytic site, failed to trigger plasma membrane potassium and calcium conductance in the root plasma membrane (Wang et al., 2018). Thus, the data are consistent with the conclusion that the kinase activity of P2K1, either directly or indirectly, activates channels that modulate $\left[\mathrm{Ca}^{2+}\right]_{\text {cyt. }}$.

In animal, eATP , via P2 receptors, activates MAPK (Loomis et al., 2003; Chang et al., 2008). Choi et al. (2014) also demonstrated that the kinase activity of P2K1 is required for eATP-induced activation of the mitogen-activated protein kinase (MAPK) cascade (Choi et al., 2014). However, the specific phosphorylation targets of P2K1 that mediate these events have yet to be identified.

\section{I.3. LecRLK family}

Receptor-like kinases (RLKs) comprise a protein superfamily with more than 600 genes in the Arabidopsis genome (Shiu and Bleecker, 2003). Relative to animals, during evolution, there has been a large expansion of receptor gene families, which is attributed to the need for rooted plants to respond in place to changing environmental conditions and challenges. Lectin RLK proteins, with an extracellular lectin-like domain, were 
subdivided into three types: G, C and L (Bouwmeester and Govers, 2009). P2K1 belongs to the L-type lectin RLK (LecRLK) subfamily. LecRLKs are present in plants but absent in animal genomes. In Arabidopsis thaliana, the LecRLK family contains 45 members. 38 divided into nine subclades, while seven singleton members do not belong to any clade (Bouwmeester and Govers, 2009) (Figure I.1). In most cases, the function of individual plant LecRLKs is unknown. 


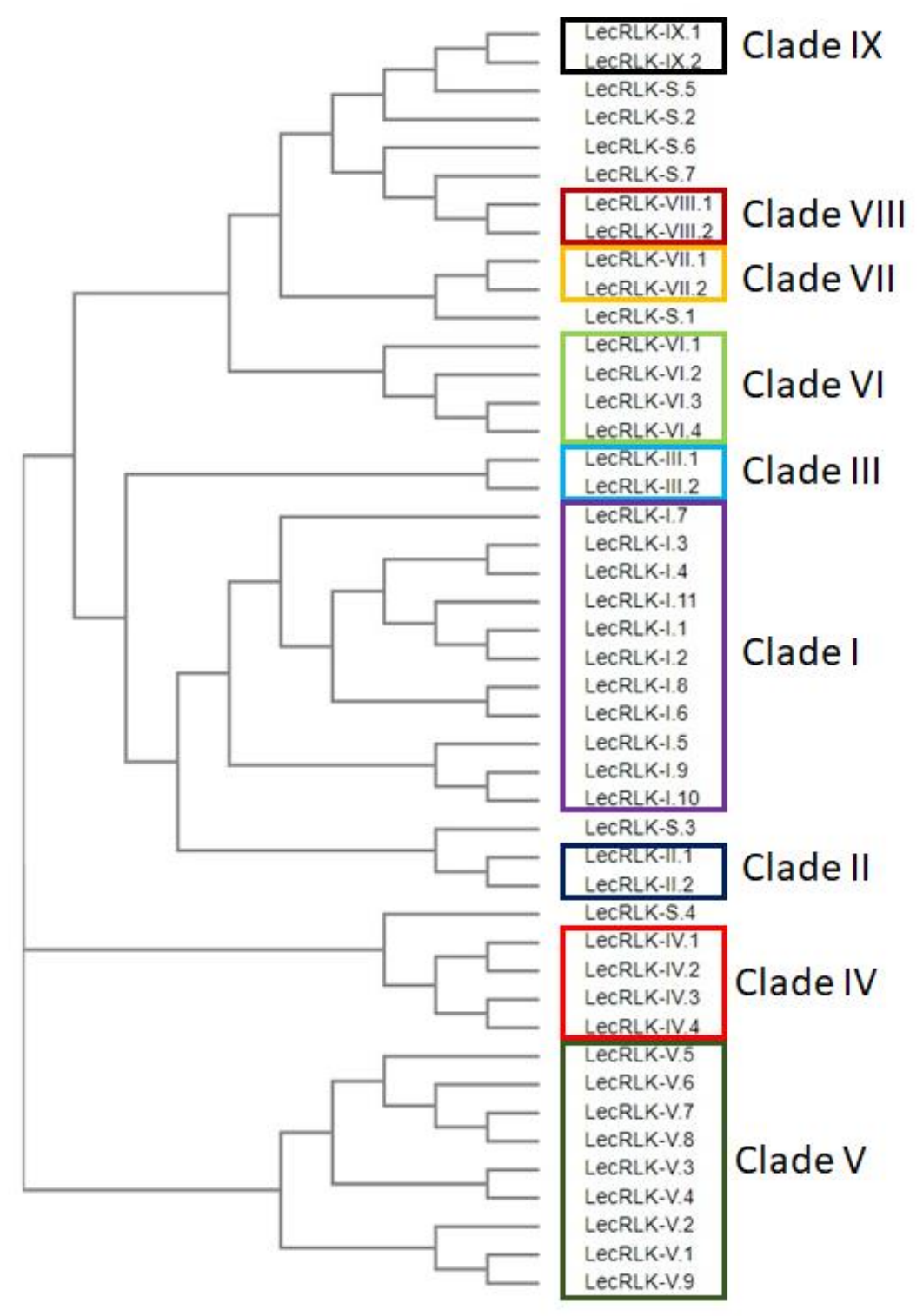

Figure I.1 Phylogenetic tree of AtLecRLK family. The full-length amino acid sequences of 45 AtLecRLKs were collected from the TAIR database (www.arabidopsis.org). The multiple sequence alignment was generated and used to build a phylogenetic tree by Clustal OMEGA (www.ebi.ac.uk/Tools/msa/clustalo/). The cladogram is a neighbor-joining tree without distance corrections. Colored boxes indicate nine LecRLK clades (Bouwmeester and Govers, 2009). 


\section{Diversity of LecRLKs in plants}

Different plant species contain multiple subclades of LecRLKs. For example, Arabidopsis thaliana has nine subclades, while Cucumis sativus has only six subclades. Solanum lycopersicum has nine subclades, but only five are similar to Arabidopsis thaliana. In monocots, Oryza sativa has only five subclades, but one has 36 members, while the largest subclade of Arabidopsis thaliana has only 11 members (Wang and Bouwmeester, 2017).

The diversity of the LecRLK family in plants was proposed to be the result of tandem- and whole-genome duplication (Hofberger et al., 2015). As a result of duplication events, proteins can diverge to have diverse functions or may share similar functions with different expression patterns (Moore and Purugganan, 2003). For example, in AtLecRLK clade I, LecRLK I.9 is an eATP receptor, while LecRLK I.8 was shown to be a nicotinamide adenine dinucleotide $\left(\mathrm{NAD}^{+}\right)$receptor (Choi et al., 2014; Wang et al., 2017). In clade IX, LecRLK IX.1 and LecRLK IX.2 share analogous functions, regulating Phytophthora resistance and plant cell death respectively (Wang et al., 2015).

\section{LecRLK proteins play essential roles in plant immunity}

Wang et al. (2014) reported a survey of the phenotypes of T-DNA single mutant lines of 41 of the 45 AtLecRLKs. This study failed to find any significantly abnormal morphologies with any of the mutations (Wang et al., 2014). Moreover, under normal growth conditions, only LecRLK I.9, LecRLK IV.1 and LecRLK VIII.1 were expressed at a high level, while also being expressed in most plant tissues. The other LecRLK genes showed lower expression and only in specific tissues. However, the expression of 
individual LecRLK genes was found to be responsive to specific hormone treatments, abiotic stresses, elicitor treatments or pathogen infection, suggesting a functional role for these receptors in these processes (Bouwmeester and Govers, 2009). Interestingly, most of the reports about LecRLK member functions relate to pathogen or stress responses (Table I.1). Most appear to be involved in triggering secondary defense signaling, such as increases in $\left[\mathrm{Ca}^{2+}\right]_{\mathrm{cyt}}$, NO or ROS levels. Notable exceptions are P2K1, largely through our studies demonstrations that $\mathrm{P} 2 \mathrm{~K} 1$ interacts with and phosphorylates RBOHD to generate ROS, regulating stomatal aperture and bacterial pathogen resistance (Chen et al., 2017). Calcium-dependent kinases (CPKs) were also reported to interact with LecRLK IX.2, phosphorylate RBOHD to generate ROS and trigger pathogen-associated molecular pattern (PAMP)-triggered immunity (PTI). However, LecRLK IX.2, containing a kinase domain, cannot phosphorylate RBOHD (Luo et al., 2017). In short, while the specific functions of most LecRLK family members remain unknown, there appears to be a general association of these receptors with the plant response to both abiotic and biotic stress.

Table I.1 Known related biological functions of LecRLK members.

\begin{tabular}{|l|l|l|l|}
\hline \multicolumn{1}{|c|}{ Name } & \multicolumn{1}{c|}{ AGI } & \multicolumn{1}{c|}{ Biological Functions } & \multicolumn{1}{c|}{ Reference } \\
\hline $\begin{array}{l}\text { AtLecRLK } \\
\text { I.3 }\end{array}$ & At3G45410 & - Salt stress & (He et al., 2004) \\
\hline $\begin{array}{l}\text { AtLecRLK } \\
\text { I.8 }\end{array}$ & At5G60280 & $\begin{array}{l}\text { - NAD receptor } \\
\text { - Insect egg perception }\end{array}$ & $\begin{array}{l}\text { (Mou, 2017; Wang et al., } \\
\text { 2017) } \\
\text { (Gouhier-Darimont et al., } \\
\text { 2019) }\end{array}$ \\
\hline $\begin{array}{l}\text { AtLecRLK } \\
\text { I.9 }\end{array}$ & At5g60300 & - ATP receptor & (Choi et al., 2014) \\
\hline
\end{tabular}




\begin{tabular}{|c|c|c|c|}
\hline & & $\begin{array}{l}\text { - Plasma membrane and cell } \\
\text { wall adhesion } \\
\text { - Pseudomonas syringae } \\
\text { resistance } \\
\text { - Phytophthora infestans } \\
\text { resistance } \\
\text { - Stomatal immunity }\end{array}$ & $\begin{array}{l}\text { (Gouget et al., 2006) } \\
\text { (Balague et al., 2017) } \\
\text { (Bouwmeester et al., } \\
\text { 2014) } \\
\text { (Chen et al., 2017) }\end{array}$ \\
\hline $\begin{array}{l}\text { AtLecRLK } \\
\text { IV.3 }\end{array}$ & At4g02410 & $\begin{array}{l}\text { - Pathogen resistance and } \\
\text { salinity response }\end{array}$ & (Huang et al., 2013) \\
\hline $\begin{array}{l}\text { AtLecRLK } \\
\text { V.2 }\end{array}$ & At $1 \mathrm{G} 70130$ & - Stomatal immunity & (Yekondi et al., 2018) \\
\hline $\begin{array}{l}\text { AtLecRLK } \\
\text { V.5 }\end{array}$ & At3G59700 & $\begin{array}{l}\text { - Pseudomonas syringae } \\
\text { resistance } \\
\text { - Negatively regulate } \\
\text { Pectobacterium carotovoum }\end{array}$ & $\begin{array}{l}\text { (Desclos-Theveniau et } \\
\text { al., 2012) } \\
\text { (Arnaud et al., 2012) }\end{array}$ \\
\hline $\begin{array}{l}\text { AtLecRLK } \\
\text { VI.2 }\end{array}$ & At5G01540 & $\begin{array}{l}\text { - Pollen germination } \\
\text { - Regulate PTI } \\
\text { - Botrytis cinerea resistance } \\
\text { - Pseudomonas syringae } \\
\text { resistance }\end{array}$ & $\begin{array}{l}\text { (Xin et al., 2009) } \\
\text { (Huang et al., 2014) } \\
\text { (Singh et al., 2013) } \\
\text { (Singh et al., 2012) }\end{array}$ \\
\hline $\begin{array}{l}\text { AtLecRLK } \\
\text { VI.3 }\end{array}$ & At5G01550 & - Pollen germination & (Xin et al., 2009) \\
\hline $\begin{array}{l}\text { AtLecRLK } \\
\text { VI.4 }\end{array}$ & At5G01560 & - Pollen germination & (Xin et al., 2009) \\
\hline $\begin{array}{l}\text { AtLecRLK } \\
\text { VII.1 }\end{array}$ & At4G04960 & - Stomatal immunity & (Yekondi et al., 2018) \\
\hline $\begin{array}{l}\text { AtLecRLK } \\
\text { IX.1 }\end{array}$ & At5g 10530 & - Phytophthora resistance & $\begin{array}{l}\text { (Wang et al., 2015; } \\
\text { Wang et al., 2016) }\end{array}$ \\
\hline $\begin{array}{l}\text { AtLecRLK } \\
\text { IX.2 }\end{array}$ & At5g65600 & $\begin{array}{l}\text { - Pseudomonas syringae } \\
\text { resistance } \\
\text { - Phytophthora resistance }\end{array}$ & $\begin{array}{l}\text { (Luo et al., 2017) } \\
\text { (Wang et al., 2015) }\end{array}$ \\
\hline
\end{tabular}




\section{LecRLK perception}

Although being called receptor agonists, the information about the ligands that interact with the various LecRLK members is still largely unavailable. Most of the information about LecRLK binding is based on predictions arising from the ectodomain amino acid sequence. Due to their lectin domains, LecRLKs have a conserved hydrophobic cavity, and, therefore, were proposed to recognize hydrophobic ligands (Bouwmeester and Govers, 2009). However, true ligands are mostly unknown.

The first reported molecule that binds to LecRLK I.9 was the Phytophthora infestans effector protein, IPI-O, which targets this receptor as a means of suppressing immunity. Two Arg-Gly-Asp (RGD) binding motifs (ASYY and PHPR), both involved in IPI-O binding, were also proposed to play essential roles in plasma membrane - cell wall (PM-CW) adhesion mediated by LecRLK I.9 (Gouget et al., 2006; Bouwmeester et al., 2011). As expected, the lecrk i.9 (p2kl) mutant plants showed reduced resistance to Phytophthora infestans and weak PM-CW adhesion. The authors interpreted their data via a model by which IPI-O binding weakens the PM-cell wall interaction making it easier for the pathogen to gain entry into the plant. While this model may be correct, we now know that LecRLK I.9 is the eATP receptor, P2K1, and, hence, these earlier data need to be reconsidered in the context of a role for purinergic signaling in pathogen resistance. Besides LecRLK I.9, other LecRLK clade I members also have RGD binding motifs, such as LecRLK I.1, LecRLK I.2, LecRLK I.10, LecRLK I.5 (ASYF), LecRLK I.7 (ASYF) and LecRLK I.8 (ASYF) (Gouget et al., 2006). However, under normal conditions, these LecRLKs have low expression levels. The relevance of the RGD 
binding domains on these proteins and their role, if any, in PM-cell wall adhesion or plant immunity remains to be defined.

As discussed above and in greater detail through this thesis, ATP is now known to be the ligand of P2K1. However, subsequently, NAD was reported to be recognized by LecRLK I.8. LecRLK I.8 also has been proposed to be involved in insect egg perception (Mou, 2017; Wang et al., 2017; Gouhier-Darimont et al., 2019). However, the connection between NAD and insect egg perception is unclear.

Although many L-type lectin RLK members appear to function in plant defense, the ligands that interact with these receptors, except for LecRLK I.9 and LecRLK I.8, are currently unknown.

\section{I.4. The rationale of the thesis}

In animal systems, extracellular ATP plays a critical role as an extracellular signaling molecule. Animals have two multigene receptor families, P2X and P2Y, that recognize and transduce the ATP signal. Given the importance of purinergic signaling in animals, which necessitates multiple $\mathrm{P} 2 \mathrm{X}$ and $\mathrm{P} 2 \mathrm{Y}$ receptor subtypes, and the growing realization of purinergic signaling in plants which has been discussed above and summarized in Figure I.2, it seems logical to hypothesize that plants also possess multiple eATP receptors, in addition to $\mathrm{P} 2 \mathrm{~K} 1$.

$\mathrm{P} 2 \mathrm{~K} 1$ is a member of LecRLK family. The similarity of amino acid sequence and protein structure in this family suggests similar functions. Therefore, we expect that other LecRLKs also have the ability to recognize eATP. The low expression level of such 
receptors may have limited our ability to identify additional receptors through the forward genetic screens that we conducted.

Our research goal was to identify additional eATP receptors in plants. In the previous study, the $p 2 k 1-3$ mutant (T-DNA insertion knock out $p 2 k 1$ mutant) showed no response to eATP in assays designed to measure an elevation in $\left[\mathrm{Ca}^{2+}\right]_{\text {cyt }}$ using aequorin luminescence. We hypothesized that ectopic expression of other LecRLK genes in the p2k1-3 mutant background could identify alternative ATP receptors with the ability to complement the mutant phenotype. Following that idea, we ectopically over-expressed each of the clade I LecRLK members in the $p 2 k 1-3$ mutant. The stable transgenic lines were treated with exogenous ATP and monitored for their ability to increase $\left[\mathrm{Ca}^{2+}\right]_{\mathrm{cyt}}$ in response to eATP.

The results of our complementation test identified LecRLK I.5 as a good candidate, and we subsequently named this gene $P 2 K 2$. Further work documented that $\mathrm{P} 2 \mathrm{~K} 2$ is able to bind ATP with high affinity and is an active kinase with the ability to autophosphorylate and transphosphorylate other proteins. A variety of assays suggest that $\mathrm{P} 2 \mathrm{~K} 1$ and P2K2 can self-interact as well as form heteromers. Similar to $P 2 K 1$, a functional $P 2 K 2$ gene is essential for a robust plant defense response to pathogen infection. The data are consistent with $\mathrm{P} 2 \mathrm{~K} 1$ and $\mathrm{P} 2 \mathrm{~K} 2$ showing partial functional redundancy, perhaps working in a heterocomplex to bind and respond to eATP. 


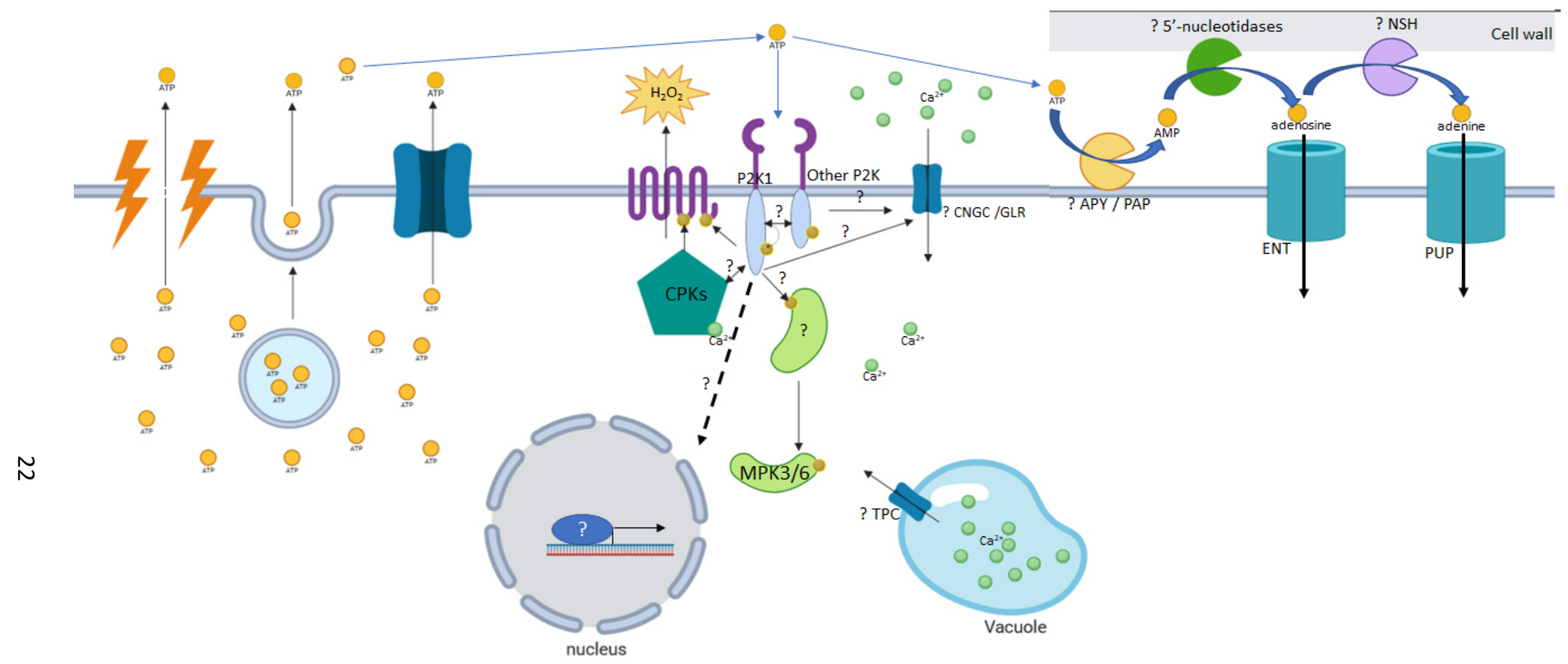

Figure I.2 Overview of ATP release, recognition, signal transduction and homeostatic control. ATP (yellow dots) can be released into the extracellular matrix due to wounding or broken cells. A variety of stimuli, such as biotic or abiotic stresses, can trigger the release of ATP. Exocytotic processes and transporters are proposed to be involved in these excitation processes. By analogy to animals, vesicular loading of ATP would require vesicular nucleotide transporters (VNUT), which have not yet been identified in plants. Plant homologs of human multiple drug resistance/P-glycoprotein 1 (PGP1) or plasma membrane ATP transporter 
1 (PM-ANT1) were suggested as ATP exporters. However, the connection between these transporters and stimuli is still missing.

When the concentration of extracellular ATP increases, it can be recognized by eATP receptors, such as P2K1 or yet unknown P2Ks.

With active kinase activity, P2K1 can phosphorylate downstream proteins, such as respiration burst oxidase homolog protein D

(RBOHD), which can generate reactive oxygen species (ROS). RBOHD also can be phosphorylated by calcium-dependent kinase

(CPK) proteins. The connection between CPKs and P2Ks is still unclear. However, LecRLK IX.2, a homolog of P2K1, can interact

with CPKs to activate RBOHD. P2K1 is a critical component of ATP-induced MAPK activation. However, the kinase substrates of P2K1 (or upstream of MPK3/6) are unknown. As a result of eATP perception, the concentration of cytosolic calcium (green dots) is

$\tilde{\omega}$ increased. In plants, the identified calcium channels include cyclic nucleotide-gated channels (CNGCs) and glutamate like-receptors (GLRs), which regulate calcium influx from the extracellular matrix, as well as two-pore channel 1 (TPC1), which can export calcium from vacuoles. However, their connection to the eATP-induced cytosolic calcium increase is still unclear. To control the extracellular ATP concentration, plant cells have ectoapyrase (APY) and purple acid phosphatase (PAP) proteins. AMP, the product of eATP hydrolysis, can be further processed to adenosine and adenine by ecto-5'-nucleotidase and nucleoside hydrolase. The plant 5'nucleotidases have not been identified, while the plant nucleoside hydrolase protein was proposed to be NSH3. Adenosine and adenine generated from eATP hydrolysis can be transported into the cytosol by equilibrative nucleoside transporters (ENTs) and purine permeases (PUPs). The figure was generated by the Biorender application (www.Biorender.com). 


\title{
Chapter II:
}

\author{
Material and methods
}




\section{II.1. Phylogenetic tree analysis}

The 45 LecRLK protein sequences were collected from the Arabidopsis Information Resource website (TAIR https://www.arabidopsis.org/). The AGI numbers are: LecRLK-I.1 (AT3G45330.1); LecRLK-I.10 (AT5G60310.1); LecRLK-I.11 (AT5G60320.1); LecRLK-I.2 (AT3G45390.1); LecRLK-I.3 (AT3G45410.1); LecRLKI.4 (AT3G45420.1); LecRLK-I.5 (AT3G45430.1); LecRLK-I.6 (AT3G45440.1); LecRLK-I.7 (AT5G60270.1); LecRLK-I.8 (AT5G60280.1); LecRLK-I.9 (AT5G60300.3); LecRLK-II.1 (AT5G59260.1); LecRLK-II.2 (AT5G59270.1); LecRLKIII.1 (AT2G29220.1); LecRLK-III.2 (AT2G29250.1); LecRLK-IV.1 (AT2G37710.1); LecRLK-IV.2 (AT3G53810.1); LecRLK-IV.3 (AT4G02410.1); LecRLK-IV.4 (AT4G02420.1); LecRLK-IX.1 (AT5G10530.1); LecRLK-IX.2 (AT5G65600.1); LecRLK-S.1 (AT1G15530.1); LecRLK-S.4 (AT3G55550.1); LecRLK-S.5 (AT5G06740.1); LecRLK-S.6 (AT5G42120.1); LecRLK-S.7 (AT5G55830.1); LecRLKV.1 (AT1G70110.1); LecRLK-V.2 (AT1G70130.1); LecRLK-V.3 (AT2G43690.1); LecRLK-V.4 (AT2G43700.1); LecRLK-V.5 (AT3G59700.1); LecRLK-V.6 (AT3G59730.1); LecRLK-V.7 (AT3G59740.1); LecRLK-V.8 (AT3G59750.1); LecRLKV.9 (AT4G29050.1); LecRLK-VI.1 (AT3G08870.1); LecRLK-VI.2 (AT5G01540.1); LecRLK-VI.3 (AT5G01550.1); LecRLK-VI.4 (AT5G01560.1); LecRLK-VII.1 (AT4G04960.1); LecRLK-VII.2 (AT4G28350.1); LecRLK-VIII.1 (AT3G53380.1) and LecRLK-VIII.2 (AT5G03140.1).

The sequence alignments and phylogenetic tree generation were performed using Clustal Omega (https://www.ebi.ac.uk/Tools/msa/clustalo/). 


\section{II.2. Plant materials}

All Arabidopsis plants used in this study are aequorin-expressing lines in the Col-0 background. Wild-type and p2k1-3 (SalK_042209) with aequorin (AEQ) stable transgenic lines were described in our previous studies (Choi et al., 2014; Chen et al., 2017). The LecRLK i.5 T-DNA mutant, $p 2 k 2$, (GK-777H06) was obtained from the Arabidopsis Biological Resource Center (ABRC, Ohio State University, Columbus, OH) and crossed with wild-type/AEQ and $p 2 k 1$-3/AEQ to generate $p 2 k 2 / \mathrm{AEQ}$ and p2k1p2k2/AEQ lines. Homozygosity for the T-DNA insertion and the aequorin transgene in F2 progeny was confirmed by PCR-based genotyping using the specific primers listed in Table II.1 and qRT-PCR using primer set in table II.4.

Table II.1 Primers used for T-DNA homozygosity confirmation.

\begin{tabular}{|c|c|c|c|}
\hline & & Names & Sequences \\
\hline \multirow{4}{*}{$\begin{array}{l}\text { For } p 2 k 1-3 \\
\text { T-DNA } \\
\text { mutant } \\
\text { genotyping }\end{array}$} & \multirow{2}{*}{$\begin{array}{l}\text { No insertion } \\
\text { specific }\end{array}$} & *Mlecat5g60300s & TCCATGCAACAGTTGCGTTGTCT \\
\hline & & *P2K1-R & CTGCAATACCCAAACAGTGGTA \\
\hline & \multirow{2}{*}{$\begin{array}{l}\text { T-DNA } \\
\text { specific }\end{array}$} & *Mlecat5g60300s & TCCATGCAACAGTTGCGTTGTCT \\
\hline & & LBb1 & GCGTGGACCGCTTGCTGCAACT \\
\hline \multirow{4}{*}{$\begin{array}{l}\text { For } p 2 k 2 \\
\text { T-DNA } \\
\text { mutant } \\
\text { genotyping }\end{array}$} & \multirow{2}{*}{$\begin{array}{l}\text { No insertion } \\
\text { specific }\end{array}$} & P2K2-F & $\begin{array}{l}\text { ATGATCCTTTGAGTTATTGGCTG } \\
\text { A }\end{array}$ \\
\hline & & P2K2-R & TACAATTTGCGCTGATTATC \\
\hline & \multirow{2}{*}{$\begin{array}{l}\text { T-DNA } \\
\text { specific }\end{array}$} & GABI_8474 & $\begin{array}{l}\text { ATAATAACGCTGCGGACATCTA } \\
\text { CATTTT }\end{array}$ \\
\hline & & $\mathrm{P} 2 \mathrm{~K} 2-\mathrm{R}$ & TACAATTTGCGCTGATTATC \\
\hline \multirow{4}{*}{$\begin{array}{l}\text { For } A E Q \\
\text { insertion } \\
\text { genotyping }\end{array}$} & \multirow{2}{*}{$\begin{array}{l}\text { No insertion } \\
\text { specific }\end{array}$} & *AEQgtF & $\begin{array}{l}\text { ATACCAATCCAACCCTAATCCTA } \\
\text { AAATAC }\end{array}$ \\
\hline & & *AEQgtR & $\begin{array}{l}\text { TATTATAAGAAGGTTCCTCTTTC } \\
\text { CTCCTA }\end{array}$ \\
\hline & \multirow{2}{*}{$\begin{array}{l}\text { T-DNA } \\
\text { specific }\end{array}$} & *AEQgtF & $\begin{array}{l}\text { ATACCAATCCAACCCTAATCCTA } \\
\text { AAATAC }\end{array}$ \\
\hline & & LBb1 & GCGTGGACCGCTTGCTGCAACT \\
\hline
\end{tabular}

* Primers from previous sturdy (Choi et al., 2014). 


\section{II.3. Seed sterilization}

Arabidopsis seeds were sterilized in $1.5 \mathrm{ml}$ tubes by adding $500 \mu 170 \%$ (v/v) ethanol and briefly vortexing. After washing with autoclaved water one time, the seeds were sterilized by adding $200 \mu 150 \%$ (v/v) bleach solution containing $0.1 \%(\mathrm{v} / \mathrm{v})$ triton X-100 and briefly vortexing for 10 seconds. After removing the bleach, seeds were washed at least three times with $1 \mathrm{ml}$ autoclaved water. Sterilized seeds were submerged in autoclaved water and put at $4^{\circ} \mathrm{C}$ from 4-7 days before sowed onto half-strength Murashige and Skoog (1/2 MS) phytagel medium plates. The $1 / 2 \mathrm{MS}$ medium contains $1 \%$ (w/v) sucrose, $0.4 \%(\mathrm{w} / \mathrm{v})$ phytagel and $2.56 \mathrm{mM}$ MES-KOH $\mathrm{pH}$ 5.7. The plates were placed in a long-day condition growth chamber with the setting of $16 \mathrm{~h}$ light, $8 \mathrm{~h}$ dark, $22^{\circ} \mathrm{C}, 70 \%$ humidity, and $100 \mu \mathrm{E} \mathrm{cm} \mathrm{sec}^{-1}$ light intensity.

\section{II.4. Molecular complementation and ectopic expression}

Full-length genomic DNA of clade I LecRLK members were amplified using specific primers (Table II.2) from chromosomal DNA of wild-type (Col-0). The PCR products were cloned into the pDONZ-Zeo vector using Gateway BP Clonase II enzyme mix (Invitrogen). Target sequences were then cloned into pGWB14 destination vectors using Gateway LR Clonase II Enzyme Mix (Invitrogen). These constructs were electroporated into Agrobacterium tumefaciens GV3101 for transforming into the $p 2 k 1$ 3/AEQ line using the floral dipping method (Davis et al., 2009). The stable transgenic lines were selected on $25 \mu \mathrm{g} / \mathrm{L}$ hygromycin medium. Target gene insertion events were confirmed using specific forward primers of target genes and an HA reverse primer (Table II.2) 
Table II.2 Primers for full-length AtLecRLK clade I member cloning.

\begin{tabular}{|c|c|}
\hline LecRLK-I.1F & GGGGACAAGTTTGTACAAAAAAGCAGGCTccATGGCTCAAAGATTGCATCTCCTTCTTC \\
\hline LecRLK-I.1R & GGGGACCACTTTGTACAAGAAAGCTGGGTtTCATCTTCCATCACCATATATAATG \\
\hline LecRLK-I.2F & GGGGACAAGTTTGTACAAAAAAGCAGGCTccATGGCTCAAAGATTTTATCTTCTTCTTCTC \\
\hline LecRLK-I.2R & GGGGACCACTTTGTACAAGAAAGCTGGGTtTCATCTTCCATCACCATTTAAGATGGTGTG \\
\hline LecRLK-I.3F & GGGGACAAGTTTGTACAAAAAAGCAGGCTccATGGCTTGTAGACTATATTTGGCTTTGATC \\
\hline LecRLK-I.3R & GGGGACCACTTTGTACAAGAAAGCTGGGTtTTATCTTCCATGCCCGTCCAAGATTGTGTG \\
\hline LecRLK-I.4F & GGGGACAAGTTTGTACAAAAAAGCAGGCTccATGGATTGTAGACTGCATCTGGTTTTGTTC \\
\hline LecRLK-I.4R & GGGGACCACTTTGTACAAGAAAGCTGGGTtTCATCTTCCATACCCTTCCAAGATCGAGTG \\
\hline LecRLK-I.5F & GGGGACAAGTTTGTACAAAAAAGCAGGCTccATGTCTAAAGGATTGTTTCTAATCTGGTTG \\
\hline LecRLK-I.5R & GGGGACCACTTTGTACAAGAAAGCTGGGTtTCAGCTCTTAAATTCCAATGGTTGTTCATG \\
\hline LecRLK-I.6F & GGGGACAAGTTTGTACAAAAAAGCAGGCTccATGGCTCAAGGATTGCATCTGATCTGGGTG \\
\hline LecRLK-I.6R & GGGGACCACTTTGTACAAGAAAGCTGGGTtTTACCGTCCATCCCCATGGATAATTG \\
\hline LecRLK-I.7F & GGGGACAAGTTTGTACAAAAAAGCAGGCTccATGATTCGAGGATTGCTTTTGGGAATCATC \\
\hline LecRLK-I.7R & GGGGACCACTTTGTACAAGAAAGCTGGGTtTCATCGCCCACTCCCGTAGAGGACTGAGTG \\
\hline LecRLK-I.8F & GGGGACAAGTTTGTACAAAAAAGCAGGCTccATGGCTCCAGGATTGGATCTGATCTGGATG \\
\hline LecRLK-I.8R & GGGGACCACTTTGTACAAGAAAGCTGGGTtTCATCGTCCAATTCCGTATTGAATCGAGTG \\
\hline LecRLK-I.10F & GGGGACAAGTTTGTACAAAAAAGCAGGCTccATGGCTTGGGGATTGTTTCAGATCCTGATG \\
\hline LecRLK-I.10R & GGGGACCACTTTGTACAAGAAAGCTGGGTtTTAAGGTGAGTTAGTGGCCGACGAAGCAGC \\
\hline LecRLK-I.11F & GGGGACAAGTTTGTACAAAAAAGCAGGCTccATGGCTTCTGAAAGATTGCATCTGATCTTATTG \\
\hline LecRLK-I.11R & GGGGACCACTTTGTACAAGAAAGCTGGGTtTCACCTCCCATCTCCGTATGTGATTGTATG \\
\hline x3HA-R & CGTATGGGTAAAAGATGTTAATTAACCC \\
\hline Promoter I.5F & GGGGACAAGTTTGTACAAAAAAGCAGGCTccTCCCATCTTGTTCGGAC \\
\hline Promoter I.5R & GGGGACCACTTTGTACAAGAAAGCTGGGTtTTGCTGCTGATGAAACAG \\
\hline
\end{tabular}


Full-length genomic DNA of $P 2 K 2$ (At3g45430) with or without $\sim 1.5 \mathrm{~kb}$ of the 5'-flanking region were amplified using specific primers (Table II.2) from genomic DNA of wild-type. The products were cloned into pDONR-Zeo vectors. Target sequences were then cloned into pGWB13 or pGWB14 destination vectors using LR cloning. These constructs were electroporated into Agrobacterium tumefaciens GV3101 for transforming into wild-type/AEQ, $p 2 k 2 / A E Q$ or $p 2 k 1 / A E Q$ lines using the floral dipping method (Davis et al., 2009). The stable transgenic lines were confirmed by hygromycin resistance and qRT-PCR using the appropriate specific primer set (Table II.4)

\section{II.5 Cytoplasmic calcium assay}

Five-day-old Arabidopsis seedlings were individually transferred into separated wells of white $96-$-well plates. Each of the wells contained $50 \mu 1$ of CTZ buffer, including $10 \mu \mathrm{M}$ coelenterazine (Nanolight technology, Pinetop, AZ), $2 \mathrm{mM}$ MES and $10 \mathrm{mM}$ $\mathrm{CaCl}_{2}, \mathrm{pH}$ 5.7. After being incubated at room temperature overnight in the dark, $50 \mathrm{ul}$ of $2 \mathrm{X}$ treatment solution were directly applied to the wells by multiple channel pipette. The production of luminescence was immediately measured using an image-intensified CCD camera (Photek 216; Photek, Ltd.). The remaining unchelated aequorin was estimated by applying discharging buffer, including $2 \mathrm{M} \mathrm{CaCl}_{2}$ and $20 \%$ (v/v) ethanol and measured by the camera. The Photon counting data were normalized and converted into calcium concentration using the following equation (Mithofer and Mazars, 2002):

$$
\Delta\left[\mathrm{Ca}^{2+}\right]=\sum \frac{\left(\frac{L(x)}{L \max }\right)^{\frac{1}{3}}+55\left(\frac{L(x)}{L \max }\right)^{\frac{1}{3}}}{2 \times 10^{6}-2 \times 10^{6}\left(\frac{L(x)}{L \max }\right)^{\frac{1}{3}}}
$$


$\mathrm{L}(\mathrm{x})$ is the luminescence intensity each second and Lmax is the total amount of luminescence in the sample. All experiments were repeated at least three times independently. The results were converted to histograms.

\section{II.6 Plasmid construction for protein purification}

The full-length genomic DNA of $P 2 K 2$ in the pDONR-Zeo vector was used as the template for further cloning. The extracellular domain and kinase domain of $P 2 K 2$ were amplified using gene-specific primers (Table II.3) by PCR. The PCR products were digested by restriction enzymes BamHI and XhoI for extracellular domain cloning. After gel extraction and purification, the DNA products were cloned into the PGEX-2T vector (for extracellular domain cloning) and the pET 41a or pET 28a vectors (for kinase domain cloning) using T4 DNA ligase enzyme. To generate mutations, the wild-type $P 2 K 2$ extracellular domain in PGEX-2T or the kinase domain in pET 41a or pET28a was used as a template. The site-direct mutagenesis method used the specific primer sets in Table II.3. The mutations were amplified by PCR and the PCR products were digested by DpnI and transformed into E.coli. 
Table II.3 Primers for P2K2 kinase domain and extracellular domain cloning.

\begin{tabular}{|c|c|c|}
\hline \multirow{6}{*}{$\begin{array}{l}\text { Kinase } \\
\text { domain }\end{array}$} & P2K2-KD_F & $\begin{array}{l}\text { CGCGGATCCGTTTATTACCACAGGAAGAAG } \\
\text { AAG }\end{array}$ \\
\hline & P2K2-KD_R & $\begin{array}{l}\text { GGTGCTCGAGTTCAGCTCTTAAATTCCAATG } \\
\text { G }\end{array}$ \\
\hline & $\begin{array}{l}\text { P2K2- } \\
\text { KD_D467N_F }\end{array}$ & CTATAACCAATGTATATGCTTTCGG \\
\hline & $\begin{array}{l}\text { P2K2- } \\
\text { KD_D467N_R }\end{array}$ & ATATACATTGGTTATAGTGGAAGCTC \\
\hline & $\begin{array}{l}\text { P2K2- } \\
\text { KD_D525N_F }\end{array}$ & CTGCACCGAAATATCAAAGCTTCCAAC \\
\hline & $\begin{array}{l}\text { P2K2- } \\
\text { KD_D525N_R }\end{array}$ & CTTTGATATTTCGGTGCAGAACAACTTG \\
\hline \multirow{8}{*}{$\begin{array}{c}\text { Extracellul } \\
\text { ar } \\
\text { domain }\end{array}$} & P2K2-ED_F & GGATCC GATACCAGTTTTGTCTTCAACG \\
\hline & P2K2-ED_R & GTCGAC GCTGAAACTCCACCCAAGAAGATA \\
\hline & $\begin{array}{l}\text { P2K2- } \\
\text { ED_H99A_F }\end{array}$ & CGGGATTTGAAGGCGGTGCCGGC ATT \\
\hline & $\begin{array}{l}\text { P2K2- } \\
\text { ED_H99A_R }\end{array}$ & CACAAAGGTAATGCCGGCACCGCCTT \\
\hline & $\begin{array}{l}\text { P2K2- } \\
\text { ED_R144A_F }\end{array}$ & TTGAGCTCGACACTGTTGCGAATCCAGA \\
\hline & $\begin{array}{l}\text { P2K2- } \\
\text { ED_R144A_R }\end{array}$ & TCACGAAAATCTGGATTCGCAACAGTGT \\
\hline & $\begin{array}{l}\text { P2K2- } \\
\text { ED_T245A_F }\end{array}$ & GCTGCAGCAACAGGGGCATCAATC \\
\hline & $\begin{array}{l}\text { P2K2- } \\
\text { ED_T245A_R }\end{array}$ & ATAATGGTAACTGATTGATGCCCCTGT \\
\hline
\end{tabular}

\section{II.7 Protein purification}

The constructs used for protein purification were transformed into E.coli BL21-AI (Invitrogen). The bacteria were cultured in $\mathrm{LB}$ medium to reach $0.6<\mathrm{OD}_{600}<0.9$ at $37^{\circ} \mathrm{C}$. The bacteria were shaken at $25^{\circ} \mathrm{C}$ for 30 minutes before the target proteins were induced by IPTG $0.1 \mathrm{mM}$, at $25^{\circ} \mathrm{C}$ for 2 hours. The culture was then centrifuged at 4,500 rpm for 10 minutes at $4^{\circ} \mathrm{C}$. After removing LB medium, the bacterial pellet for GSTfused protein purification was resuspended in TBS buffer, containing $50 \mathrm{mM}$ Tris- $\mathrm{HCl}$, 
$\mathrm{pH} 7.5,150 \mathrm{mM} \mathrm{NaCl}, 0.1 \%$ (v/v) triton X-100, 1X protease inhibitor cocktail (Pierce) and $2 \mathrm{mM}$ PMSF, while cells for HIS-fused protein purification were resuspended in HIS-lysis buffer, containing $50 \mathrm{mM}$ sodium phosphate, $\mathrm{pH}$ 7.5, $300 \mathrm{mM} \mathrm{NaCl}, 8 \mathrm{mM}$ imidazole, $0.05 \%(\mathrm{v} / \mathrm{v})$ NP-40, $1 \mathrm{X}$ protease inhibitor cocktail (Pierce) and $2 \mathrm{mM}$ PMSF. The cells were broken by sonication followed by centrifugation at $12,000 \mathrm{rpm}$ and $4^{\circ} \mathrm{C}$ for 10 minutes. The supernatant was then applied to glutathione sepharose 4B R10 resin (GE healthcare) for GST-fused proteins, while TALON Metal Affinity Resin (Clontech) was used for HIS-fused proteins. The supernatant was incubated with gentle rotation with the resin for 1 hours at $4^{\circ} \mathrm{C}$; the resin was collected by centrifugation at 5,000 rpm for 5 minutes at $4^{\circ} \mathrm{C}$. The resin was washed three times with $1 \mathrm{X}$ TBS buffer (for GST-fused proteins) or HIS washing buffer, containing $50 \mathrm{mM}$ sodium phosphate, $\mathrm{pH} 7.5,300 \mathrm{mM}$ $\mathrm{NaCl}$ and $8 \mathrm{mM}$ imidazole. After removing the washing buffer, elution buffer, containing $50 \mathrm{mM}$ Tris-HCl, $\mathrm{pH}$ 8.0, $150 \mathrm{mM} \mathrm{NaCl}, 25 \mathrm{mM}$ reduced glutathione (for GST-fused proteins) or $150 \mathrm{mM}$ Imidazole (for His-fused proteins), and 10\% (v/v) glycerol. Purified proteins were stored at $-80^{\circ} \mathrm{C}$ until use.

\section{II.8 Arabidopsis protoplast preparation and transformation}

The protoplast isolation and transformation were performed, as previously

described (Cao et al., 2016). Approximately, 2 g of two-week-old Arabidopsis leaf tissue were sliced with a fresh razor blade and incubated with enzyme solution $[1 \%(\mathrm{w} / \mathrm{v})$ cellulase R10, 0.2\% (w/v) macerozyme R10, 0.4 M mannitol 20 mM KCl, 20mM MES $\mathrm{pH}$ 5.7, $10 \mathrm{mM} \mathrm{CaCl} 2,5 \mathrm{mM}$ 2-mercaptoethanol and $0.1 \%$ (w/v) bovine serum albumin] at room temperature for 3 hours. The protoplasts were isolated by pouring the solution into 50-ml falcon tubes using $75 \mu \mathrm{m}$ nylon mesh filters, followed by centrifugation for 2 
minutes at $100 \mathrm{x}$ g. After removal of the supernatant, the protoplasts were gently resuspended in cold W5 solution $\left(154 \mathrm{mM} \mathrm{NaCl}, 125 \mathrm{mM} \mathrm{CaCl}_{2} 5 \mathrm{mM} \mathrm{KCl}\right.$ and $2 \mathrm{mM}$ MES, pH 5.7) and kept on ice for at least 30 minutes before further use.

The 50-ml falcon tubes containing the protoplasts were centrifuged at $60 \mathrm{x} \mathrm{g}$ for 2 minutes at $4^{\circ} \mathrm{C}$. After removal of the supernatant, protoplasts were resuspended in the MaMg solution (0.4 M mannitol, $15 \mathrm{mM} \mathrm{CaCl}_{2}$ and $4 \mathrm{mM}$ MES pH 5.7) and aliquoted at $300 \mu 1 / 50$-ml falcon tube. Twenty $\mu$ l DNA constructs (total $20-30 \mu$ g of plasmid) were added and gently mixed. After that, $320 \mu \mathrm{l}$ PEG solution (4 g PEG 4000, 0.4 M mannitol and $100 \mathrm{mM} \mathrm{CaCl}_{2}$ ) was added and gently mixed. After incubating the transfection mixture at room temperature for 30 minutes, the mixture was slowly diluted with $5 \mathrm{ml}$ W5 solution and gently mixed. The transfection protoplasts were collected by centrifugation at $60 \mathrm{x} \mathrm{g}$, and resuspended in $2 \mathrm{ml}$ W5 solution. The protoplasts were incubated in the dark at $23^{\circ} \mathrm{C}$, overnight.

\section{II.9 In vitro ATP binding assay (Performed by Dr. Cho Sung-Hwan)}

The purified $\mathrm{P} 2 \mathrm{~K} 2$ extracellular domain protein was mixed in a $50 \mu 1$ reaction including $10 \mathrm{mM}$ HEPES ( $\mathrm{pH} 7.5$ ), $5 \mathrm{mM} \mathrm{MgCl}_{2}$, in presence or absence of a 100-fold excess of unlabeled ATP (for specific binding assays) or unlabeled other nucleotide (for competitive binding assays), and $\left[\alpha{ }^{32} \mathrm{P}\right]$ ATP (PerkinElmer, $800 \mathrm{Ci} \mathrm{mmol}^{-1}$ ). The reactions were incubated at $4^{\circ} \mathrm{C}$ for 30 minutes. After that, the reactions were loaded onto Sephadex G-25 gel filtration columns (GE Healthcare). The free nucleotides were trapped in the column, while the bound radioligand goes through the column and was collected in scintillation vials. After mixing with scintillation cocktail (MP Biomedicals), the signal 
of bound radioligand was measured using liquid scintillation counting (Tri-Carb 2810TR, PerkinElmer). The data were analyzed using GraphPad Prism 7.

\section{II.10 Computational analysis of putative 3D protein structure (Performed by Dr. Cuong T. Nguyen)}

A computational approach was used to predict ATP-binding sides within the $\mathrm{P} 2 \mathrm{~K} 2$ lectin domain and to guide the construction of specific mutations that disrupt ATP binding. Initially, a sequence search of the Protein Data Bank (http://www.rcsb.org/) identified more than 40 homologous P2K2 lectin domain structures. Among these homologous structures, 4 top-ranked templates (PDB accession 1G7Y, 1DBN, 1HQL and 1AVB) with high sequence identity and similarity, as well as structural resolution and sequence coverage, were selected for homology modeling of the P2K2 3D structure.

A homology modeling approach was carried out using Modeller v9.21

(https://salilab.org/modeller/), and the top-ranked model was chosen using the Modeller energy score from a set of 3000 decoys for further structure assessment, binding site prediction and ligand docking. The quality of the P2K2 structural model was assessed by Ramachandran plots with the Rampage online tool (http://mordred.bioc.cam.ac.uk/ rapper/rampage.php). The 3D model of the P2K2 ectodomain was refined using the refined Modeller tool. 


\section{II.11 Identification of putative ATP-binding sites of P2K2 (Performed by Dr. Cuong T. Nguyen)}

The ATP binding site of P2K2 was predicted using sequence-based and structurebased prediction tools, including COACH, COFACTOR, FINDSITE and TM-Site (https://zhanglab.ccmb.med.umich.edu). Once the binding site was predicted, a target docking of ATP to the predicted ligand binding site of the P2K2 model was performed repeatedly with the AutoDockVina tool (http://vina.scripps.edu/) keeping the ligand flexible and P2K2 rigid, until the energy score of the ATP-P2K2 3D model reached the lowest value.

Finally, the best P2K2-ATP binding complex, having the lowest energy score in terms of kcal per mol, was visualized with the Chimera visualization tool (https://www.cgl.ucsf.edu/chimera/). The interaction map between P2K2 interacting residues and the ATP ligand was mapped and generated using the LigPlot+ tool (https://www.ebi.ac.uk/thornton-srv/software/LigPlus/).

\section{II.12 In vitro kinase assay}

As described by (Choi et al., 2014), the kinase assays were performed with minor modifications. For the kinase assay, $5 \mu \mathrm{g}$ of GST or GST-fusion proteins were mixed with or without $2 \mu \mathrm{g}$ myelin basic protein in kinase assay buffer $(50 \mathrm{mM}$ Tris- $\mathrm{HCl}, \mathrm{pH}$ 7.5, $50 \mathrm{mM} \mathrm{KCl}, 10 \mathrm{mM} \mathrm{MgCl} 2,4 \mu \mathrm{M}$ ATP and $0.2 \mu 1\left[\gamma^{-32} \mathrm{P}\right]$ ATP (PerkinElmer); specific activity $\left.6000 \mathrm{Ci} \mathrm{mmol}^{-1}\right)$ and incubated for $30 \mathrm{~min}$ at $30^{\circ} \mathrm{C}$. After $10 \%(\mathrm{w} / \mathrm{v})$ SDS-PAGE, the gels were exposed for $3 \mathrm{~h}$ for autoradiography. 
After the kinase assay, samples were treated with $0.5 \mu$ of Lambda protein phosphatase (NEB). Results were detected by $10 \%$ SDS-PAGE and Coomassie blue staining.

\section{II.13 Detection of promoter-GUS fusion expression}

The P2K1 promoter (1.5 kb of the 5'-flanking region) was amplified using the specific primer set in Table II.2. After gel extraction and purification, the PCR products were cloned into the pDONR-Zeo vector followed by the pGWB3 gateway destination vector. The destination constructs were electroporated into Agrobacterium GV3101 for the Arabidopsis floral dipping process. The $\mathrm{T}_{2}$ transgenic lines were used for further experiments.

For GUS staining, plants were incubated in the GUS staining solution containing $50 \mathrm{mM} \mathrm{NaPO}_{4}, \mathrm{pH} 7.0,0.2 \%(\mathrm{w} / \mathrm{v})$ triton $\mathrm{X}-100$ and $1 \mathrm{mM} \mathrm{X-Gluc} \mathrm{(100mM} \mathrm{stock} \mathrm{in}$ DMF) at $37^{\circ} \mathrm{C}$ for 16 hours or overnight. The samples were washed at least three times with $70 \%(\mathrm{v} / \mathrm{v})$ ethanol before observation under the microscope.

\section{II.14 Bimolecular fluorescence complementation (BiFC)}

Full-length genomic DNA of $P 2 K 2$ from the pDONR-Zeo vector, described above, was cloned into pAM-PAT-35s:YFP:GW (for identification of P2K2 subcellular localization) and pAM-PAT-35s:YFPn (for the BiFC assay) destination vectors. For the free YFP control, a $66 \mathrm{bp}$ fragment of YFP was subcloned into the pDONR-Zeo vector and then cloned into pAM-PAT-35s:YFP:GW, pAM-PAT-35s:YFPn:GW and pAMPAT-35s:YFPc:GW. The full-length cDNA of $P 2 K 1$ in pAM-PAT-35s:YFPc:GW was 
described in our previous study (Chen et al., 2017). These constructs were transformed or co-transformed into Arabidopsis protoplasts, as described above.

The YFP fluorescence was observed under a Leica DM 5500B compound microscope using a Leica DFC290 color digital camera. FM4-64 dye (Invitrogen, T3166) was directly added into the W5 solution containing protoplasts for plasma membrane staining before visualization under the fluorescence microscope.

\section{II.15 Split-luciferase complementation assay}

The pCambia-NLuc and pCambia-CLuc vectors were kindly provided by Dr. Jian-Min Zhou (Chen et al., 2008). $P 2 K 1$ and $P 2 K 2$ in pDONR-Zeo constructs were used for LR reactions to generate $P 2 K 1$ and $P 2 K 2$ in pCambia-NLuc and pCambia-CLuc. These constructs were electroporated into Agrobacterium GV3101. These constructs were co-infiltrated into 3-week-old N.benthamiana leaves, following a published protocol (Li, 2011). After three days, the infiltrated leaves were treated with $200 \mu \mathrm{M}$ ATP or 50 mM MES or non-treated. After 30 minutes of treatment, the leaves were sprayed with 1 $\mathrm{mM}$ luciferin and kept in the dark for 6 minutes before observed with a CCD imaging apparatus (Photek 216; Photek, Ltd.).

\section{II.16 Co-immunoprecipitation and immunoblot analysis}

Full-length cDNA of $P 2 K 1$ and genomic DNA of $P 2 K 2$ in the pDONR-Zeo vector were cloned into pGWB14 and pGWB5 destination vectors. These constructs were electroporated into Agrobacterium tumefaciens GV3101 for transient expression in tobacco. After two days, transfected tobacco leaves were infiltrated with $200 \mu \mathrm{M}$ ATP or $50 \mathrm{mM}$ MES pH 5.7. After 30 minutes incubation at room temperature, tobacco tissues 
were ground in liquid nitrogen and incubated with protein extraction buffer, containing 10 mM Tris-HCl pH 7.5, 100 mM NaCl, 1 mM EDTA, 0.1\% (v/v) NP-40, 1 mM DTT, 2 mM PMSF and $1 \mathrm{X}$ protein inhibitor (Pierce), in ice for 30 minutes. The mixture was centrifuged at $20,000 \mathrm{x}$ g for 20 minutes at $4^{\circ} \mathrm{C}$. The supernatant was transferred to new tubes and incubated with $50 \mu 1$ protein A resin for 30 minutes to prevent the nonspecific binding. After centrifugation at $20,000 \mathrm{x}$ g for 5 minutes at $4^{\circ} \mathrm{C}$, the supernatant was transferred to new tubes and incubated with $1 \mu \mathrm{g}$ anti-GFP antibody (Cat. no. A11122, Thermo) at $4^{\circ} \mathrm{C}$ for 1 hour. Fifty $\mu 1$ protein A resin was added and incubated for 1 hour. This solution was then centrifuged at 3,000 $\mathrm{x} g$ for 1 minute and the resin pellet washed 4 times with RIPA buffer, containing $10 \mathrm{mM}$ Tris-HCl, $\mathrm{pH}$ 7.5, $100 \mathrm{mM} \mathrm{NaCl}, 1 \mathrm{mM}$ EDTA, 0.1\% (v/v) NP-40, 1 mM DTT, 0.5\% (w/v) sodium deoxycholate, $2 \mathrm{mM}$ PMSF and $1 \mathrm{X}$ protein inhibitor (Pierce). After removing all the supernatant, $2 \mathrm{X}$ Laemmli protein loading buffer, containing 4\% (w/v) SDS, $20 \%$ (v/v) glycerol, $0.004 \%(\mathrm{w} / \mathrm{v})$ bromophenol blue, $10 \%$ (v/v) beta-mercaptoethanol and $0.125 \mathrm{M}$ Tris-HCl, $\mathrm{pH}$ 6.8, was added to the resin. The solution was then heated in boiling water for 10 minutes. The proteins were separated by $8 \%(\mathrm{w} / \mathrm{v})$ SDS-PAGE. The results were detected by immunoblotting with anti-HA-HRP antibody (Cat. no. 12013819001, Roche).

\section{II.17 GST-HIS pull-down assay}

The LYK5 in PGEX-5X-1 was kindly provided by Dr. Dongqin Chen (Chen et al., 2017). The $p 2 k 1-1$ kinase-dead and wild-type $P 2 K 1$ kinase domain in PGEX-5X-1 was kindly provided by Dr. Jeongmin Choi (Choi et al., 2014). The in vitro pull-down assay was performed as described by Chen et al. (2018) with minor modification. In brief, $2 \mu \mathrm{g}$ of HIS-fused and GST-fused proteins were mixed in a $1 \mathrm{ml}$ pull-down buffer, containing 
$50 \mathrm{mM}$ Tris- $\mathrm{HCl}, \mathrm{pH} 7.5,100 \mathrm{mM} \mathrm{NaCl}$ and $0.5 \%(\mathrm{v} / \mathrm{v})$ triton-X 100, followed by incubation for 1 hour at $4^{\circ} \mathrm{C}$. After that, $25 \mu \mathrm{l}$ of glutathione resin was added and incubated for 1 hour at $4^{\circ} \mathrm{C}$. The resin was washed at least ten times with pull-down buffer. The proteins were eluted using GST elution buffer, containing $50 \mathrm{mM}$ Tris- $\mathrm{HCl}$, $\mathrm{pH} 8.0,150 \mathrm{mM} \mathrm{NaCl}$ and $25 \mathrm{mM}$ reduced glutathione. The results were detected by SDS-PAGE, followed by immunoblotting using anti-HIS (SAB1305538, Sigma) and anti-GST (A01380-40, GeneScript) antibodies.

\section{II.18 Bacterial inoculation assay}

The assay was modified from the Arabidopsis seedling flood inoculation assay (Ishiga et al., 2011). In detail, 3-week-old Arabidopsis seedlings grown in square Petri dishes were used for this assay. Forty $\mathrm{ml}$ of $P$. syringae pv. tomato DC3000 Lux (Fan et al., 2008) $\left(\mathrm{OD}_{600}=0.05\right)$ bacterial suspension in sterile water with $0.025 \%(\mathrm{v} / \mathrm{v})$ silwet L77 was dispensed into the dishes for 2-3 mins. After removing the bacterial suspension, the plants were incubated in a growth chamber. One-day post-inoculation, the seedlings, without roots, were collected and the weight determined followed by washing with sterile water for 5 minutes. Bacterial growth was visualized and analyzed under a CCD camera (Photek 216; Photek, Ltd.). The seedling tissue was ground in $10 \mathrm{mM} \mathrm{MgCl}$, diluted serially, and dropped onto King B agar plates containing rifampicin and kanamycin. The number of colonies (CFU) was counted and analyzed after incubation at room temperature for two days. 


\section{II.19 MAPK assay}

Ten-day-old Arabidopsis seedlings were incubated in sterile water at room temperature overnight. After treatment with $200 \mu \mathrm{M}$ ATP, total protein was extracted from whole seedlings by homogenization in RIFA buffer, containing $10 \mathrm{mM}$ Tris- $\mathrm{HCl}$, pH 7.5, $100 \mathrm{mM} \mathrm{NaCl}, 1 \mathrm{mM}$ EDTA, 0.1\% (v/v) NP-40, $1 \mathrm{mM}$ DTT, 0.5\% (w/v) sodium deoxycholate, $2 \mathrm{mM}$ PMSF and 1X protein inhibitor cocktail (Pierce). The clear lysate was mixed with 5X Laemmli loading buffer, containing $10 \%(\mathrm{w} / \mathrm{v})$ SDS, $50 \%$ (v/v) glycerol, $0.01 \%(\mathrm{w} / \mathrm{v})$ bromophenol blue, $10 \%(\mathrm{v} / \mathrm{v})$ beta-mercaptoethanol and $0.3 \mathrm{M}$ Tris-HCl, $\mathrm{pH}$ 6.8, and heated in boiling water for 10 minutes. The total extracted proteins were separated by $10 \%(\mathrm{w} / \mathrm{v})$ SDS-PAGE and transferred to polyvinylidene difluoride (PVDF) membranes. The transblots were blocked with 5\% (w/v) skim milk in TBST buffer and then incubated with rabbit anti-phospho-p44/p42 MAPK antibody (Cell Signaling Technology). After washing by TBST, the immunoblots were incubated with horseradish peroxidase-conjugated goat anti-rabbit IgG antibody (Jackson ImmunoResearch Laboratories). The final signal on immunoblots was visualized using a Fuji LAS3000 luminescence imaging system (FujiFilm).

\section{II.20 qRT-PCR assay}

Five-day-old Arabidopsis seedlings were incubated in sterile water at room temperature overnight. After treatment with $200 \mu \mathrm{M}$ ATP, samples were collected for total RNA extraction using Trizol reagent (Invitrogen). One microgram of total RNA was treated with Turbo DNA-free DNase (Ambion). The RNA was then used for cDNA synthesis using the M-MLV kit (Promega). The SYBR Green and 7500 Realtime PCR 
system (Applied Biosystems) was used to perform the real-time PCR with specific primer sets defined in Table II.4. RNA levels were normalized against the expression of the reference gene, SAND (At2g28390) (Choi et al., 2014).

Table II.4. Primer for qRT-PCR.

\begin{tabular}{|l|l|}
\hline$* P 2 K{ }_{-} q P C R \_\mathrm{F}$ & TGGAGTTTGTCAGGTCCATCG \\
\hline$* P 2 K{ }_{-} q P C R \_\mathrm{R}$ & CTGAGGATCTTCTGCAGGCAA \\
\hline$P 2 K 2 \_q P C R \_\mathrm{F}$ & GGTTTCATGACCATGGAGGCA \\
\hline$P 2 K 2 \_q P C R \_\mathrm{R}$ & ACTTGCACCCCGAATTCCAC \\
\hline$* * M Y C 2-F$ & TCCGAGTCCGGTTCATTCT \\
\hline$* * M Y C 2-R$ & TCTCGGGAGAAAGTGTTATTGAA \\
\hline$* * Z A T 10-F$ & GGACAAAGGGTAAGCGATCTAA \\
\hline$* * Z A T 10-R$ & AGAAGCATGAGGCAAAAAGC \\
\hline$* S A N D-\mathrm{F}$ & AACTCTATGCAGCATTTGATCCACT \\
\hline$* S A N D-\mathrm{R}$ & TGATTGCATATCTTTATCGCCATC \\
\hline
\end{tabular}

Primers from previous sturdy * (Choi et al., 2014) and ** (Balague et al., 2017) 


\section{Chapter III:}

Results 


\section{III.1 Screening for the second extracellular ATP receptor in Arabidopsis thaliana}

\section{III.1.1 P2K1, DORN1 belongs to group I of the AtLecRLK family}

As discussed in Chapter I, the first extracellular receptor identified in plants, P2K1 (DORN1; LecRLKI.9) is a member of the Lectin receptor like kinase (LecRLK) family. In 9 sub-clades of this family, $P 2 K 1$ belongs to the largest group, clade I, with 11 members (Figure I.1, Chapter I). Although ATP in the plant was demonstrated to play essential roles in growth, development and stress responses, mutants lacking $P 2 K l$ do not exhibit any morphological changes under normal growth conditions. In animal, purinoreceptor family comprises seven $\mathrm{P} 2 \mathrm{X}\left(\mathrm{P} 2 \mathrm{X}_{1-7}\right)$ and eight $\mathrm{P} 2 \mathrm{Y}\left(\mathrm{P} 2 \mathrm{Y}_{1}, \mathrm{P}_{2} \mathrm{Y}_{2}, \mathrm{P}_{2} \mathrm{Y}_{4}\right.$, $\left.\mathrm{P}_{2} \mathrm{Y}_{6}, \mathrm{P}_{2} \mathrm{Y}_{11-14}\right)$ receptor suptypes. The information gave us the idea that plants should have additional extracellular ATP receptors, which may play similar or distinct functions to $\mathrm{P} 2 \mathrm{~K} 1$ and animal $\mathrm{P} 2$ receptors. Assuming that other plant extracellular ATP receptors are homologous to $P 2 K 1$, we focused on clade I LecRLK members.

Choi et al. (2014) identified $P 2 K 1$ as the first extracellular ATP receptor based on a forward genetic screening which looked for mutant lines that do not respond to exogenous ATP. The experiment used 5-day-old plants (very early stage) for the screening. To roughly check the expression level of eleven members of sub-clade I LecRLK family members at this early seedling stage, we consulted the Arabidopsis eFP Browser (Winter et al., 2007), which visualizes microarray data, to construct a gene expression map of Arabidopsis (Schmid et al., 2005). 


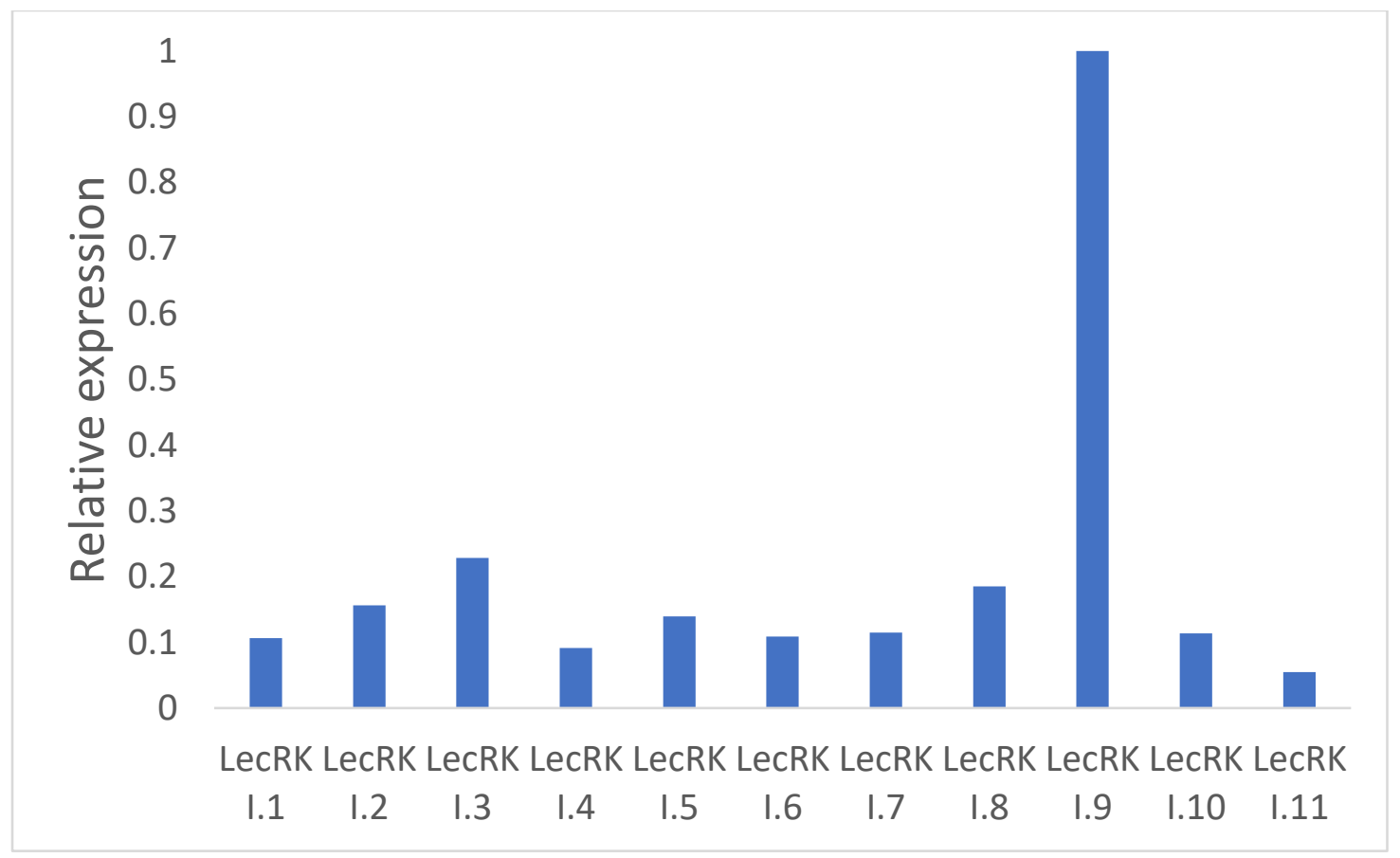

Figure III.1: Relative gene expression levels of clade I LecRLK members in comparison to P2K1 (LecRLK I.9) (set at 1). Microarray data of young seedling root was collected from Arabidopsis eFG Browser, http://bar.utoronto.ca/efp/cgibin/efpWeb.cgi. (Schmid et al., 2005; Winter et al., 2007). 
Interestingly, we saw that, with the exception of P2K1, all of the other LecRLK clade I members were expressed at relatively low levels (Figure III.1). This information raised the hypothesis that some members of LecRLK group I, which are the closest homologs to $P 2 K 1$, may have similar functions, but only in specific tissues or under specific conditions.

\section{III.1.2 LecRLK I.5 can partially reverse the p2k1-3 mutant in response to eATP addition}

To test our hypothesis, we cloned each of the clade I LecRLK members into the pGWB14 destination vector in such a way that each gene was expressed from the cauliflower mosaic virus promoter p35S. Subsequently, each gene was transformed into the Arabidopsis p2k1-3 T-DNA mutant with AEQ, using the floral dipping method to generate stable transgenic lines. The $\mathrm{T} 2$ generation of these stable transgenic lines was selected on hygromycin and kanamycin $1 / 2$ MS selective medium and subsequently used to measure changes in intracellular calcium levels upon addition of exogenous ATP. The results of these calcium assays showed that only transgenic lines expressing LecRLKI.5 (P2K2) showed a significant response to ATP addition (Figure III.2). The figure shows that five independent lines showed partial restoration of the calcium response to ATP in the p2k1-3 mutant background. The kinetics of the calcium responses of p35S:P2K2/p2kl-3 shows early calcium response to additional ATP, comparing with p2k1-3 mutant and wild-type (Figure III.3). 


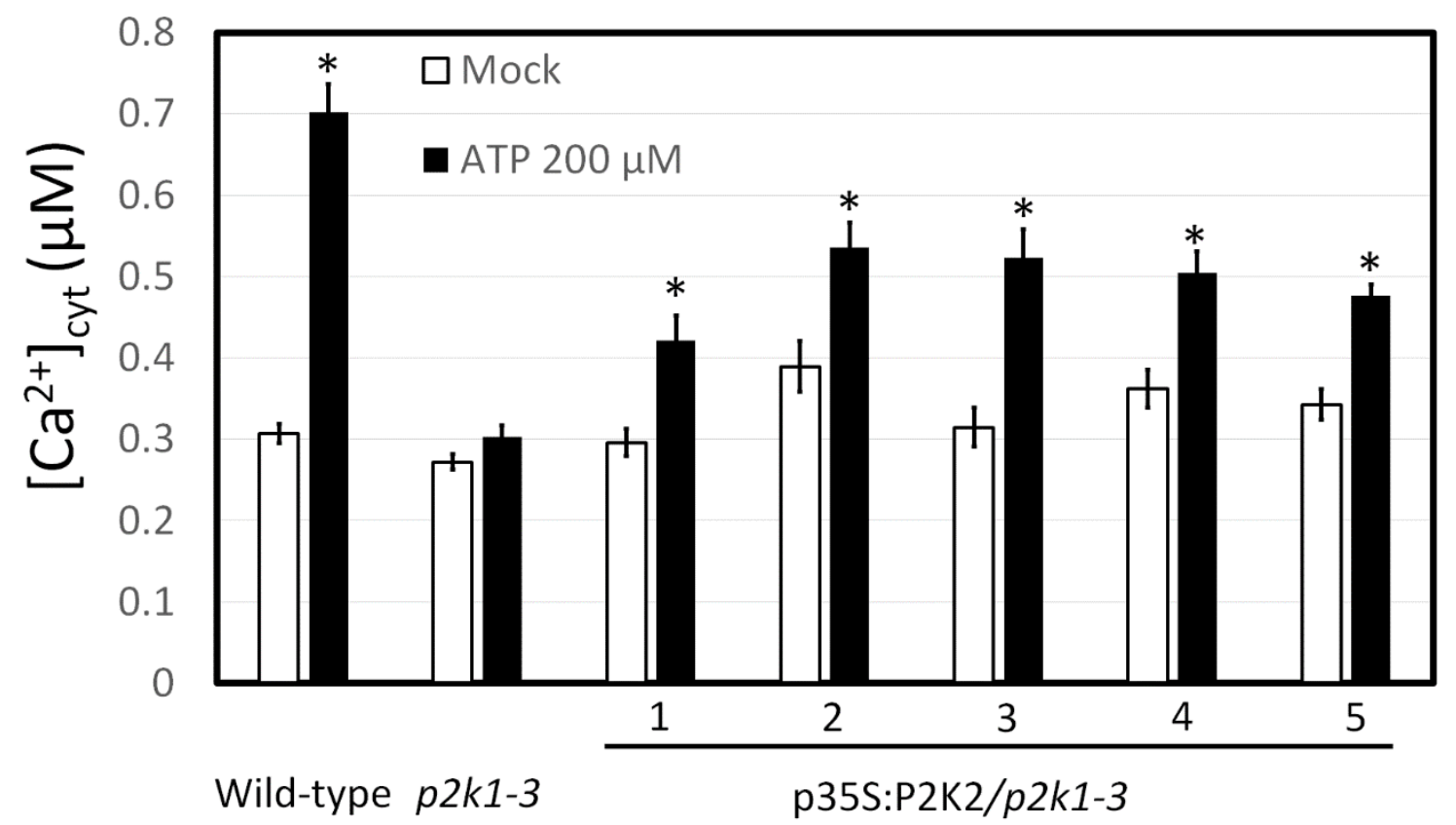

Figure III.2: Ectopic expression of P2K2 (p35S:LecRLK-I.5) in p2k1-3 mutant plants confers partial complementation of the ATP-triggered cytosolic calcium response phenotype. 1 to 5 represent independent transgenic plants. The bar graphs show total cytosolic $\left[\mathrm{Ca}^{2+}\right]$ after $200 \mu \mathrm{M}$ ATP treatment over 400 seconds. The wild-type and $p 2 k l$ 3 mutant were used as controls. Data represent means \pm SEs, $n=8$; asterisks denote values significantly different from $p 2 k 1-3$ mutant $\left({ }^{*} P<0.01\right.$, Student's $t$-test). Experiment was repeated at least three times with similar results. 


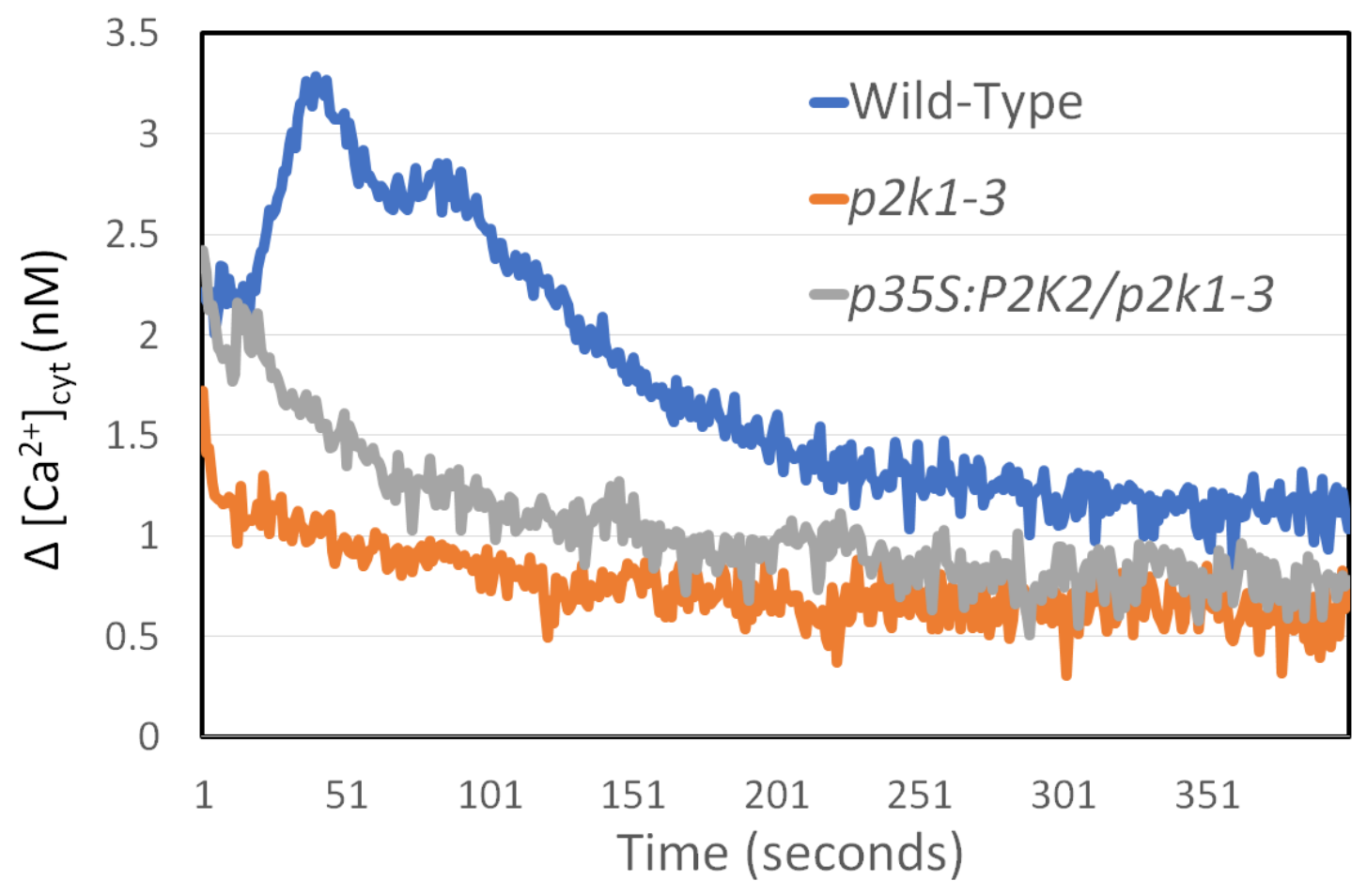

Figure III.3: The kinetics of the calcium responses of p35S:P2K2/p2k1-3. The kinetics show the amount of $\left[\mathrm{Ca}^{2+}\right]_{c y t}$ increase each second after wild-type (as positive control), p2k1-3 (as negative control) and p35S:P2K2/p2k1-3 were treated with $200 \mu \mathrm{M}$ ATP. Experiment was repeated at least three times with similar results. 


\section{III.1.3 Plants ectopically expressing LecRLK I.5 (P2K2) showed an increased calcium response to nucleotides}

To confirm the ability of LecRLK I.5 to serve as an extracellular ATP receptor, we ectopically expressed LecRLK I.5 (p35S:P2K2) in wild-type plants (Col-0 background). As we expected, these p35S:P2K2 plants responded stronger to ATP than the wild-type (Figure III.4 and III.5). The figures also show that $p 2 k 2$ T-DNA mutant plants significantly response weaker to eATP, comparing to the wild-type. These data and the ability of LecRLK I.5 to partially recover ATP-triggered calcium response in $p 2 k 1-3$ mutant suggest that LecRLK I.5 (P2K2) can function as an ATP receptor. 


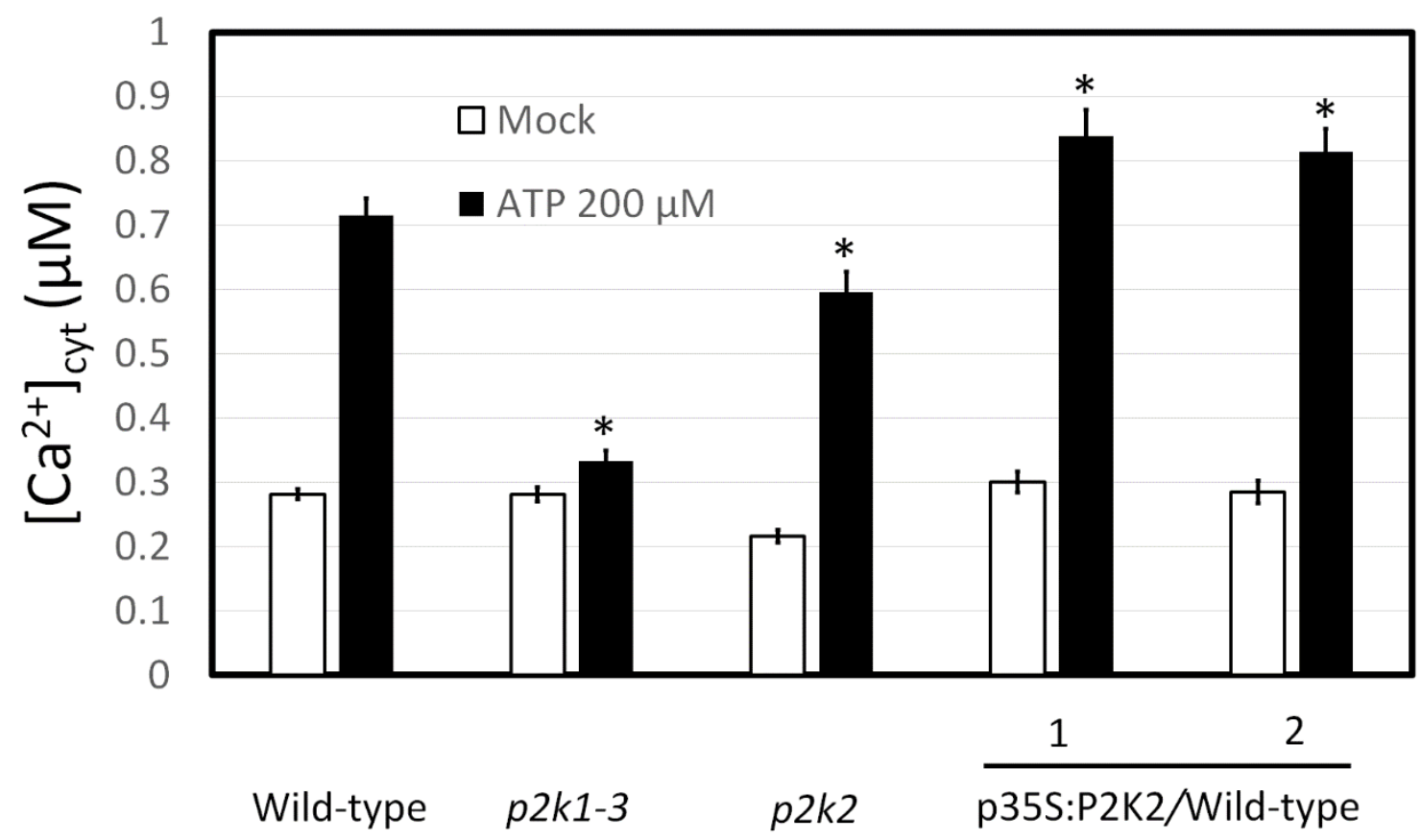

Figure III.4: eATP-triggered calcium response of $p 2 k 2$ T-DNA mutant and two independent P2K2 overexpression lines. The bar graphs show total cytosolic $\left[\mathrm{Ca}^{2+}\right]$ after $200 \mu \mathrm{M}$ ATP treatment over 400 seconds. The wild-type and $p 2 k 1-3$ mutant were used as controls. Data represent means \pm SEs, $n=8$; asterisks denote values significantly different from wild-type. ( $* P<0.01$, Student's $t$-test). Experiment was repeated at least three times with similar results. 


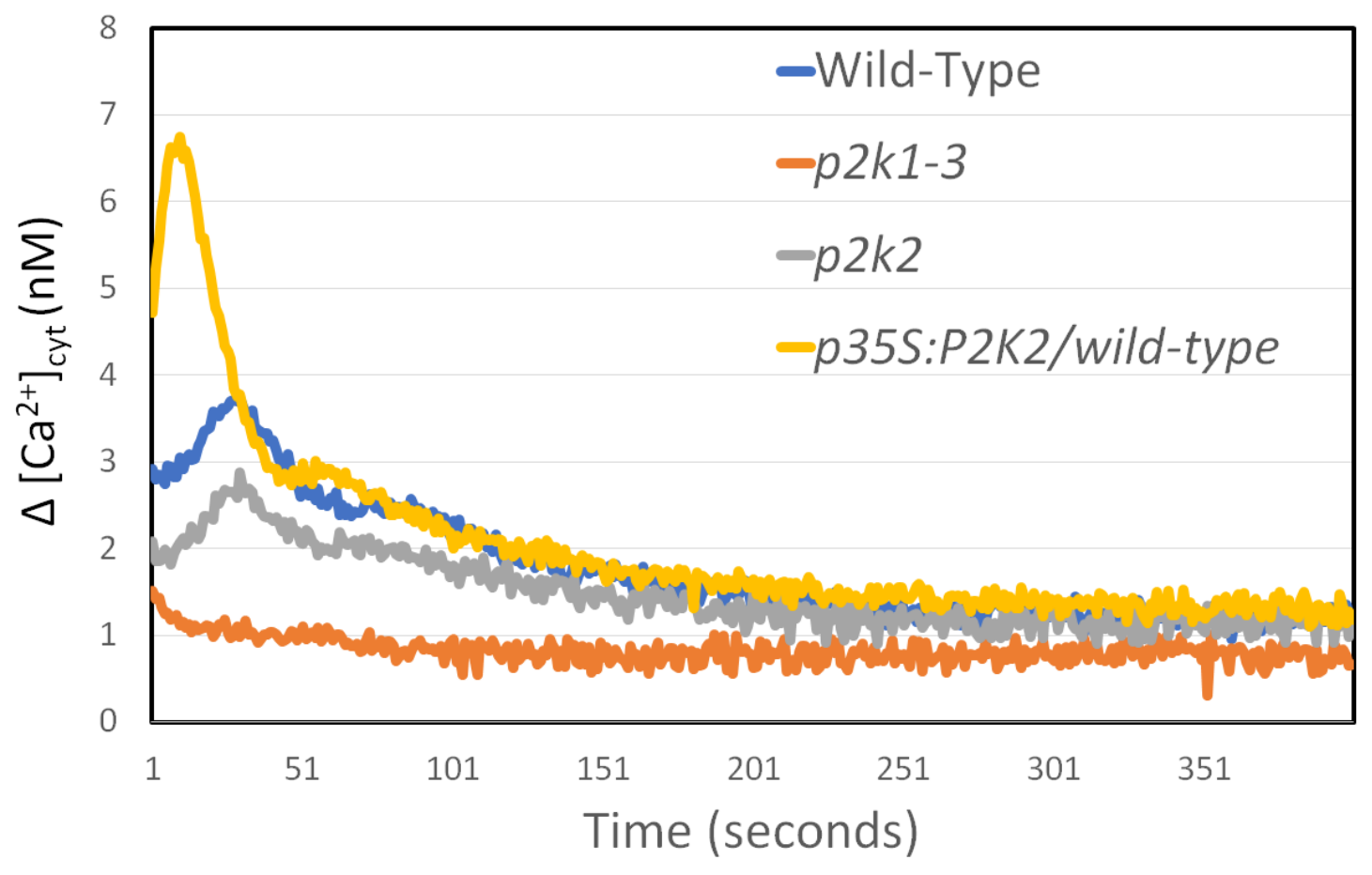

Figure III.5: The kinetics of the calcium responses of $p 35 S: P 2 K 2 /$ wild-type and p2k2. The calcium response kinetics show that ectopic expression of $P 2 K 2$ in wild-type responds to $200 \mu \mathrm{M}$ ATP faster and stronger than wild-type, while $p 2 k 2$ shows a lower response compared to wild-type. Experiment was repeated at least three times with similar results. 


\section{III.1.4 Protein domain map of P2K2}

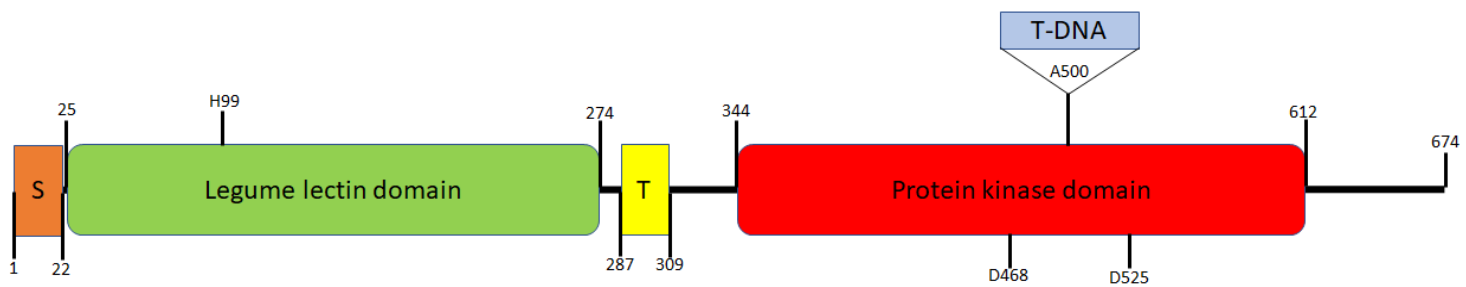

Figure III.6: Map of P2K2 protein. " $\mathrm{S}$ " indicates signal sequence. H99 is one of the critical eATP binding residues. "T" indicates transmembrane domain. D468 and D525 are two crucial residues of the kinase catalytic domain. The T-DNA of $p 2 k 2$ (GK-777H06) locates at A500.

The amino acid sequence of P2K2 protein was collected from the TAIR database (www.arabidopsis.org) and uploaded to the SMART database (http://smart.emblheidelberg.de/) to predict protein domains and their putative functions (Letunic et al., 2015). As shown in Figure III.6, the P2K2 protein is predicted to include a lectin-like extracellular domain, a transmembrane domain and an intracellular kinase domain. Because P2K2 was expected to be an extracellular ATP receptor, (1) the P2K2 extracellular domain was hypothesized to have high ATP binding affinity; (2) a transmembrane domain was anticipated to localize P2K2 to the plasma membrane; and (3) an intracellular kinase domain likely transmits the eATP signal through phosphorylation of downstream protein targets. In this chapter, we will show supporting information for these various functions. 


\section{III.2 P2K2 extracellular domain}

\section{III.2.1 P2K2 shows high ATP binding affinity (experiment performed Dr. Cho Sung-}

\section{Hwan)}
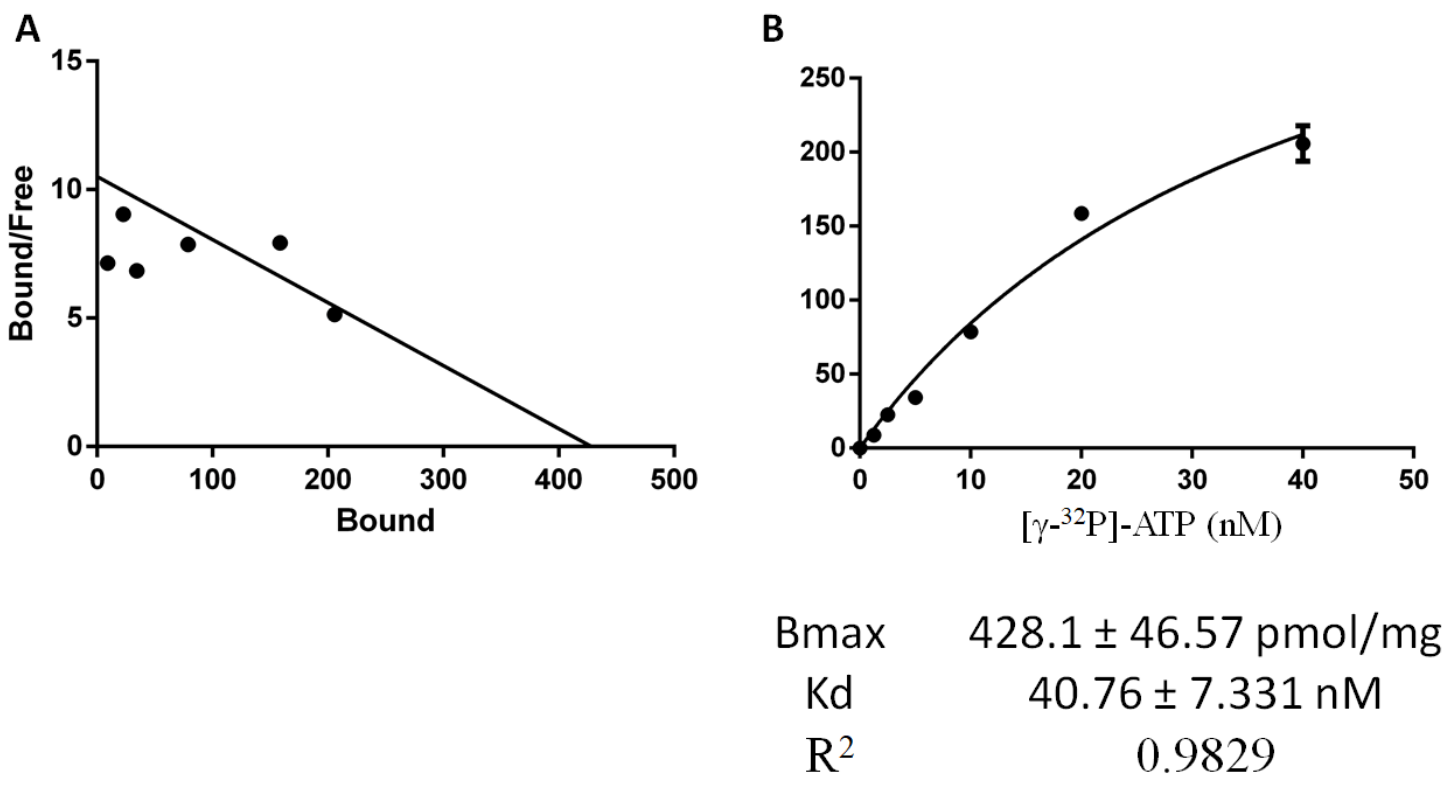

Figure III.7: ATP-P2K2 in vitro binding assay. The extracellular domain of P2K2 was mixed with the indicated concentration of $\left[\gamma^{3}{ }^{32} \mathrm{P}\right]$-labeled ATP for 30 minutes. After doing gel filtration chromatography to separate bound ATP and free ATP, samples were measured by scintillation counting. The results were plotted to generate (A) a Scatchard plot of ATP binding to the P2K2 extracellular domain or (B) a non-linear regression saturation curve of ATP binding to the P2K2 extracellular domain. Experiment was repeated two times with similar results.

An in vitro binding assay was used to examine whether the extracellular domain of P2K2 can bind ATP. To measure the binding affinity, purified P2K2 extracellular domain was incubated with different concentrations $(0,1.25,2.5,5,10,20$ and $40 \mathrm{nM})$ of 
$\left[\gamma-{ }^{32} \mathrm{P}\right]$-labeled ATP in the absence (for total binding) or presence (for non-specific binding) of an 100-fold excess of unlabeled ATP. Specific bound ATP at each concentration was measured by scintillation counting. Using a non linear model, we calculated that P2K2 binds ATP at high affinity $\left(\mathrm{K}_{\mathrm{d}}=40.76 \mathrm{nM}, \mathrm{Bmax}=428.1\right.$ $\mathrm{pmol} / \mathrm{mg}$ ) (Figure III.7B). To confirm, we also used the linear model to estimate the binding affinity. Figure III.7A shows a similar result as the non-linear model that ATP binds to P2K2 with high affinity. From these results, we demonstrated that P2K2 binds ATP by its extracellular domain.

III.2.2 P2K2 specifically binds to ATP and ADP (experiment performed Dr. Cho Sung-Hwan)

\begin{tabular}{|cc|}
\hline Ligand & $\mathbf{K}_{\mathbf{i}}$ (nM) \\
\hline ATP & 31.7 \\
ADP & 97.3 \\
AMP & $>5,000$ \\
\hline Adenosine & $>5,000$ \\
\hline Adenine & $>5,000$ \\
\hline GTP & 2,232 \\
ITP & $>5,000$ \\
\hline CTP & $>5,000$ \\
\hline TTP & $>5,000$ \\
UTP & $>5,000$ \\
\hline
\end{tabular}

Figure III.8: Competitive binding assay for P2K2. Twenty five $n M\left[\gamma^{-}{ }^{32} \mathrm{P}\right]$-labeled ATP and $10 \mathrm{nM}$ to $10 \mathrm{mM}$ of unlabeled nucleotides were used for the assay. The results were obtained by measuring specific binding of labeled ATP. The inhibition constant $\left(\mathrm{K}_{\mathrm{j}}\right)$ 
values were calculated using a one site - fit $\mathrm{K}_{\mathrm{i}}$ non-linear regression model. Experiment was repeated two times with similar results.

Our next question was whether P2K2 could bind other nucleotides or ligands that are similar to ATP. To answer this question, we performed an in vitro competitive binding assay. In this assay, we tested the ability of unlabeled ligands to compete with the binding of radiolabeled ATP. The results showed that unlabeled ATP is the strongest competitor $\left(\mathrm{K}_{\mathrm{j}}=31.7 \mathrm{nM}\right)$. Unlabeled ADP can also compete with radio labeled ATP, but with a higher $K_{j}$ value $\left(K_{j}=97.3\right)$. Unlabeled GTP was a weak competitor while the other ligands (AMP, adenosine, adenine, or other nucleotides such as ITP, CTP, TTP and UTP) showed no competition (Figure III.8). In brief, besides ATP as a preferred ligand, P2K2 can bind ADP with a lower affinity and GTP weakly while AMP, adenosine, adenine or ITP, CTP, TTP and UTP are not P2K2 ligands.

\section{III.2.3 Computational analysis of P2K2 structure (experiment performed by Dr. Cuong T. Nguyen)}

To further understand how ATP can bind to the extracellular domain of P2K2, we used homology modeling to predict the protein structure of P2K2. Among $40 \mathrm{P} 2 \mathrm{~K} 2$ homologous crystal structures present in the Protein Data Bank (www.rcsb.org), we chose four candidates with the highest sequence identity to P2K2: 1G7Y (26\%), 1DBN (26.3\%), 1HQL (26.7\%) and 1AVB (25.1\%). Starting from these structures, Dr. Nguyen used Modeller v9.21 (https://salilab.org/modeller/) to predict the P2K2 extracellular domain structure. The quality of the raw $\mathrm{P} 2 \mathrm{~K} 2$ modeling structure was checked with Ramachandran plots using the Rampage online tool 
(http://mordred.bioc.cam.ac.uk/ rapper/rampage.php). Finally, the refined P2K2 structural model was visualized using Modeller (Figure III.9). The putative extracellular domain structure of $\mathrm{P} 2 \mathrm{~K} 2$ contains $13 \beta$-strains, four defined loops (named loop A, B, C and D), two $\beta$-turns and an extended loop. The extended loop is only found in the Brassica lectin receptor kinase family.

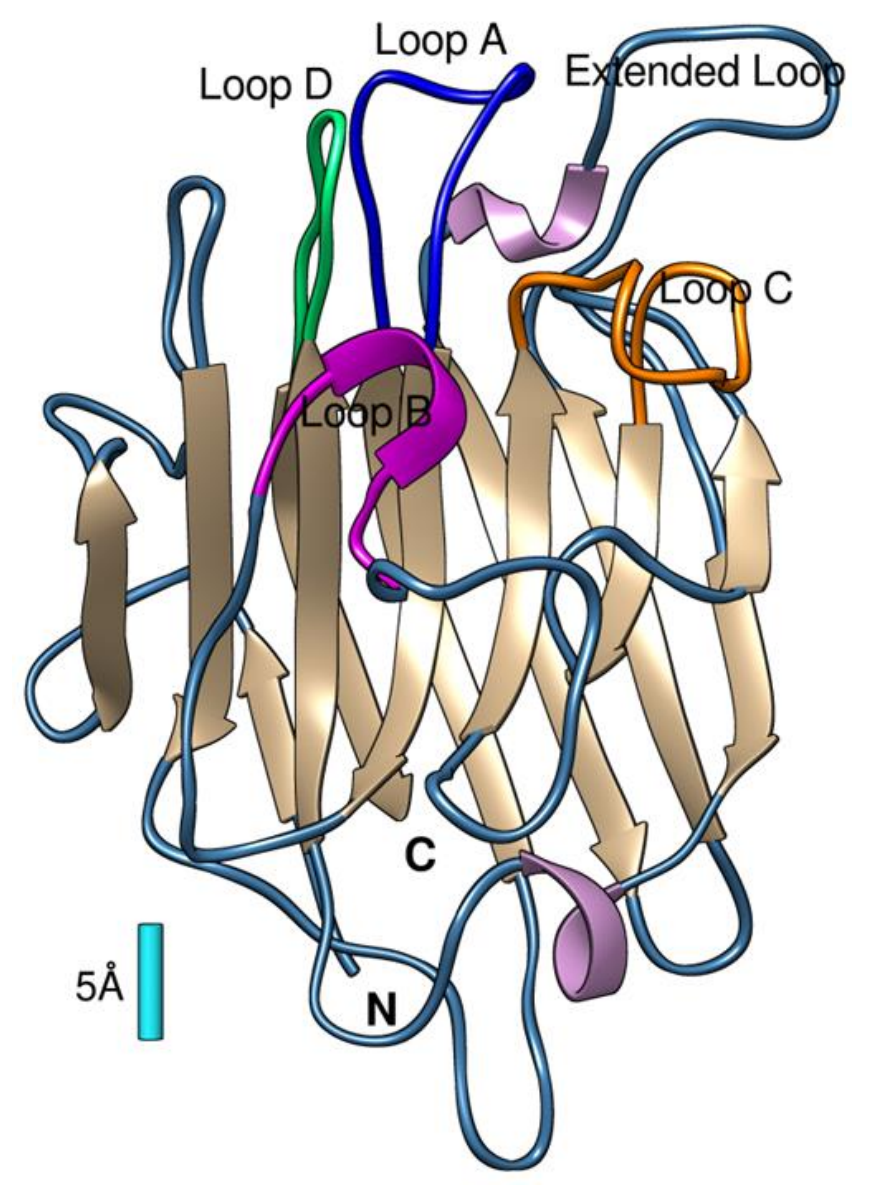

Figure III.9: P2K2 extracellular domain 3D structure. The putative backbone alphacarbon traces of P2K2 include $13 \beta$-strands (brown); 4 defined loops ( A-blue; Bmagenta; C-orange; D-green); an extended loop (dark blue) and $2 \beta$-turns (purple). The cyan bar shows relative scale $\left(1\right.$ angstrom $\left.=10^{-10} \mathrm{~m}\right)$. 


\section{III.2.4 Identification of putative ATP-binding sites (experiment performed by Dr.}

\section{Cuong T. Nguyen)}

Starting from the predicted structure of the P2K2 extracellular domain, we used sequence-based and structure-based methods to predict the ATP-binding sites. Using four different prediction tools (COACH, COFACTOR, FindSite and TM-Site), we obtained similar binding site predictions (Figure III.10). The results showed that ATP binds to four defined loops at specific residues shown in Table III.1.

With the predicted binding site, we used AutiDockVina (http://vina.scripps.edu/) for ATP target docking and potential key ATP-binding residue identifying. The best P2K2-ATP binding complex with the lowest energy score, $-8.1 \mathrm{kcal} / \mathrm{mol}$, is shown in Figure III.11A and B. Interestingly, besides the nine predicted binding sites above, we identified six more potential key binding residues that are in Table III.2. The interaction map between P2K2 and ATP was visualized using LigPlot+ (https://www.ebi.ac.uk/thornton-srv/software/LigPlus/) (Figure III.11C). 
Table III.1: List of predicted P2K2 interacting residues with ATP ligand obtained from different prediction tools. * Values range in between [0-1]; where a higher score indicates a more reliable ligand-binding site prediction.

\begin{tabular}{|c|c|c|c|c|c|}
\hline Prediction tools & LOOP A & LOOP B & LOOP C & LOOP D & Score* \\
\hline $\mathrm{COACH}$ & $\begin{array}{l}\text { Gly98, } \\
\text { His99 }\end{array}$ & $\begin{array}{l}\text { Glu115, } \\
\text { Thr117, } \\
\text { Arg118 }\end{array}$ & $\begin{array}{l}\text { Val143, } \\
\text { Asn145 }\end{array}$ & $\begin{array}{l}\text { Gly244, } \\
\text { Thr245, } \\
\text { Ser246 }\end{array}$ & 0.56 \\
\hline COFACTOR & $\begin{array}{l}\text { Gly98, } \\
\text { His99 }\end{array}$ & $\begin{array}{l}\text { Thr117, } \\
\text { Arg118 }\end{array}$ & $\begin{array}{l}\text { Val143, } \\
\text { Asn145 }\end{array}$ & $\begin{array}{l}\text { Gly244, } \\
\text { Thr245, } \\
\text { Ser246 }\end{array}$ & 0.52 \\
\hline FindSite & $\begin{array}{l}\text { Gly98, } \\
\text { His99 }\end{array}$ & $\begin{array}{l}\text { Thr117, } \\
\text { Arg118 }\end{array}$ & $\begin{array}{l}\text { Val143, } \\
\text { Asn145 }\end{array}$ & $\begin{array}{l}\text { Gly244, } \\
\text { Thr245, } \\
\text { Ser246 }\end{array}$ & 0.55 \\
\hline TM-Site & $\begin{array}{l}\text { Gly98, } \\
\text { His99 }\end{array}$ & $\begin{array}{l}\text { Thr117, } \\
\text { Arg118 }\end{array}$ & $\begin{array}{l}\text { Val143, } \\
\text { Asn145 }\end{array}$ & $\begin{array}{l}\text { Gly244, } \\
\text { Thr245, } \\
\text { Ser246 }\end{array}$ & 0.40 \\
\hline $\begin{array}{l}\text { Consensus } \\
\text { residues }\end{array}$ & $\begin{array}{l}\text { Gly98, } \\
\text { His99 }\end{array}$ & $\begin{array}{l}\text { Thr117, } \\
\text { Arg118 }\end{array}$ & $\begin{array}{l}\text { Val143, } \\
\text { Asn145 }\end{array}$ & $\begin{array}{l}\text { Gly244, } \\
\text { Thr245, } \\
\text { Ser246 }\end{array}$ & \\
\hline
\end{tabular}




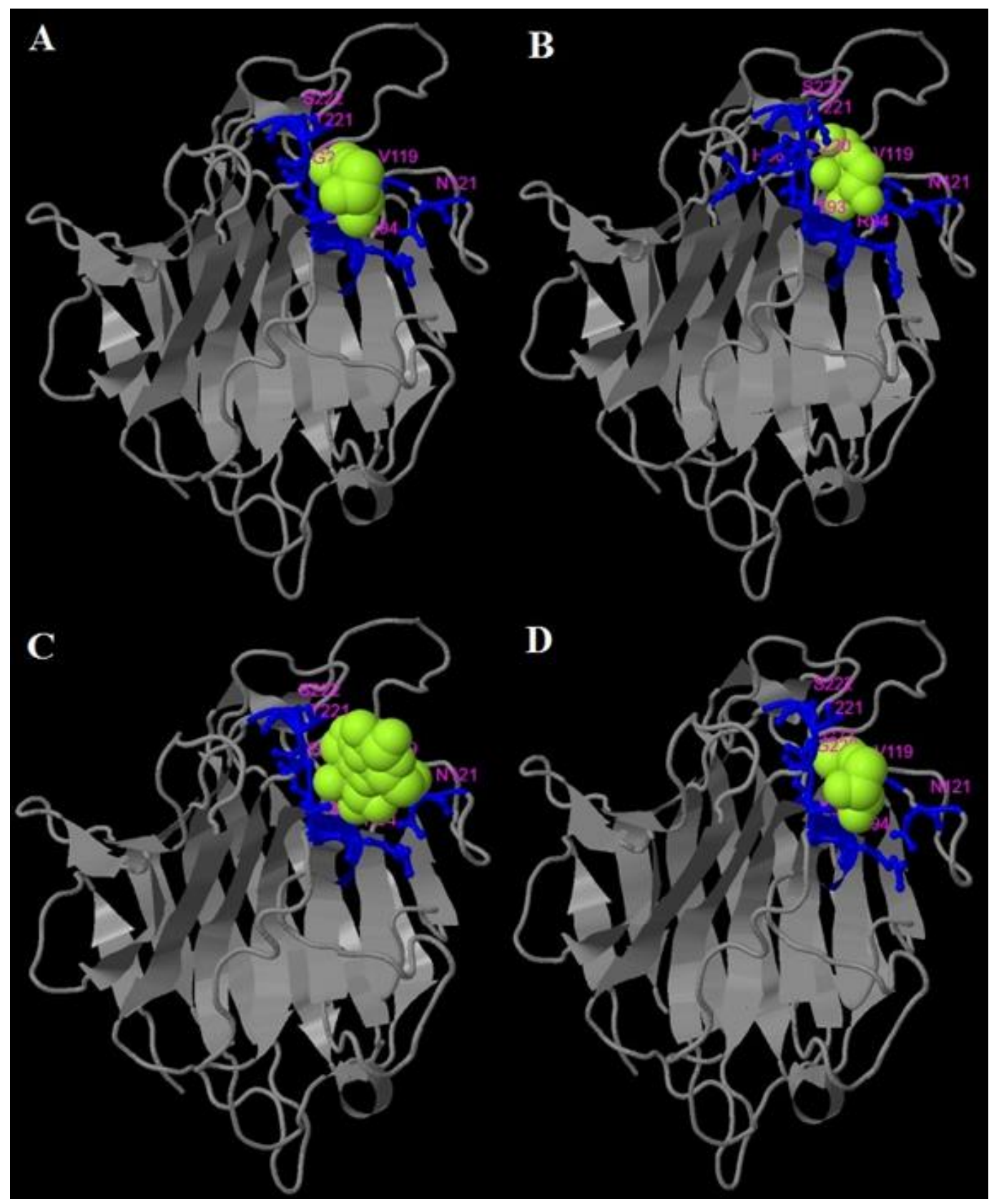

Figure III.10: ATP-P2K2 free docking. Ribbon-cartoon representations of P2K2 predicted binding site and predicted P2K2 interacting residues with ATP ligand obtained from A) COACH, B) COFACTOR, C) FINDSITE and D) TM-SITE. Blue color sticks with the corresponding label are P2K2 predicted interacting residues. Green balls are different types of predicted ligands inferred from templates. 

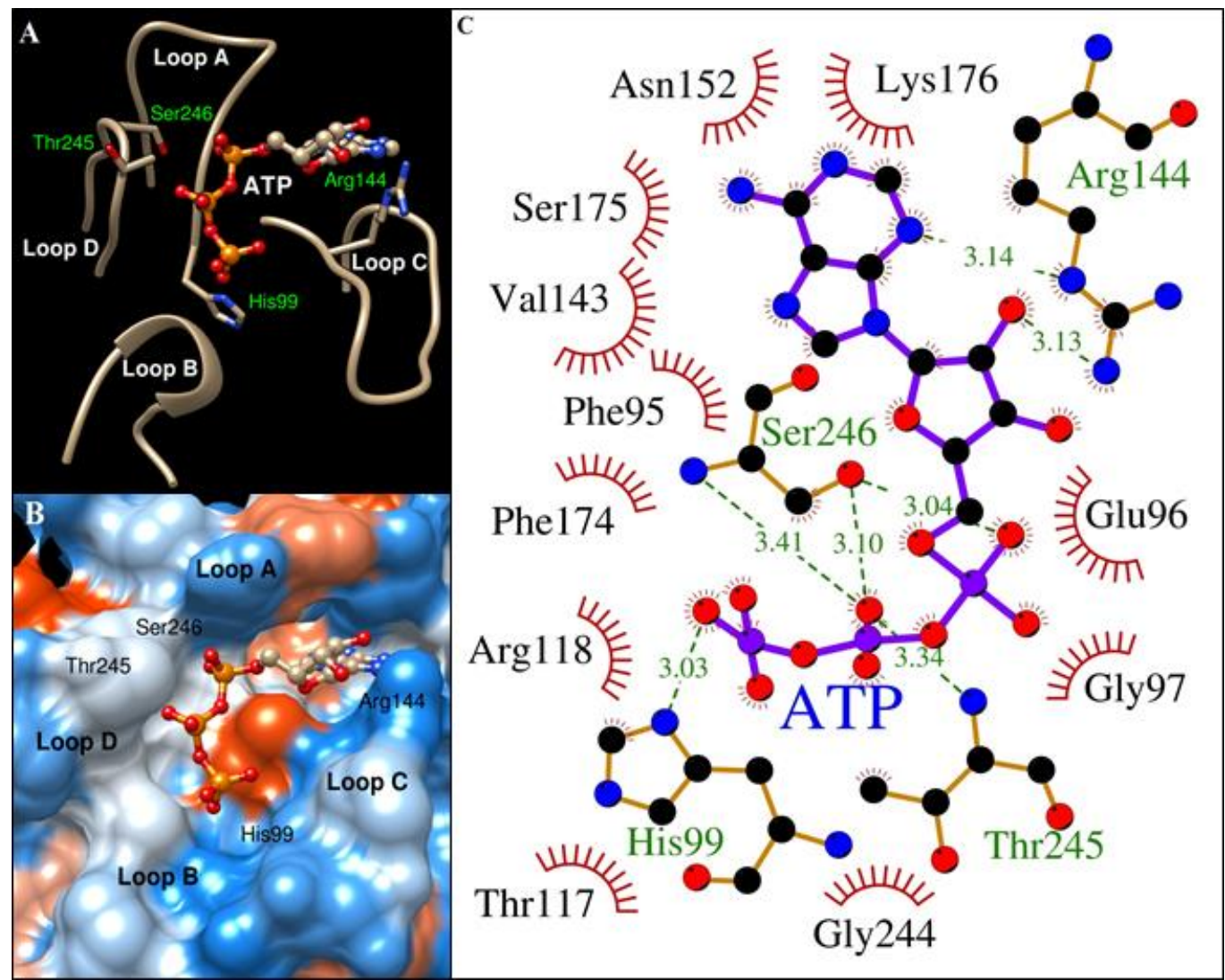

Figure III.11: Putative ATP-binding site of P2K2 in target docking. Cartoon

representations of the ATP-binding site and interacting map between ATP and residues of P2K2 of the best binding mode $(-8.1 \mathrm{kcal} / \mathrm{mol})$. (A) A close-up of the P2K2 binding loops and ATP molecule in ball and stick mode. (B) A close up of the electrostatic potential molecular surface of the P2K2 binding pocket and ATP molecule in ball and stick mode. (C) A detailed map of interaction between P2K2 and ATP in the docking complex. ATP resides in the middle of the map, and it is surrounded by interacting residues of four different loops (A to D), dashed-lines with numbers are hydrogen bonds with bond distances in angstroms shared with atoms of ATP, where residues with a red crown denote hydrophobic and Van der Waals interactions. Numbered residues represent their actual position in the P2K2 full-length sequence. 
Table III.2. List of P2K2 interacting residues with the ATP ligand obtained from target docking.

\begin{tabular}{|c|c|c|}
\hline Loop & Hydrogen bonds & $\begin{array}{c}\text { Hydrophobic and Val de Waals } \\
\text { interactions }\end{array}$ \\
\hline A & His99 & Phe95, Glu96, Gly97 \\
\hline B & - & Thr117, Arg118 \\
\hline C & Arg144 & Val143, Asn152 \\
\hline Extended loop & - & Phe174, Ser175, Lys176 \\
\hline D & Thr245, Ser246 & Gly244 \\
\hline Total & 7 & 11 \\
\hline
\end{tabular}




\section{III.2.5 Mutations at critical binding residues reduce the ATP binding affinity of P2K2 (experiment performed by Dr. Cho Sung-Hwan)}

The putative P2K2 extracellular domain structure and its ATP-binding model predicted some of the putative key residues for ATP-binding. To confirm the essential roles of those residues, we tried to mutate each of these predicted residues to alanine. Among the 15 candidates, we created three extracellular domain mutant versions, $p 2 k 2^{R 144 A}, p 2 k 2^{H 99 A}$, and $p 2 k 2^{T 245 A}$. We performed the in vitro binding assay to test the ATP-binding ability of these mutant versions compared to the P2K2 wild-type protein. Figure III. 12 shows that the binding affinity of $p 2 k 2^{R 144 A}$ and $p 2 k 2^{T 245 A}$ mutant versions do not significant differed comparing with the wild-type. Interestingly, the $p 2 k 2^{H 99 A}$ mutant version shows an inability to bind to ATP. This result not only partially supported our ATP-P2K2 binding model, but also showed that His99 is one of the critical ATPbinding residues of $\mathrm{P} 2 \mathrm{~K} 2$. 


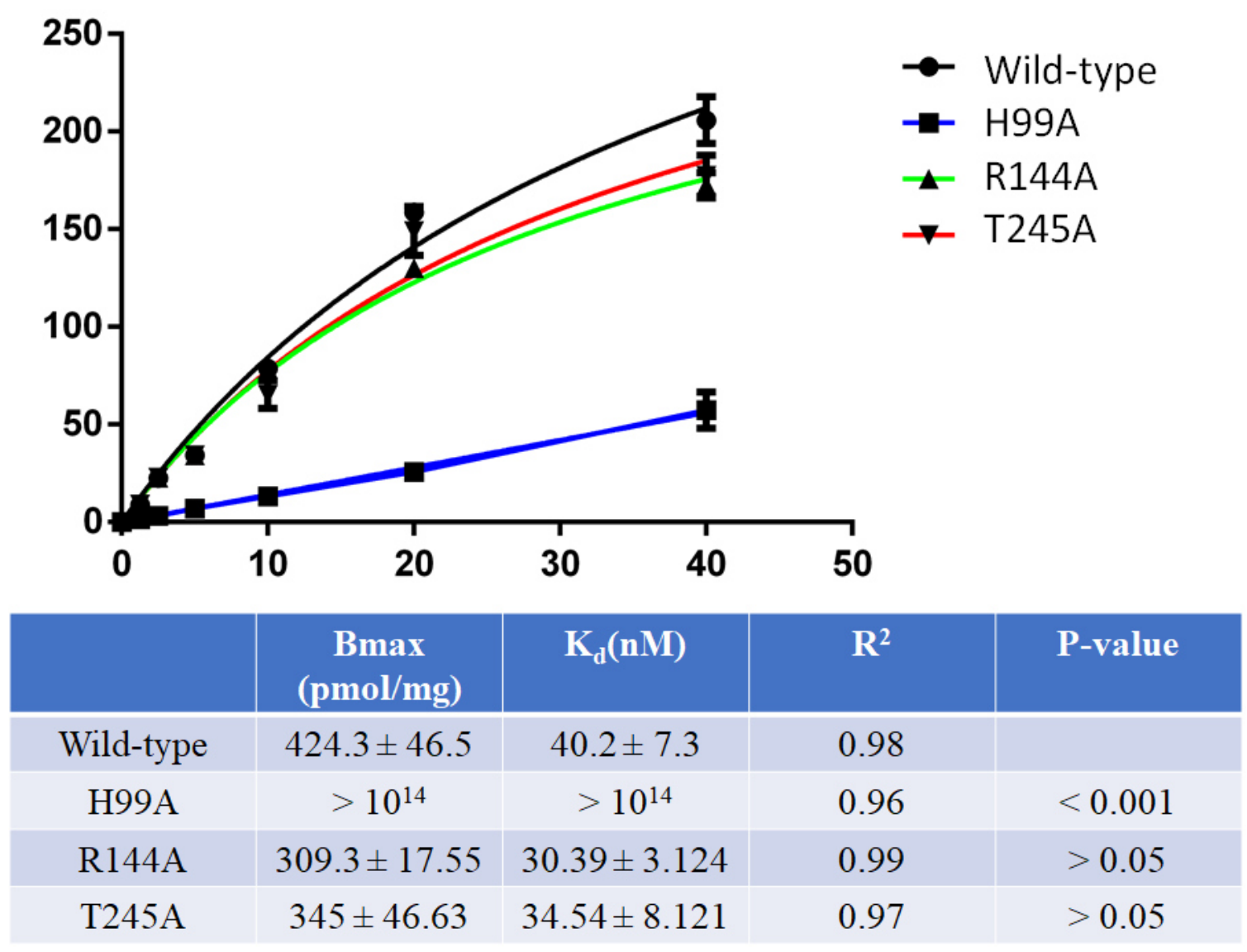

Figure III.12: In vitro binding assay of ATP binding to P2K2 wild-type and mutant versions. The curves present results based on a non-linear regression model analysis using GraphPad Prism 6. Bmax: the maximum binding capacity; $\mathrm{K}_{\mathrm{d}}$ : dissociation constant; $\mathrm{R}^{2}$ : model goodness of fit; P-value: P-value of t-test for Bmax and $\mathrm{K}_{\mathrm{d}}$ of wildtype vs. mutant versions. Experiment was repeated twice with similar results. 


\section{III.3 P2K2 intracellular domain}

\section{III.3.1 The intracellular domain of P2K2 is an active kinase}

To serve as an extracellular receptor, $\mathrm{P} 2 \mathrm{~K} 2$ should have a mechanism to translate the extracellular signal, ATP binding, into an intracellular signal. P2K2 has an intracellular domain predicted to have kinase activity based on the SMART Database. The putative kinase domain of $\mathrm{P} 2 \mathrm{~K} 2$ raises the hypothesis that $\mathrm{P} 2 \mathrm{~K} 2$ can translate the extracellular signal, eATP binding, into an intracellular signal by protein phosphorylation.

To test this hypothesis, we cloned the intracellular domain, including the kinase domain (KD), of P2K2 fused with a GST tag. The GST-P2K2KD was expressed in E.coli B121 and affinity purified using glutathione (GSH) resin. Using the GST protein as a negative control, GST-P2K1KD as a positive control and myelin basic protein (MBP) as a standard universal kinase substrate, we performed an in vitro kinase assay to measure kinase activity. Figure III.13 shows that GST protein, the negative control, has no kinase activity while GST-P2K1-KD, as reported by Choi et al. (2014), has strong kinase activity. GST-P2K2-KD, similar to P2K1, has strong auto-phosphorylation activity as well as trans-phosphorylation activity, as shown by phosphorylation of MBP. 


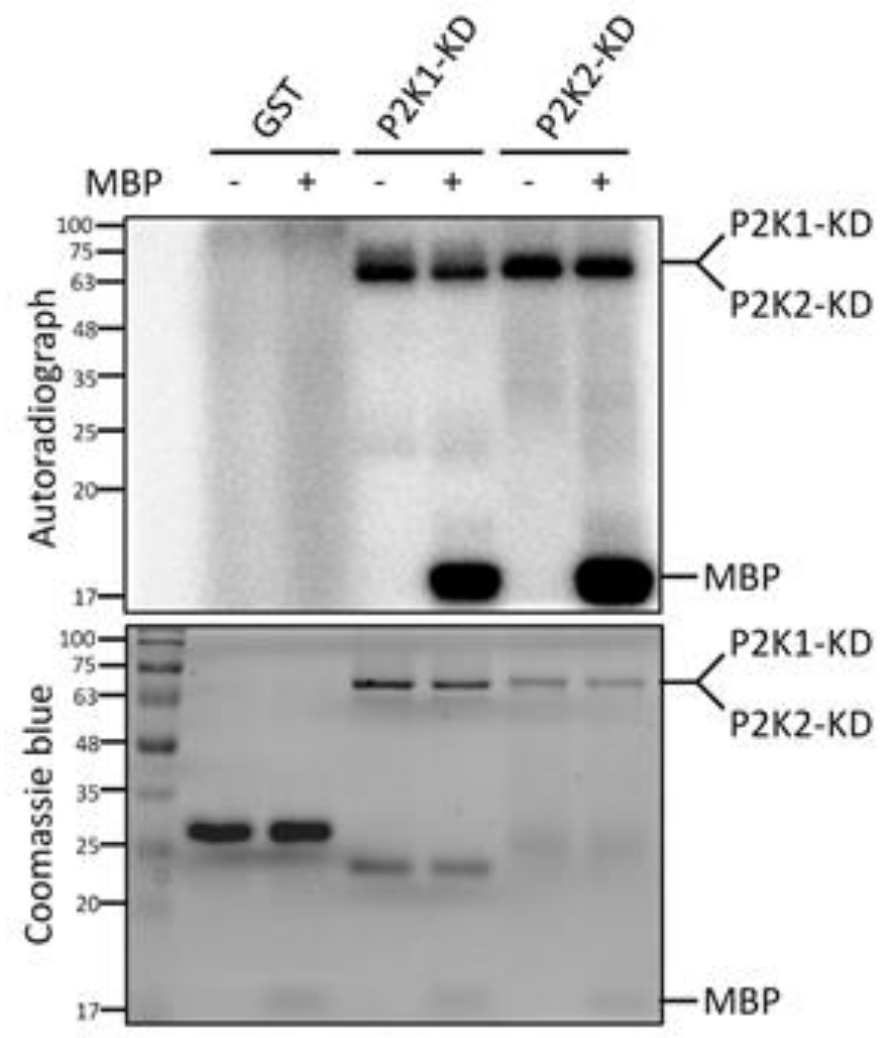

Figure III.13: Kinase activities of the P2K2 kinase domain. An autoradiograph (top panel) showing the kinase activity of P2K2 and P2K1. GST (glutathione S-transferase) was used as negative control; P2K1-KD (kinase domain of P2K1 fused with GST) was used as a positive control; P2K2-KD (kinase domain of P2K2 combined with GST); and MBP (myelin basic protein - universal kinase substrate). CCB (Coomassie brilliant blue) staining (bottom panel) shows input control. Experiment was repeated at least three times with similar results. 


\section{III.3.2 p2k2 intracellular domain mutations disrupt kinase activity}

Two mutant versions of GST-P2K2-KD were generated using site-directed mutagenesis, GST-p2k2 $2^{\mathrm{D} 467 \mathrm{~N}}$ (kinase activation motif mutant version) and $p 2 k 2^{D 525 N}$ [similar $p 2 k 1-1$ mutation version (Choi et al., 2014)]. Figure III.14 shows that $p 2 k 2^{D 467 N}$ has no kinase activity while $p 2 k 2^{D 525 N}$ has very low kinase activity, weak autophosphorylation activity and no trans-phosphorylation activity.

Protein phosphorylation usually leads to slower migration of the protein in SDS gels due to an increase in protein molecular weight, as well as effects on protein structure and SDS binding. This is illustrated in Figure III.14, where the two mutant versions of GST-P2K2-KD, incapable of autophosphorylation, migrate faster in SDS-PAGE gels compared to the wild-type version. In order to confirm that this is due to phosphorylation, the products of in vitro kinase reactions were treated with lambda phosphatase. As expected, after phosphatase treatment, both the mutant and wild-type P2K2 kinase domain proteins migrated similarly (Figure III.15).

In conclusion, the intracellular domain of P2K2 is an active kinase. Site-directed mutagenesis of key residues of the P2K2 cytoplasmic domain significantly reduced or eliminated kinase activity. 


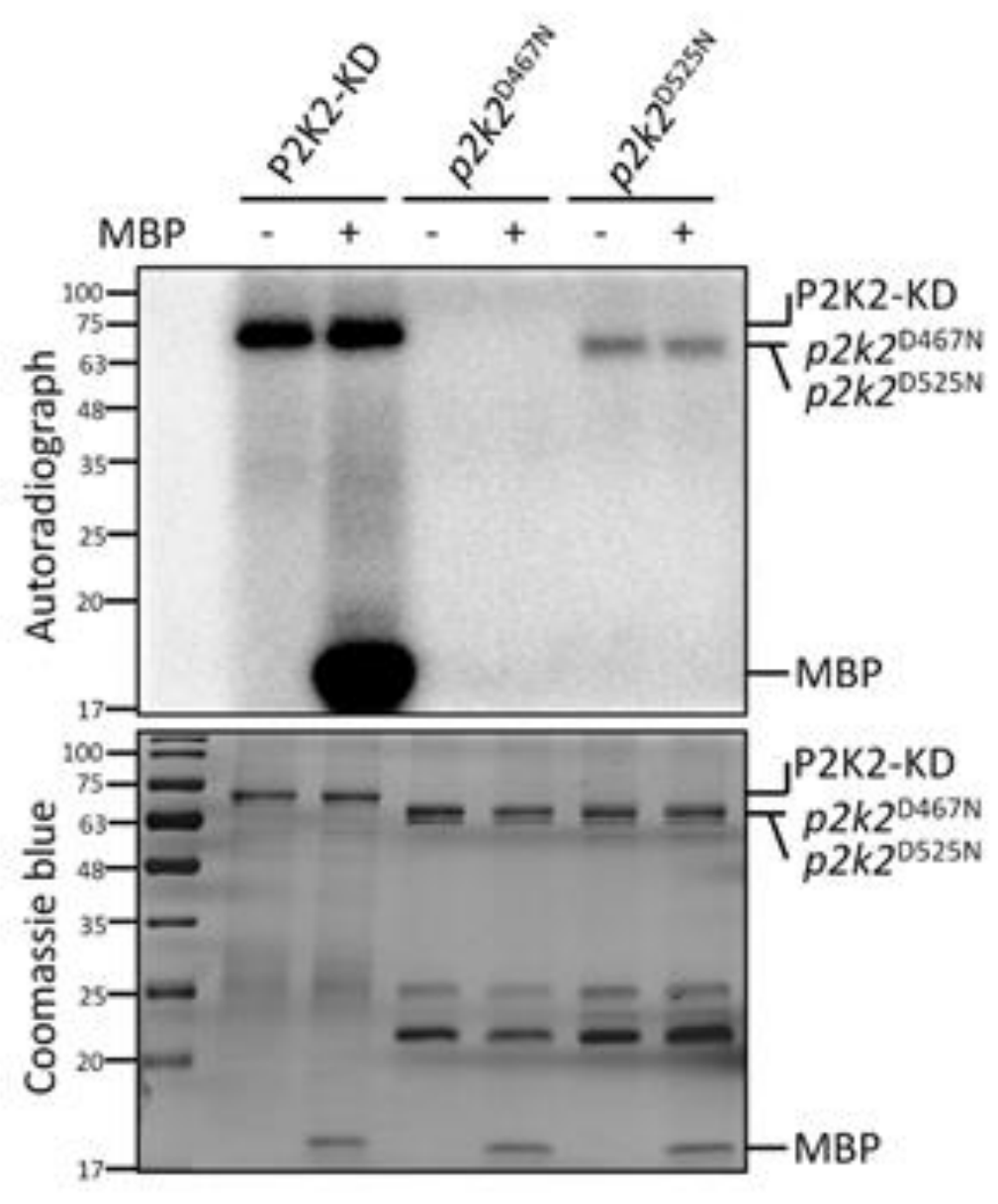

Figure III.14: Kinase activity of mutation versions of P2K2. P2K2-KD (kinase

domain of P2K2 fused with GST) was used as a positive control; $p 2 k 2^{D 467 N}$ and $p 2 k 2^{D 525 N}$ are point mutations of key catalytic domain residues within the P2K2 kinase domain. CCB (Coomassie brilliant blue) staining (bottom panel) shows input control. Experiment was repeated at least three times with similar results. 


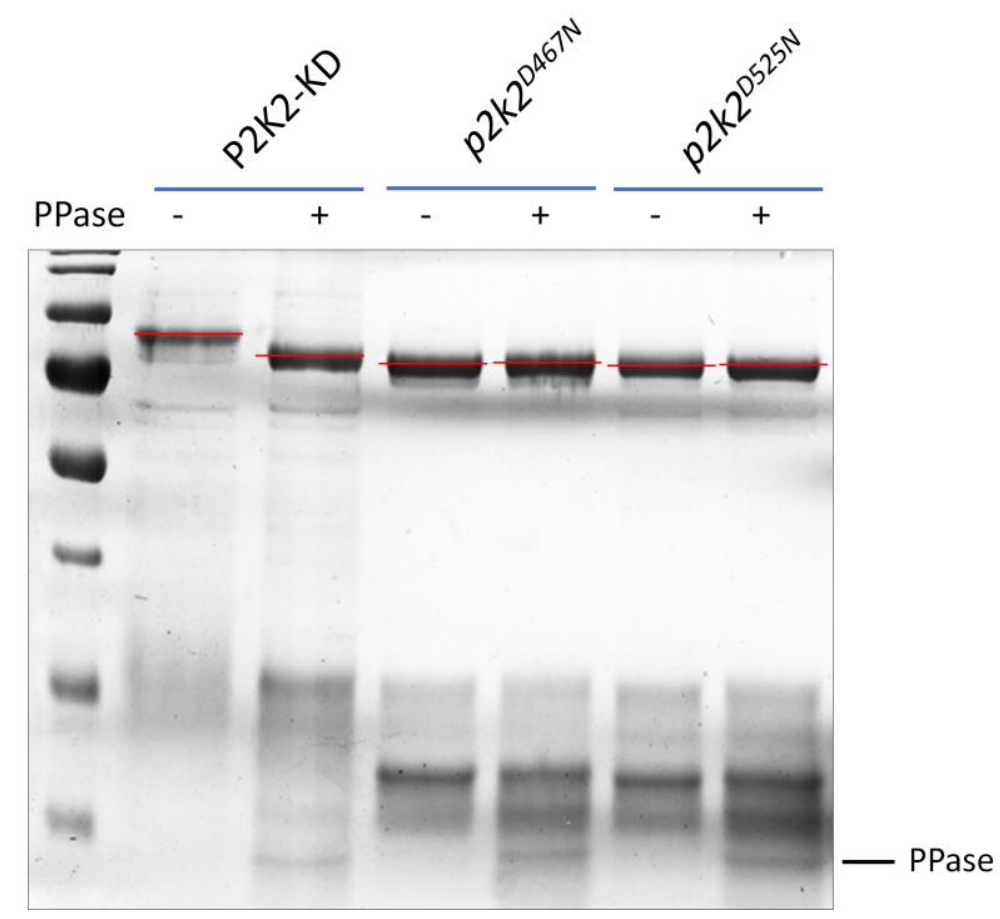

Figure III.15: P2K2 kinase domains, wild-type and mutant versions, were treated with Lambda protein phosphatase (PPase). SDS gel mobility of wild-type P2K2 kinase domain was reduced after being treated with PPase while the mobility of the mutant protein, incapable of phosphorylation, was not affected. Experiment was repeated at least three times with similar results. 


\section{III.3.3 Mutations in the kinase domain abolish kinase activity leading to the loss of P2K2 receptor function}

Our in vitro kinase assays showed that $\mathrm{P} 2 \mathrm{~K} 2$ has strong kinase activity. However, the roles of P2K2 kinase activity in ATP signal transduction requires testing. Importantly, we demonstrated that $p 2 k 2^{D 467 N}$ and $p 2 k 2^{D 525 N}$ versions had no or weak kinase activity. We also showed that ectopic overexpression of $\mathrm{P} 2 \mathrm{~K} 2$ in the $p 2 k 1-3$ mutant line could partially complement the ability to respond to eATP (Figure III.2). To test the critical role of the P2K2 kinase activity in eATP signal transduction, we examined the ability of the $p 2 k 2$ kinase mutated versions to complement the $p 2 k 1-3$ mutant phenotype; i.e., specifically the ability of ATP to induce an intracellular calcium response. We generated transgenic plants in which full-length $p 2 k 2^{D 467 N}$ or $p 2 k 2^{D 525 N}$ was expressed from the p35S promoter in the $p 2 k 1-3$ mutant background. As discussed above, we then used aequorin luminescence to measure the intracellular calcium response of seedlings upon addition of ATP. We used $p 2 k 1-3$ mutant plants as a negative control and oeP2K $2 / p 2 k 1-3$ plants as a positive control.

The results showed that both $p 2 k 2$ kinase mutant versions could not complement the $p 2 k 1-3$ mutant phenotype (Figure III.16). We conclude from this experiment that P2K2 kinase activity is required for receptor function. 


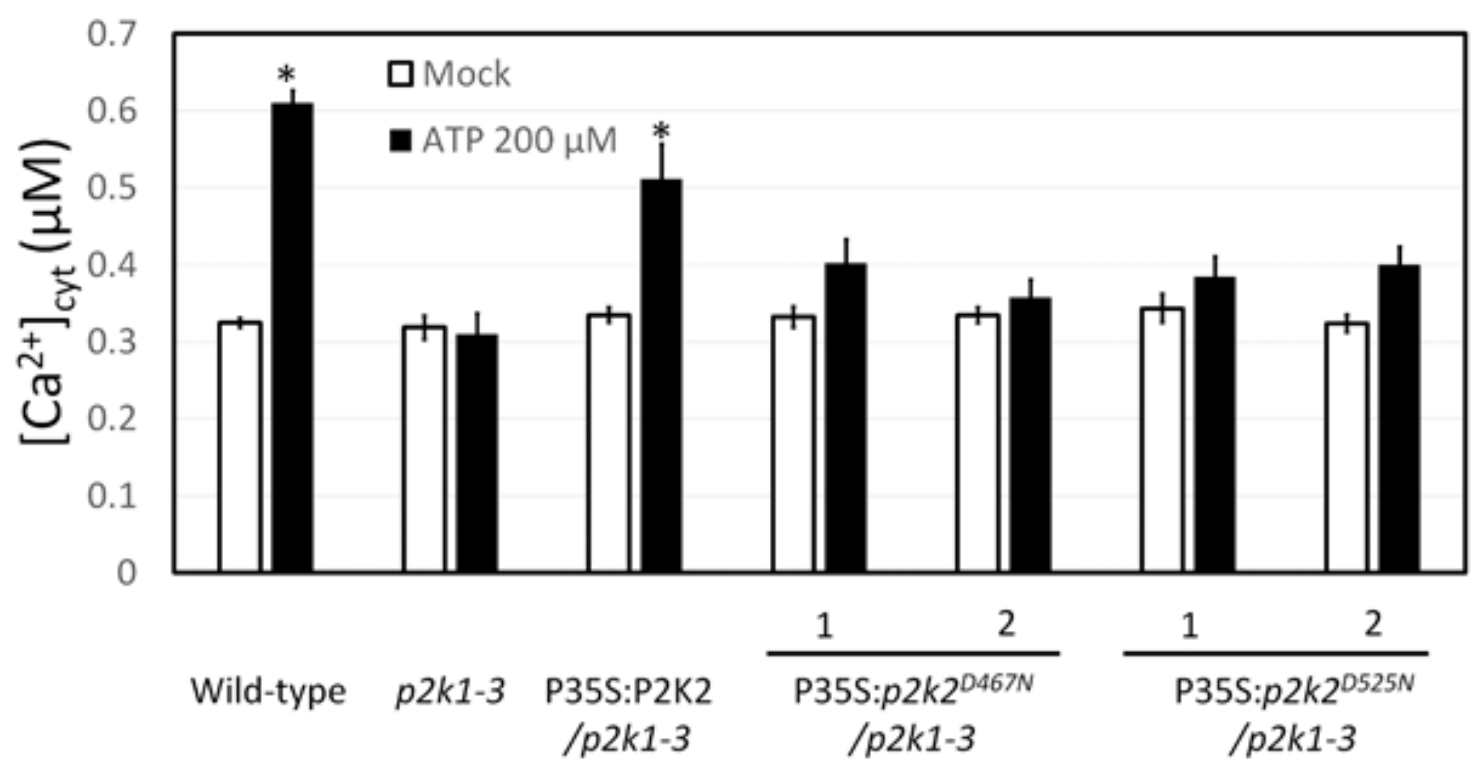

Figure III.16: Ectopic expression of kinase-dead mutant P2K2 in p2k1-3 mutant line failed to complement the eATP-triggered cytosolic calcium response phenotype. The wild-type, $p 2 k 1-3$ mutant and ectopic expression of $\mathrm{P} 2 \mathrm{~K} 2$ in $p 2 k 1-3$ were used as controls. 1 and 2 represent independent transgenic lines. Data represent means \pm SEs, $n=$ 8 ; asterisks denote values significantly different from $p 2 k 1-3$ mutant $(* P<0.01$, Student's $t$-test). Experiment was repeated at least twice with similar results. 


\section{III.4 P2K2 localizes to the plasma membrane}

Sequence-based predictions using the SMART database suggested that P2K2 has a single transmembrane domain. Predictions using SUBA4 (http://suba.live/), a subcellular consensus prediction website, suggested that P2K2 should localize to the plasma membrane. In order to confirm these predictions, we expressed full-length P2K2 with a YFP-C-terminal tag in Arabidopsis protoplasts. Using the free YFP protein as a negative control, the FM4-64 dye to visualize the plasma membrane and chlorophyll autofluorescence to localize the chloroplasts, we found that $\mathrm{P} 2 \mathrm{~K} 2$ was localized to the plasma membrane (Figure III.17). As shown, free YFP protein shows a strong signal in the nucleus, cytosol and plasma membrane, while P2K2:YFP was exclusively localized to the plasma membrane.

To confirm the subcellular localization of P2K2, we generated full-length P2K2 with a GFP-C-terminal tag and stably expressed it in transgenic Arabidopsis lines. To avoid the strong auto-fluorescent signal of chlorophyll, we observed the result in roots. In Figure III.18, full-length P2K2:GFP stably expressed from the p35S promoter in transgenic lines showed a strong signal at the plasma membrane. The results of these experiments are consistent with $\mathrm{P} 2 \mathrm{~K} 2$ functioning at the plasma membrane as a receptor that recognizes extracellular ATP. 


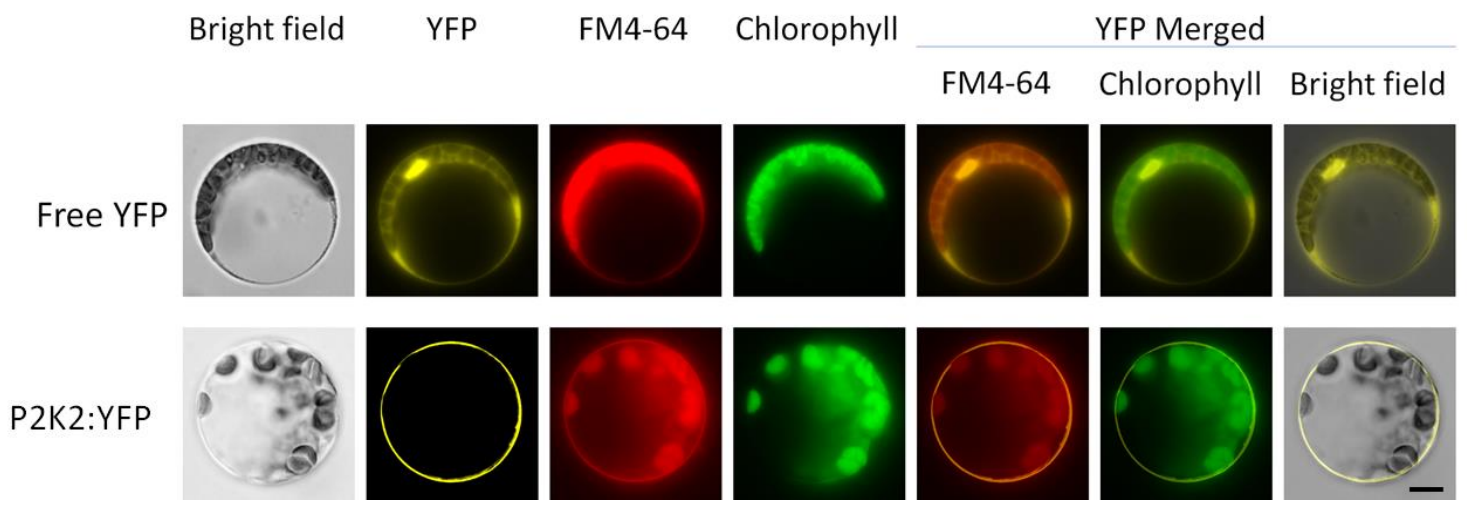

Figure III.17: Subcellular localization of P2K2 fused to YFP in Arabidopsis protoplasts. Free YFP was used as control. The protoplast plasma membrane was labeled with the FM4-64 dye. Chlorophyll was detected by auto-fluorescence. Scale bar $=20 \mu \mathrm{m}$.

Bright field

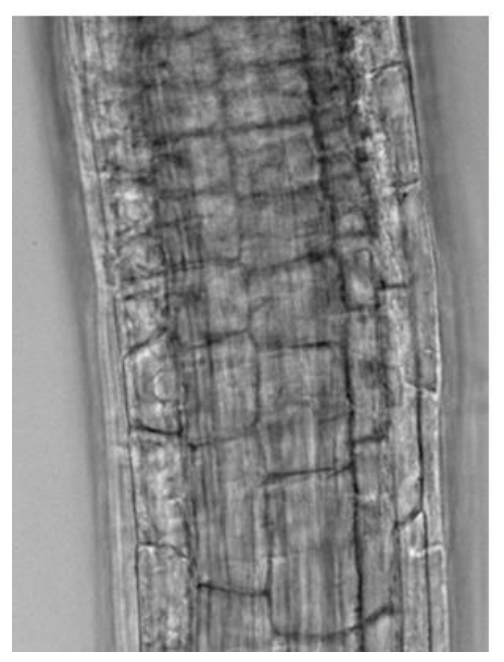

FM4-64

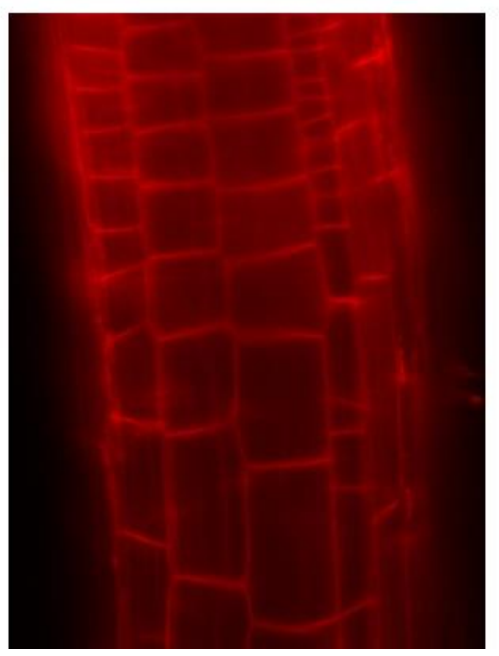

GFP

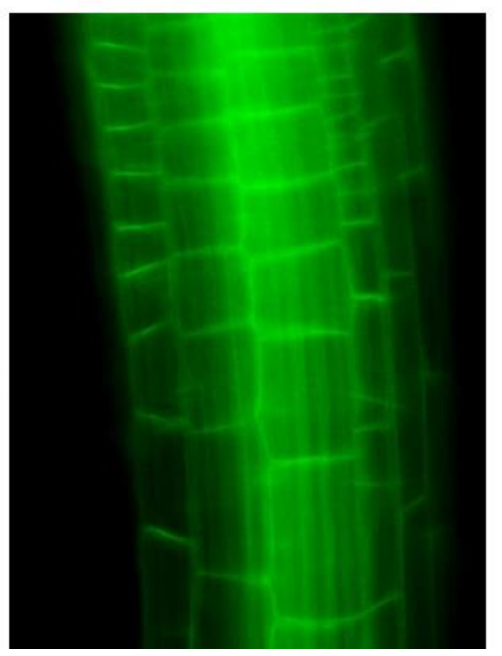

Figure III.18: P2K2 localized to the plasma membrane in the root. Full-length

P2K2:GFP stably expressed under the $\mathrm{p} 35 \mathrm{~S}$ promoter in transgenic lines showed a strong signal at the plasma membrane. 


\section{III.5 P2K2 directly interacts with P2K1 in the plasma membrane}

In many cases, both in plants and animals, ligand binding induces polymerization of receptor proteins, either as homomers or heteromers. For example, P2X receptors in animals are thought to function as trimers for ATP binding (Kawate et al., 2009). We previously reported that ATP could induce P2K1-P2K1 interaction (Chen et al., 2017). $\mathrm{P} 2 \mathrm{~K} 2$ and $\mathrm{P} 2 \mathrm{~K} 1$ share high protein sequence identity, suggesting that $\mathrm{P} 2 \mathrm{~K} 2$ may possibly interact with P2K1 forming a heteromeric receptor complex.

\section{III.5.1 P2K2 interacts with P2K1 and itself in the plasma membrane in the BiFC} assay

In order to test this hypothesis, we performed the BiFC assay in Arabidopsis thaliana protoplasts. We cloned P2K1 and P2K2 into the pAM-PAT-35s:YFPn:GW and pAM-PAT-35s:YFPc:GW vectors and co-transformed protoplasts (Figure III.19). Using FM4-64 to stain the plasma membrane and chlorophyll autofluorescence to localize the chloroplasts, the results clearly show that P2K2 can interact with itself, as well as P2K1 in the plasma membrane. 


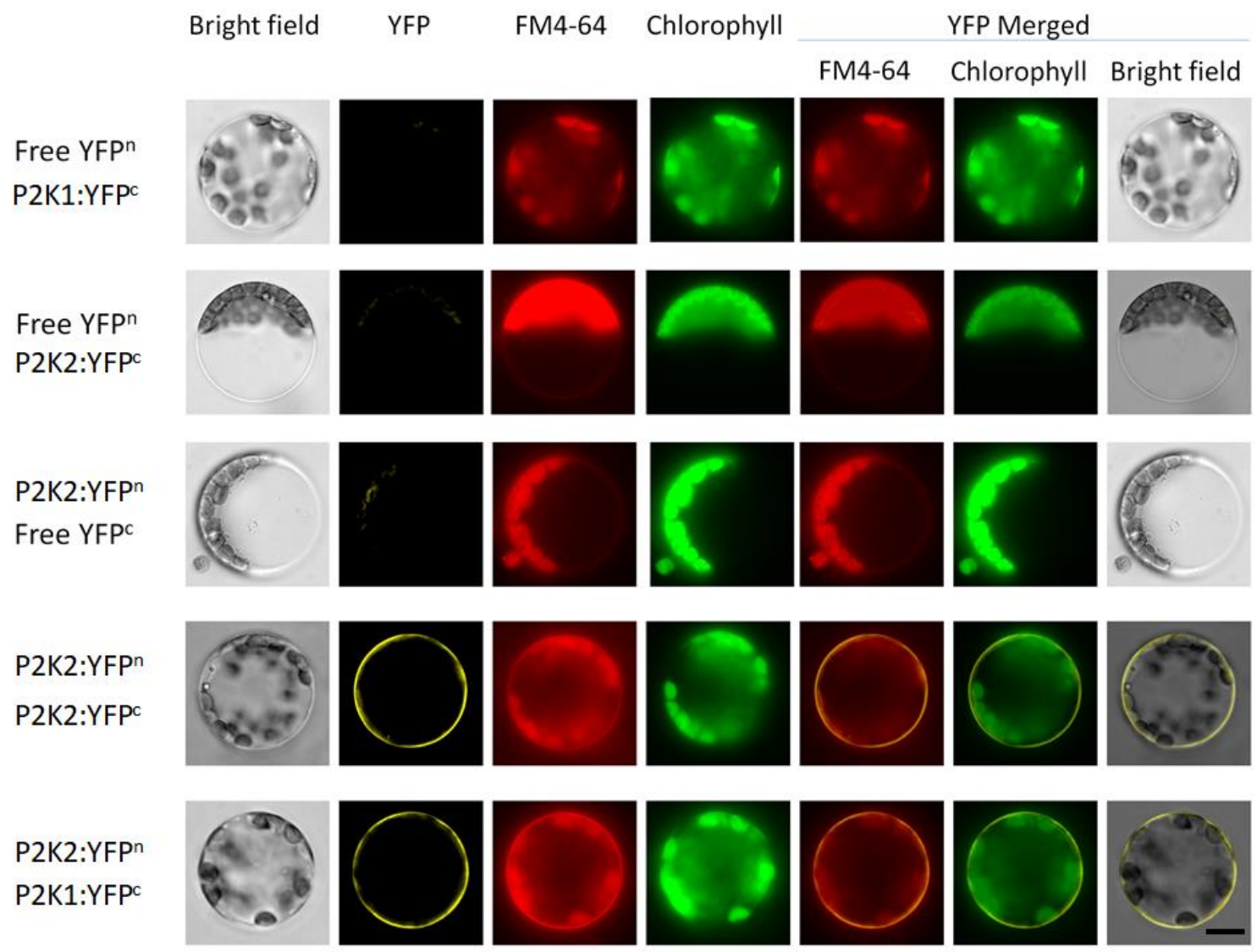

Figure III.19: P2K2 can form homomer and heteromer complexes with P2K1 in the protoplast plasma membrane. The recombinant constructs $\mathrm{P} 2 \mathrm{~K} 2$ : $\mathrm{YFP}^{\mathrm{n}}$ and $\mathrm{P} 2 \mathrm{~K} 1$ $\mathrm{YFP}^{\mathrm{c}}$ or $\mathrm{P} 2 \mathrm{~K} 2-\mathrm{YFP}^{\mathrm{c}}$ were co-transformed into Arabidopsis protoplasts. For negative controls, free $\mathrm{YFP}^{\mathrm{n}}$ and $\mathrm{YFP}^{\mathrm{c}}$ were used. Fluorescence was recorded at 20-24 h after transformation. Scale bar $=20 \mu \mathrm{m}$. 


\section{III.5.2 P2K2 directly interacts with P2K1 in an in vitro pull-down assay}

In order to provide further support for the notion that $\mathrm{P} 2 \mathrm{~K} 2$ and $\mathrm{P} 2 \mathrm{~K} 1$ can directly interact, we purified GST-P2K1-KD (wild-type P2K1 kinase domain), GST-P2K2-KD (wild-type P2K2 kinase domain), GST-LYK5-KD ( kinase domain of lysin motif receptor kinase 5 was used as negative control) and His-P2K2 (kinase domain of P2K2 fused with His tag) proteins to perform an in vitro pull-down assay.

In Figure III.20, we show that HIS-P2K2 can interact with GST-P2K1-KD and GST-P2K2 but cannot interact with GST-LYK5-KD (negative control protein). The results demonstrate that $\mathrm{P} 2 \mathrm{~K} 2$ can directly interact with $\mathrm{P} 2 \mathrm{~K} 1$ and other $\mathrm{P} 2 \mathrm{~K} 2$. 


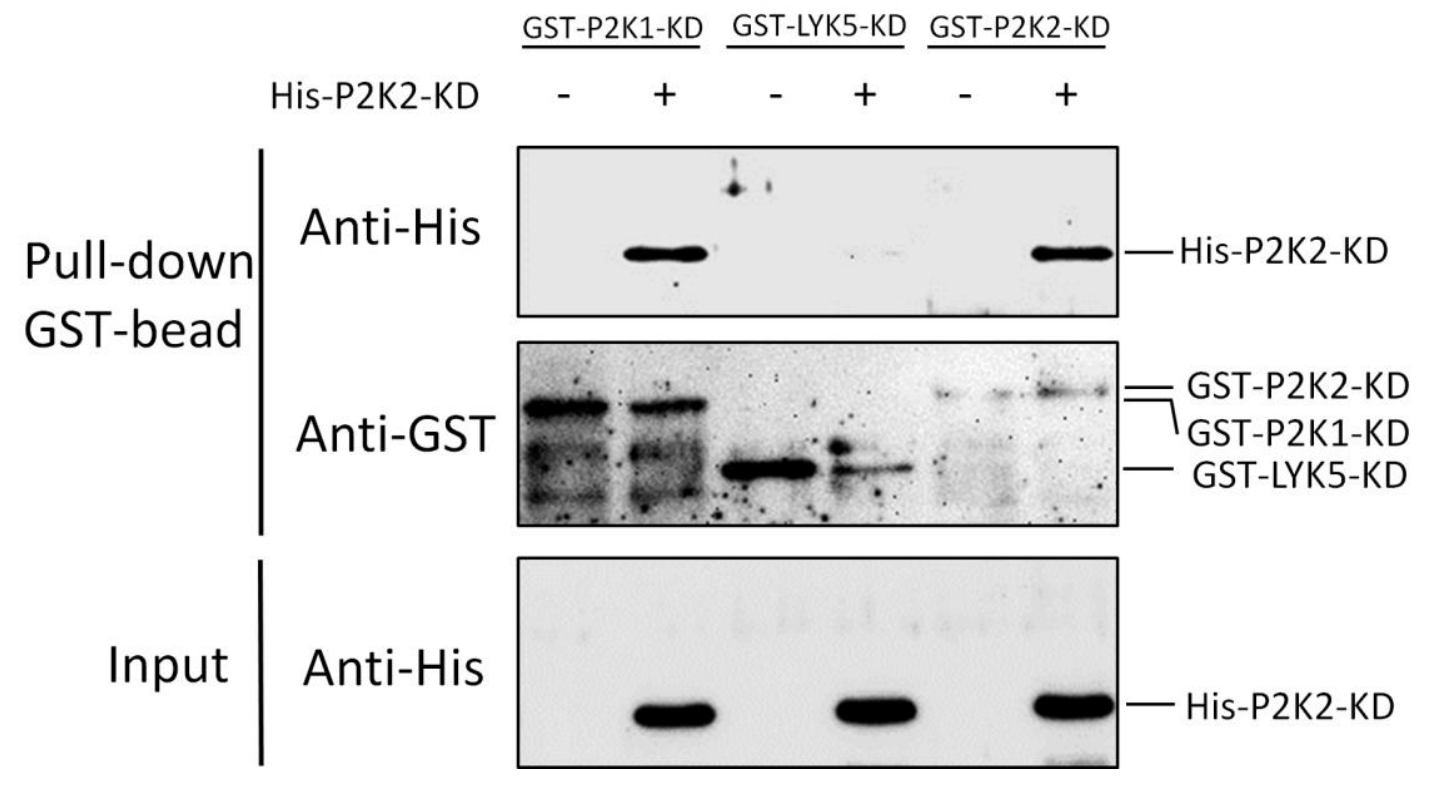

Figure III.20: P2K2 can directly interact with P2K1 and other P2K2 in vitro.

Purified proteins GST-P2K1-KD, GST-P2K2-KD and GST-LYK5-KD were mixed with

His-P2K2-KD. The pull-down assay was performed using glutathione sepharose resin to pull-down GST. The pull-downed proteins were detected by western-blot using anti-HIS (the top pannel) and anti-GST (the middle pannel) anti-body. The HIS-P2K2 input control was shown in the bottom pannel. Experiment was repeated at least twice with similar results 


\section{III.5.3 ATP enhances P2K1-P2K2 interaction}

The BiFC and in vitro pull-down assays indicate that $\mathrm{P} 2 \mathrm{~K} 1-\mathrm{P} 2 \mathrm{~K} 2$ interaction occurs but does not address the question whether ATP binding can affect this interaction. Therefore, we performed the split luciferase complementation assay in tobacco. The target proteins were co-overexpressed in tobacco leaves and incubated for three days. After that, half of the transformed leaves were treated with ATP by direct infiltration for 30 minutes while the other half were infiltrated with buffer as control. The results are shown in Figure III.21.

Our results confirmed that without addition of ATP, P2K2 could interact with both P2K1 and itself. However, the addition of ATP enhanced these interactions. With these results, from in vitro and in vivo assays, we conclude that $\mathrm{P} 2 \mathrm{~K} 2$ can interact with itself, as well as P2K1 and that these interactions are enhanced in the presence of exogenous ATP. 


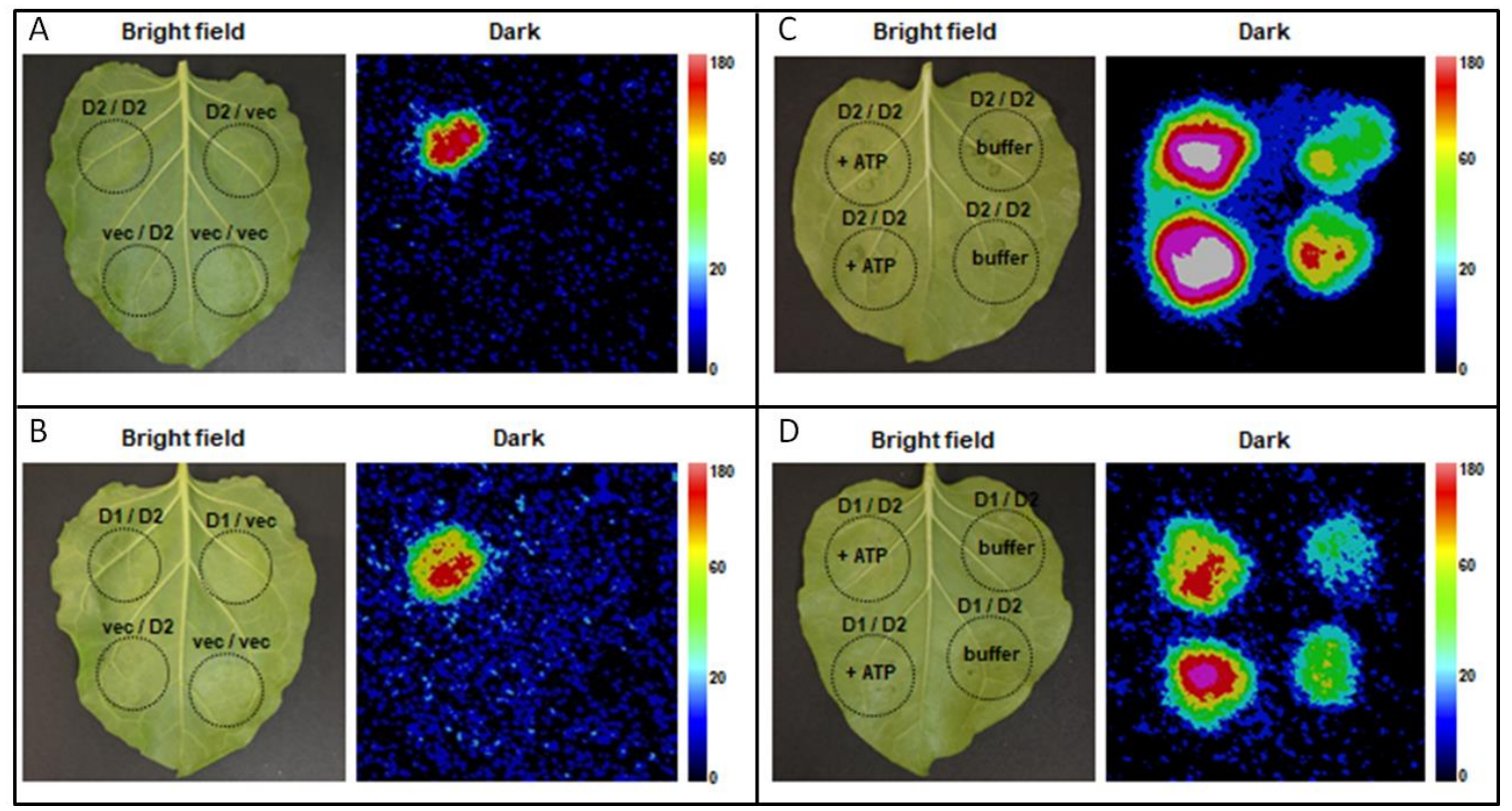

Figure III.21: Luciferase complementation imaging assay showing that ATP can enhance P2K2-P2K1 interactions in tobacco leaves. The indicated constructs were coexpressed in Nicotiana benthamiana leaves, D2: P2K2, D1: P2K1, vec: empty vector. Luciferase signals were captured using a CCD camera. (A) and (B) P2K2-nLUC or P2K1-nLUC can interact with P2K2-cLUC compared to the empty vector as negative controls. (C) and (D) P2K2-P2K2 and P2K1-P2K2 interactions were enhanced by 200 $\mu \mathrm{M}$ ATP comparing with MES buffer as negative controls. 


\section{III.5.4 P2K1 can phosphorylate P2K2 but not vice versa}

Both P2K1 and P2K2 have strong kinase activity and, given their ability to interact, raises the possibility that one or both of these proteins can trans-phosphorylate the other. To test this hypothesis, we performed an in vitro kinase assay.

First, we checked whether P2K1 and P2K2 could cross-phosphorylate P2K2 proteins. Given that P2K2 can autophosphorylate, we used the D467N kinase dead P2K2

mutant protein (GST- $\left.p 2 k 2^{D 467 N}-\mathrm{KD}\right)$ as the kinase substrate. In addition, LYK5 kinase domain (GST-LYK5-KD), which naturally lacks kinase activity, was used as a negative control. The data obtained demonstrated that both P2K1 and P2K2 could transphosphorylate the P2K2 protein (Figure III.22).

To test whether $\mathrm{P} 2 \mathrm{~K} 1$ proteins can be cross-phosphorylated by $\mathrm{P} 2 \mathrm{~K} 1$ or $\mathrm{P} 2 \mathrm{~K} 2$, we used two kinase dead mutant versions of the $p 2 k 1$ kinase domain, D525N, and D572N (reported by Choi et al. 2014). Interestingly, the GST- $p 2 k 2^{D 467 N}-\mathrm{KD}$ in this experiment, used as a positive control, was strongly phosphorylated by either the $\mathrm{P} 2 \mathrm{~K} 1$ or $\mathrm{P} 2 \mathrm{~K} 2$ kinase domain, while both kinase dead mutant versions of $p 2 k 1$ showed no signal in the presence of $\mathrm{P} 2 \mathrm{~K} 2$ or $\mathrm{P} 2 \mathrm{~K} 1$ (Figure III.23). This suggests that under this specific in vitro condition, $\mathrm{P} 2 \mathrm{~K} 1$ cannot be trans-phosphorylated by $\mathrm{P} 2 \mathrm{~K} 1$ or $\mathrm{P} 2 \mathrm{~K} 2$.

The data are consistent with the notion that both $\mathrm{P} 2 \mathrm{~K} 1$ and $\mathrm{P} 2 \mathrm{~K} 2$ can autophosphorylate with $\mathrm{P} 2 \mathrm{~K} 1$ able to trans-phosphorylate $\mathrm{P} 2 \mathrm{~K} 2$. However, $\mathrm{P} 2 \mathrm{~K} 2$ is unable to phosphorylate $\mathrm{P} 2 \mathrm{~K} 1$. 


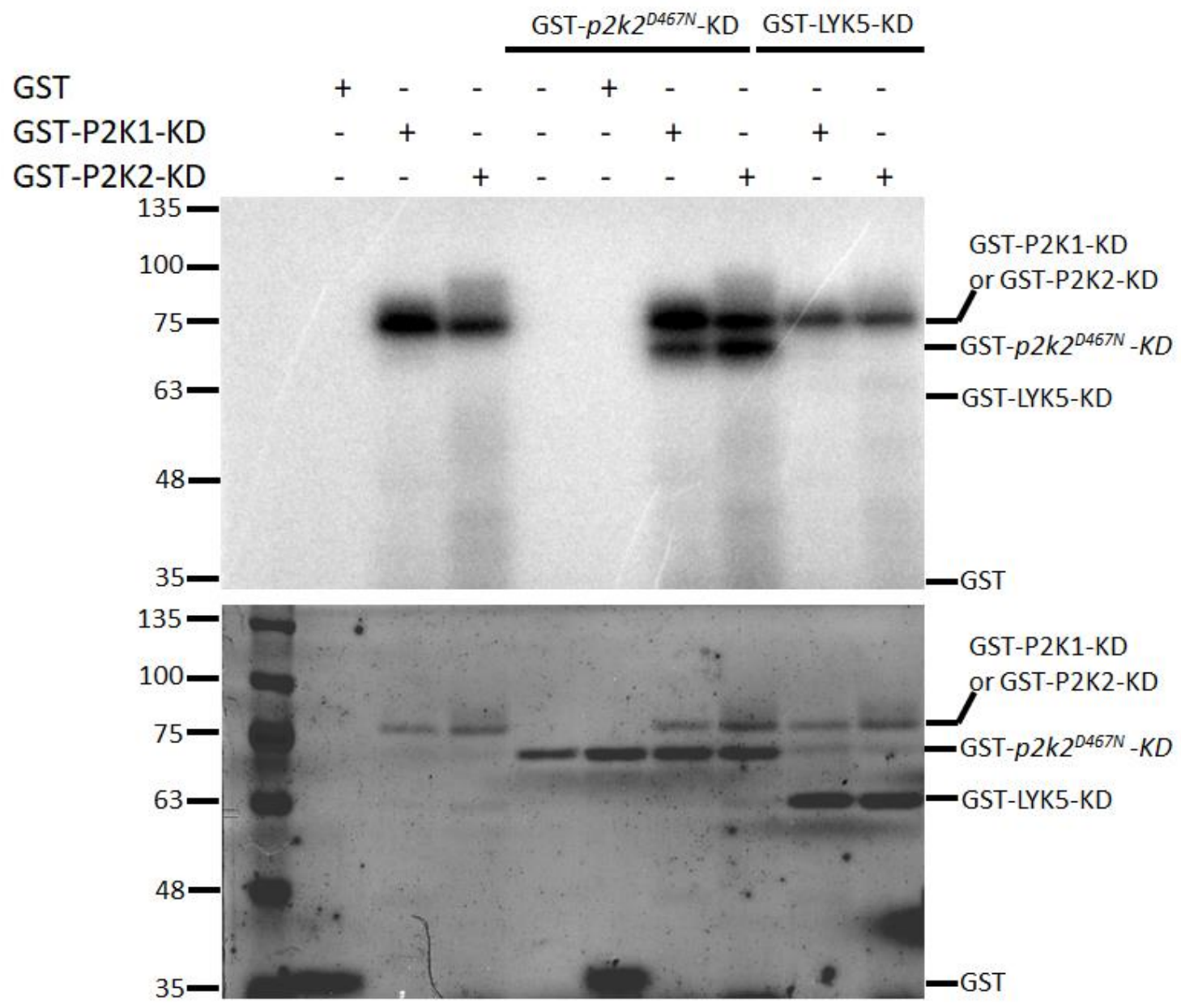

Figure III.22: P2K1 and P2K2 can phosphorylate a kinase dead version of P2K2.

Purified GST- $p 2 k 2^{D 467 N}-\mathrm{KD}$ (kinase domain of $p 2 k 2$ kinase dead mutant) was incubated with GST-P2K1-KD, GST-P2K1-KD or GST in an in vitro kinase assay. GST and GSTLYK5-KD were used as negative controls. $\gamma-\left[{ }^{32} \mathrm{P}\right]-\mathrm{ATP}$ was added for autophosphorylation and cross-phosphorylation measurement. The bottom panel shows the protein loading measured by Coomassie brilliant blue (CBB) staining. Experiment was repeated three times with similar results. 


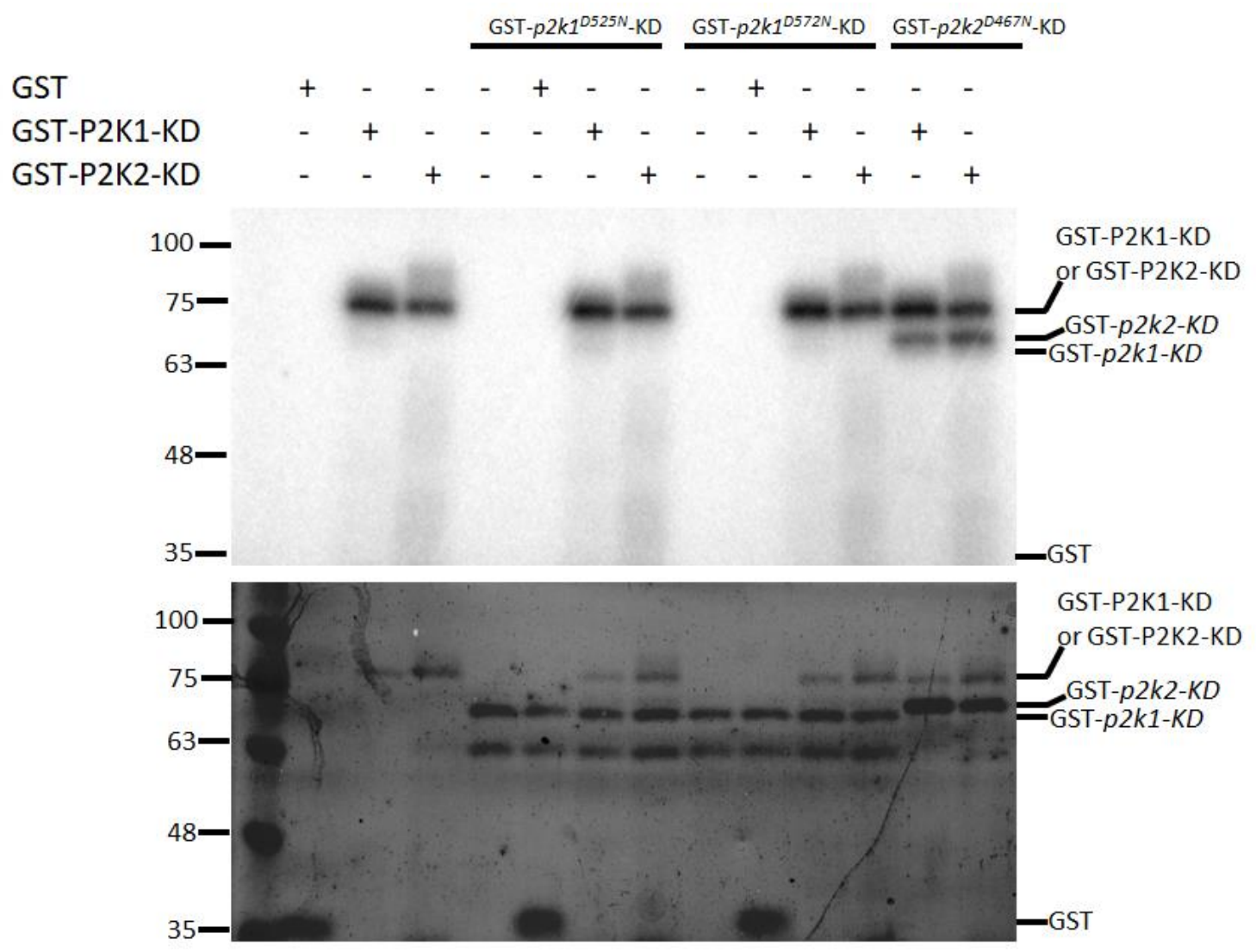

Figure III.23: P2K1 and P2K2 cannot trans-phosphorylate P2K1. Purified GST$p 2 k 1^{D 525 N}-\mathrm{KD}$ or GST- $p 2 k 1^{D 572 N}-\mathrm{KD}$ were incubated with purified GST-P2K1-KD or GST-P2K1-KD. The GST and GST- $p 2 k 2^{D 467 N}-\mathrm{KD}$ were used as negative and positive controls, respectively. In vitro kinase assay results were analyzed based on $\left[{ }^{32} \mathrm{P}\right]$ signal. The loading controls were shown by Coomassie brilliant blue (CBB) staining (bottom panel). Experiment was repeated three times with similar results. 


\section{III.6 P2K2 plays an essential role in eATP-triggered plant defense signaling}

The $p 2 k 1-3$ and $p 2 k 2$ T-DNA single mutant lines, as well as the $p 2 k 1 p 2 k 2$ double mutant line, showed no apparent growth or development phenotype. However, P2K1, previously identified as LecRLK I.9, positively regulates plant defense against Pseudomonas syringae (Balague et al., 2017; Chen et al., 2017), Phytophthora infestans and Phytophthora brassicae (Gouget et al., 2006; Bouwmeester et al., 2011; Bouwmeester et al., 2011; Bouwmeester et al., 2014) and Botrytis cinerea (Tripathi et al., 2018). Given that $\mathrm{P} 2 \mathrm{~K} 1$ and $\mathrm{P} 2 \mathrm{~K} 2$ interact and that $\mathrm{P} 2 \mathrm{~K} 2$ can partially complement the $\mathrm{P} 2 \mathrm{~K} 1$ mutant phenotype, it is possible that these two proteins function redundantly in ATP signaling, either in separate complexes or in association with one another.

\section{III.6.1 P2K2 plays a role in plant resistance to Pseudomonas syringae DC3000 infection}

Given that $p 2 k 1-3$ mutant plants are more susceptible to Pseudomonas syringae (Balague, Gouget et al. 2017) and that P2K2 can interact with and be phosphorylated by P2K1, we hypothesized that P2K2 might also be involved in pathogen defense. To test this hypothesis, we examined plant susceptibility to P.syringae upon flood inoculation of three-week-old plants. In this assay, we used wild-type (Col-0 background) and $p 2 k 1-3$ mutant seeds as controls for the $p 2 k 2$ single mutant, $p 2 k 1 p 2 k 2$ double mutant, the $P 2 K 2$ complemented line ( $p P 2 K 2: P 2 K 2)$ and the $P 2 K 2$ overexpression line ( $p 35 S: P 2 K 2)$.

After a one-day inoculation, we checked the colonization ability of $P$. syringae on the various Arabidopsis lines by a CCD camera. The $p 2 k 1-3$ and $p 2 k 2$ single mutants, and 
the $p 2 k 1 p 2 k 2$ double mutant showed significantly greater colonization than the wild-type, complemented and overexpression lines (Figure III.24A).

To confirm this result, we harvested the plants, ground the leaves in $10 \mathrm{mM}$ $\mathrm{MgCl}_{2}$, serially diluted the cells and counted the colonies on King B agar plates. Consistent with the visual assays, the results showed that the $p 2 k 1-3, p 2 k 2$ and $p 2 k 1 p 2 k 2$ double mutant were significantly more susceptible to bacterial infection when compared to the wild-type, while the P2K2 complemented line showed no significant difference to wild-type (Figure III.24B). Moreover, the P2K2 overexpression lines showed elevated resistance to bacterial infection relative to wild-type. These results implicate $\mathrm{P} 2 \mathrm{~K} 2$ in resistance to Pseudomonas syringae infection. The fact that the $p 2 k 1 p 2 k 2$ double mutant showed the highest level of susceptibility suggests that, at least for this specific phenotype, the two receptors show some level of functional redundancy. 


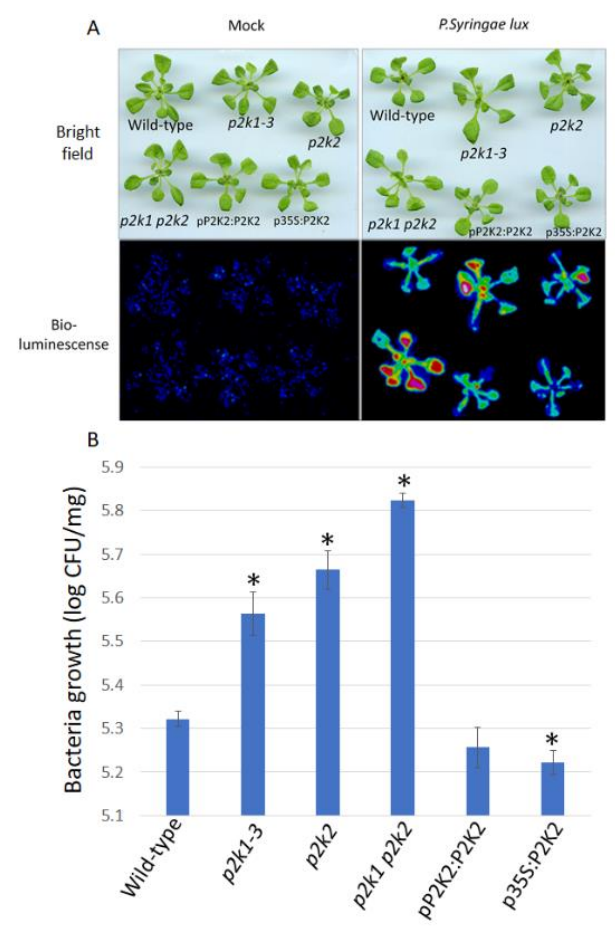

Figure III.24: Susceptibility of various Arabidopsis lines to flood-inoculation with Pseudomonas syringae DC3000 LUX. Wild-type (a negative control) and p2k1-3 (a positive control) were used to compare to $p 2 k 2, p 2 k 1 p 2 k 2$, pP2K2:P2K2 (the $p 2 k 2$ complemented line using P2K2 native promoter) and p35S:P2K2 (the P2K2 overexpression line) Arabidopsis seedlings. The seedlings were flood-inoculated with a bacterial suspension of Pst DC3000LUX (OD = 0.002) containing 0.025\% (v/v) Silwet L-77. (A) Bright-field photographs ware taken one day after inoculation using a normal camera while the bacteria invasion was detected using a CCD camera (the bioluminescence panels). (B) Bacterial populations of Pst DC3000LUX in Arabidopsis were quantified by grinding samples followed by $1 / 10$ serial dilution (up to $10^{-7}$ ) and dropped on King B medium. Vertical bars indicate the standard errors for three independent experiments. Experiments were repeated with similar results. 


\section{III.6.2 $p 2 k 2$ T-DNA mutant plants failed to induce downstream defense signaling in response to ATP}

As discussed above, in group I LecRLK genes, $P 2 K 1$ showed the highest expression level in most tissues of Arabidopsis thaliana while, in general, the expression level of $P 2 K 2$ was significantly lower at all stages and conditions. In order to test whether ATP or $P$. syringae treatment could affect $P 2 K 2$ expression, we utilized transgenic plants in which the $P 2 K 2$ gene promoter was fused to GUS. The results show that the root elongation zone of three-week-old plants showed no expression of $P 2 K 2$. However, strong $P 2 K 2$ expression was apparent when plants were either treated with $200 \mu \mathrm{M}$ ATP (for one hour) or P. syringae (for 2-3 minutes and incubated for one day) (Figure III.25). Therefore, although $P 2 K 2$ is normally expressed at a low level, upon induction, there is the possibility that $\mathrm{P} 2 \mathrm{~K} 1$ and $\mathrm{P} 2 \mathrm{~K} 2$ could form a functional complex.

To further understand how P2K2 contributes to pathogen-resistance, we measured the expression of some of the downstream signaling components involved in plantpathogen defense. To perform those experiments, we used wild-type (Col-0 background) as positive control and the $p 2 k 1-3$ mutant line as a negative control, for testing the response of the $p 2 k 2$ single mutant and $p 2 k 1 p 2 k 2$ double mutant plants. The expression level of $P 2 K 1$ and $P 2 K 2$ mutant lines was checked by qRT-PCR (Figure III.26). The data suggest that these two genes show compensatory expression in the various mutants; that is $P 2 K 1$ is expressed at a higher level in the $p 2 k 2$ mutant plants, while $P 2 K 2$ is expressed at a higher level in the $p 2 k 1$ mutant plants. 
A key aspect of the pathogen response pathway is the activation of MAPK signaling. Therefore, after ATP treatment, we measured activation of MPK3 and MPK6 in $p 2 k 2$ and $p 2 k 1 p 2 k 2$ mutant plants, relative to controls. As shown in Figure III.28, wildtype plants exhibit strong phosphorylation of MPK3 and MPK6 upon ATP treatment, while this did not occur in the $p 2 k 1-3, p 2 k 2$ or $p 2 k 1 p 2 k 2$ mutant plants. The results suggested that $\mathrm{P} 2 \mathrm{~K} 2$, in addition to $\mathrm{P} 2 \mathrm{~K} 1$, is a critical component of ATP signaling through the MAPK pathway. Again, the phenotype of the $p 2 k 1 p 2 k 2$ double mutant was stronger than each of the single mutants, consistent with the idea that the two receptors are at least partially redundant in function.

Upon pathogen infection, signaling downstream of MAPK activation triggers the expression of key genes involved in the plant immune response. For example, earlier, we showed that both pathogen and ATP treatment elevated the expression of $P 2 K 2$ (Figure III.25). Our qRT-PCR assay to measure the expression of $P 2 K 2$ in wild-type upon ATP treatment, also showed a consistent result (Figure III.28A). In addition, we measured the expression of $M Y C 2$ and ZAT10, previously reported to be regulated by $P 2 K 1$ and also known to respond to pathogen infection (Balague et al., 2017; Tripathi et al., 2018). The expression of both of these genes was significantly reduced in the $p 2 k 2$ and $p 2 k 1 p 2 k 2$ mutant plants after ATP treatment (Figure III.28B and C).

Interestingly, when we tested the ability of $\mathrm{P} 2 \mathrm{~K} 2$ proteins to interact with other receptors, we found that, in tobacco, besides P2K1, FLS2 also can strongly interact with P2K2 while CERK1 showed a weak interaction. The addition of ATP treatment also enhanced the interaction between P2K2 and FLS2 (Figure III.29). However, the significance of this interaction is unclear. 


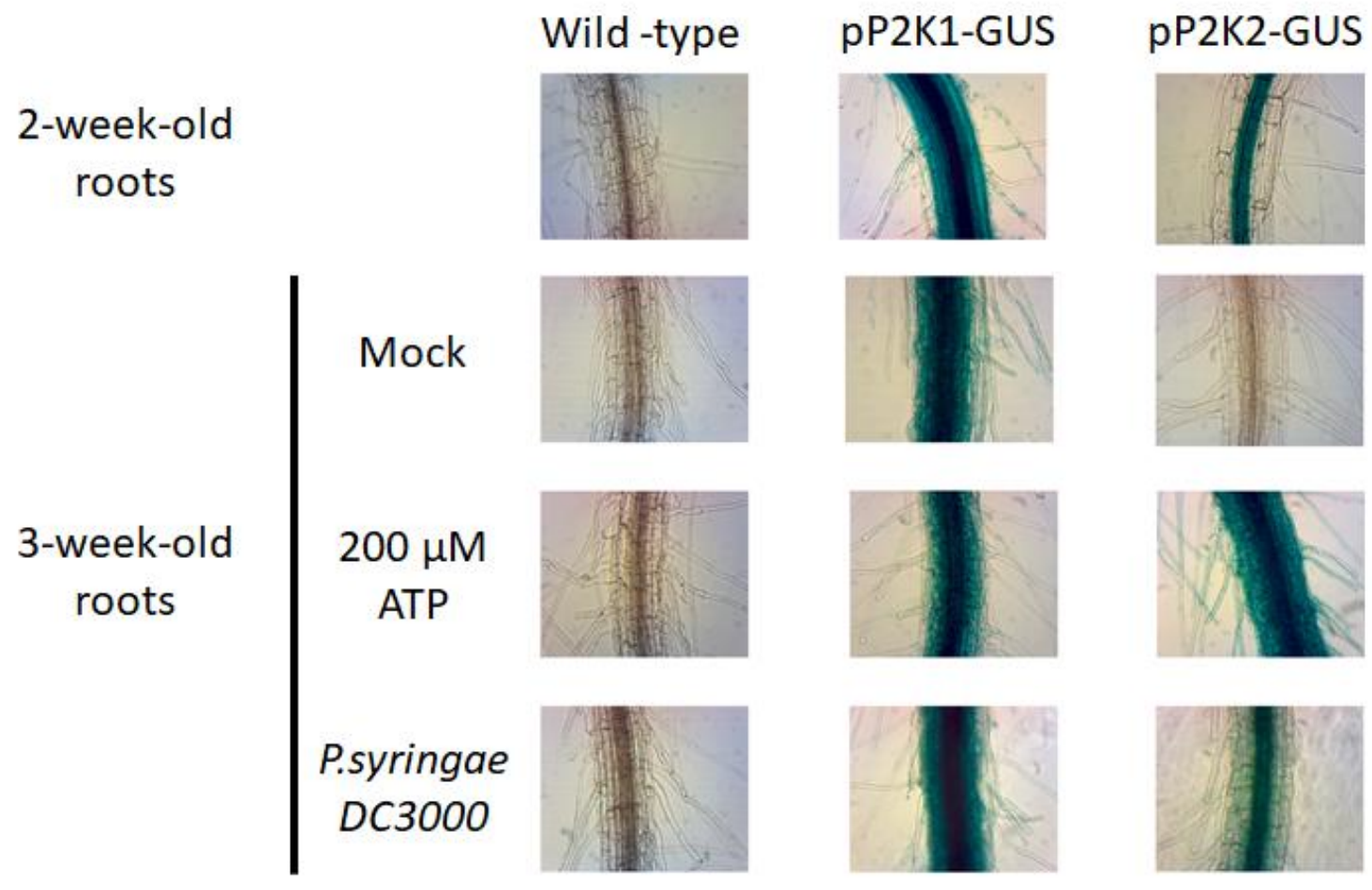

Figure III.25: P2K2 promoter activity in roots. After Gus staining, described above, pictures were taken at the similar elongation zone of roots. 

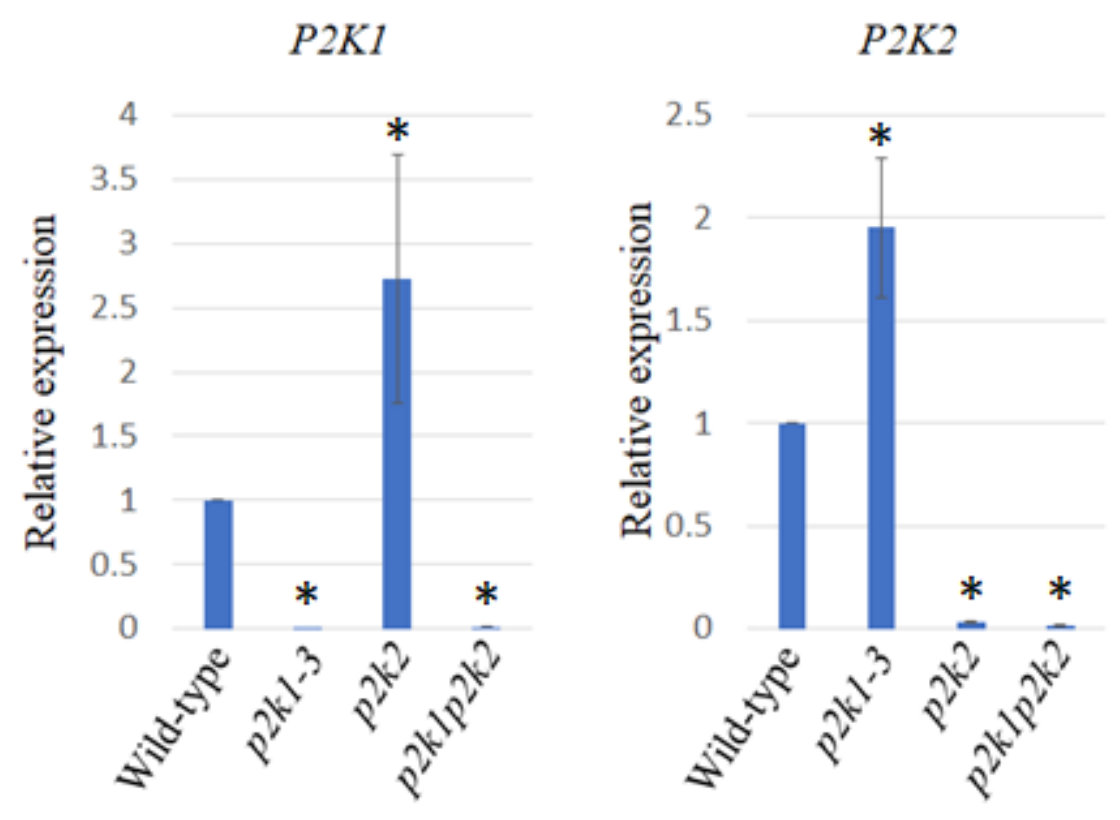

Figure III.26: Expression of $P 2 K 1$ and $P 2 K 2$ in mutant lines. The qRT-PCR analysis histograms show means and standard error of relative values to wild-type (set as 1). Asterisks show the significant difference to wild-type ( ${ }^{*} \mathrm{P}<0.05$, Student's $t$-test). 


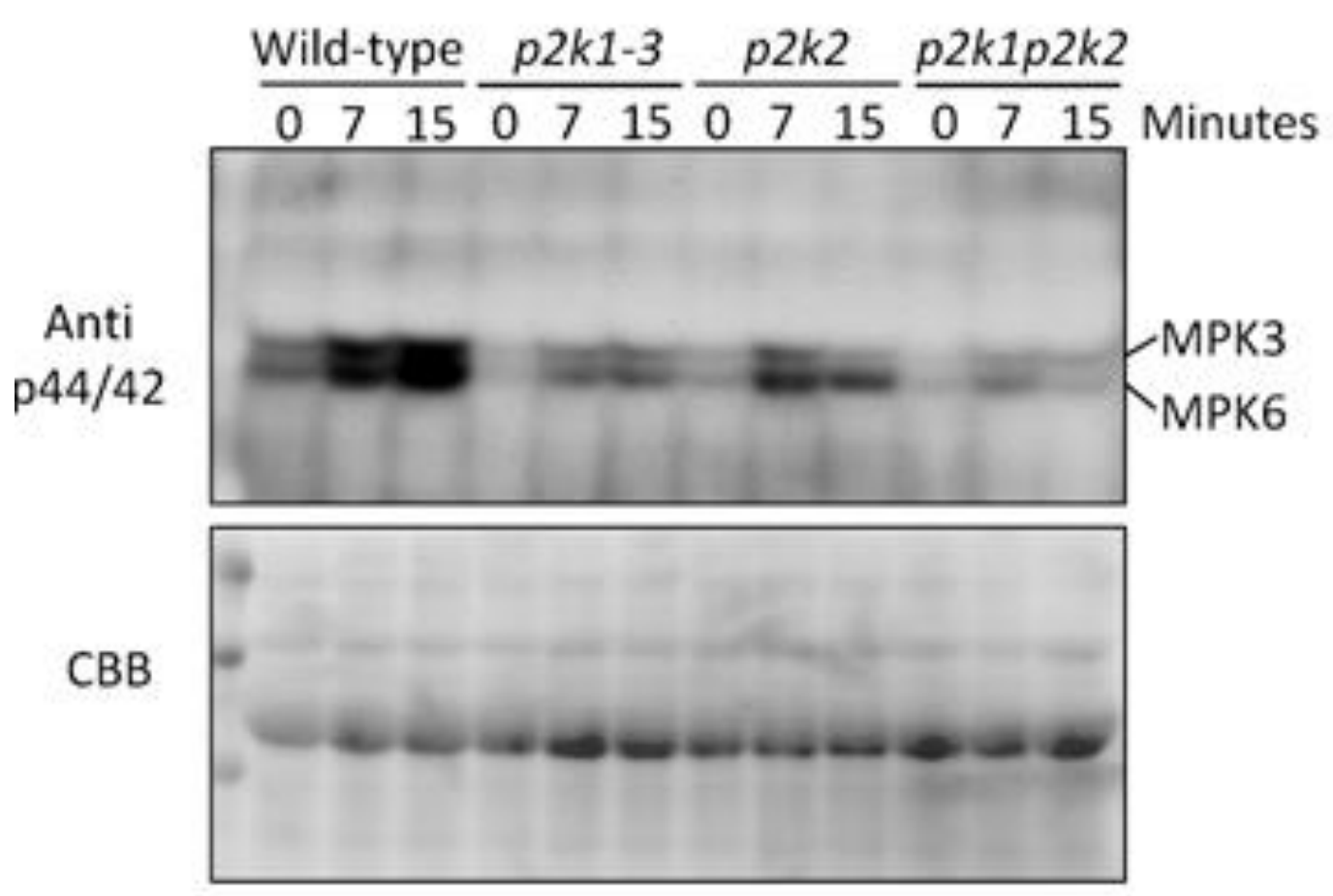

Figure III.27: MAPK signaling is impaired in $p 2 k 2$ single and $p 2 k 1 p 2 k 2$ double mutants upon ATP treatment. Ten-day-old seedlings of wild-type (a positive control), p2k1-3 (a negative control), p2k2 and $p 2 k 1 p 2 k 2$ were treated with $200 \mu \mathrm{M}$ ATP and sampled at 0,7 and 15 minutes for Western analysis. Activated MPK3 and MPK6 were detected by immunoblotting with phospho-p44/42 MAPK antibody. The CBB staining of Rubisco was used as a loading control (lower panel). Experiment was repeated with similar results. 

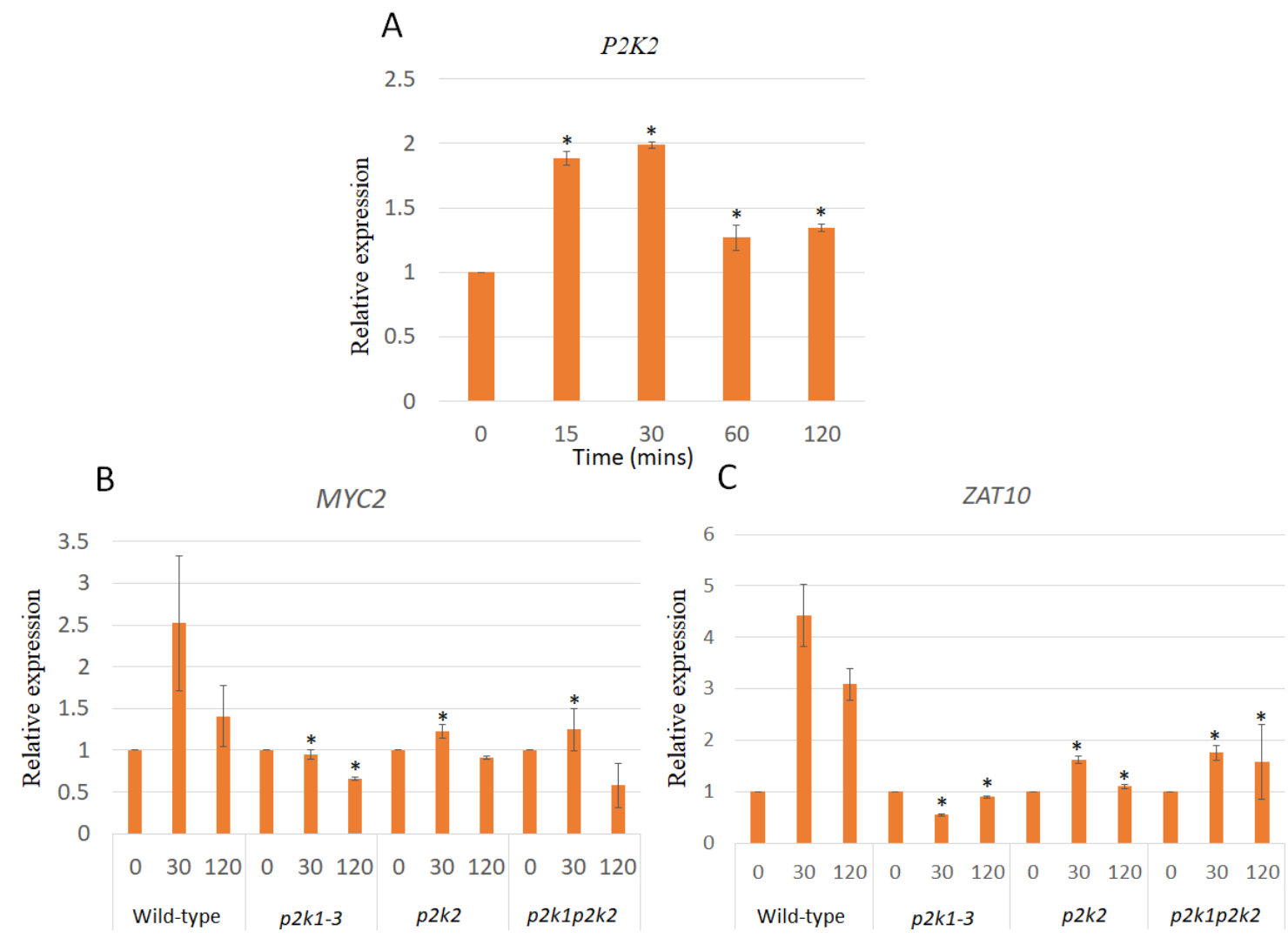

Figure III.28: qRT-PCR expression analysis of P2K2, MYC2 and ZAT10 after treatment with ATP $200 \mu \mathrm{M}$. Data were normalized using SAND as a reference gene. The results are relative to expression levels of mock treatment (set as 1). The bar graphs show means of three biological replicates ( $>30$ pooled plants each); the error bars are standard error. (A) The expression level of $P 2 K 2$ in wild-type; * indicates a significant difference to mock treatment $(0$ mins) $(\mathrm{P}$-value $<0.05)$. (B) and (C) The expression levels of ZAT10 and MYC2 in wild-type, $p 2 k 1-3, p 2 k 2$ and $p 2 k 1 p 2 k 2$. * Shows a significant difference to wild-type at the same time points (P-value $<0.05)$. 


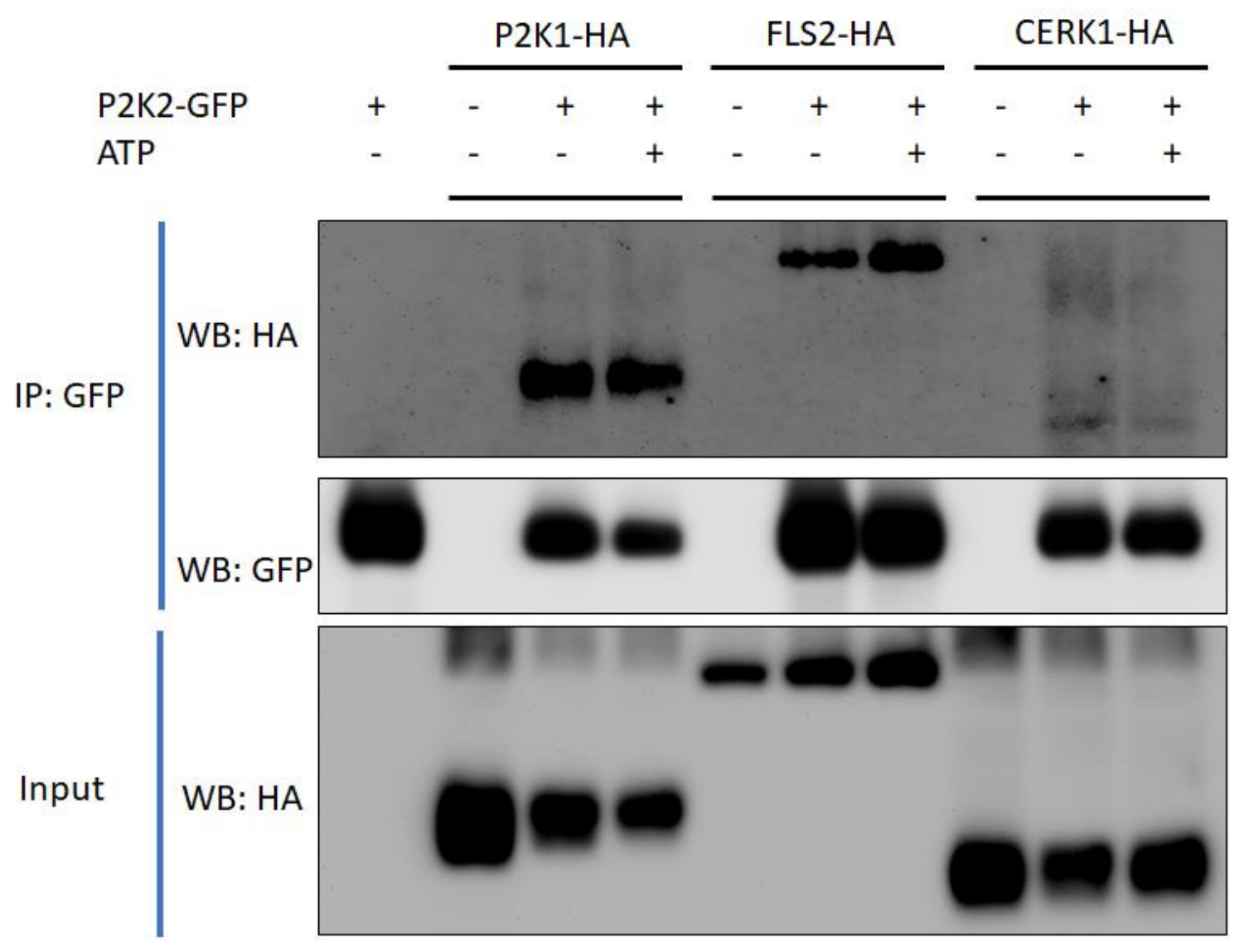

Figure III.29: Co-immunoprecipitation assay of P2K2 with P2K1, FLS2 and CERK1. P2K2-GFP and P2K1-HA, FLS2-HA or CERK1-HA were transiently cotransformed into tobacco. After $36 \mathrm{~h}$, transgenic leaves were treated with MES buffer (as mock) or with ATP $200 \mu \mathrm{M}$ for 30 minutes. The total tobacco cell lysates were prepared for Co-IP with anti-GFP and protein G agarose. Then, anti-GFP antibody immunoprecipitated products were subjected to Western blot analysis with anti-HA antibody (top) and anti-GFP antibody (middle). Also, the total cell lysates were subjected to Western analysis with anti-HA antibody (bottom, for HA-fused protein input). 


\title{
Chapter IV:
}

\author{
Discussion
}


P2K1 was identified as the first extracellular ATP receptor in the plant (Choi et al., 2014). $P 2 K 1$ mutant plants (e.g., the $p 2 k 1-3 / A E Q$ T-DNA mutant line) cannot recognize exogenous ATP or respond to it with an increase in the cytosolic calcium concentration. We expected that, similar to animals, plants may have multiple extracellular ATP receptors that share structure and function. Therefore, our first goal in this project was to identify functional homologs of P2K1 that could complement extracellular ATP perception and trigger a cytosolic calcium increase. The screening focused on the LecRLK clade I of which P2K1 is a member. Our results showed that ecotopic expression of LecRLK I.5 could partially reverse the P2K1 phenotype in $p 2 k 1-3$ mutant (Figure III.2). As a potential second member of P2K family, we termed LecRLK I.5 as P2K2. Compared with wild-type, the $p 2 k 2$ T-DNA knock out mutant line also showed a lower response to eATP, while the overexpression lines (p35S:P2K2) showed a higher response (Figure III.4). Overall, we conclude that P2K2 (or LecRLK I.5) functions as an ATP receptor and represents the second such receptor identified in plants.

Careful examination of the eATP-triggered cytosolic calcium increase in p35S:P2K2/p2k1-3, as well as p35S:P2K2/wild-type lines, showed that it is faster than wild-type (nearly immediate) (Figures III.3 and III.5). However, the intensity for the response of the $\mathrm{p} 35 \mathrm{~S}: \mathrm{P} 2 \mathrm{~K} 2 / p 2 k 1-3$ line is still lower than wild-type, while the p35S:P2K2/wild-type response is much higher. In comparison to the $p 2 k 1$ mutant lines, the phenotype of the $p 2 k 2$ mutant plants is weaker, suggesting that the function of $\mathrm{P} 2 \mathrm{~K} 1$ is dominant in eATP perception in plants. This observation and the much higher expression level of $P 2 K 1$ under normal growth conditions likely explain why our previous forward screening detected only mutations in $P 2 K 1$ and not $P 2 K 2$ (Choi et al., 
2014). It is also consistent with our hypothesis that other eATP receptors, besides P2K1, might function under specific conditions only.

\section{P2K2's eATP perception}

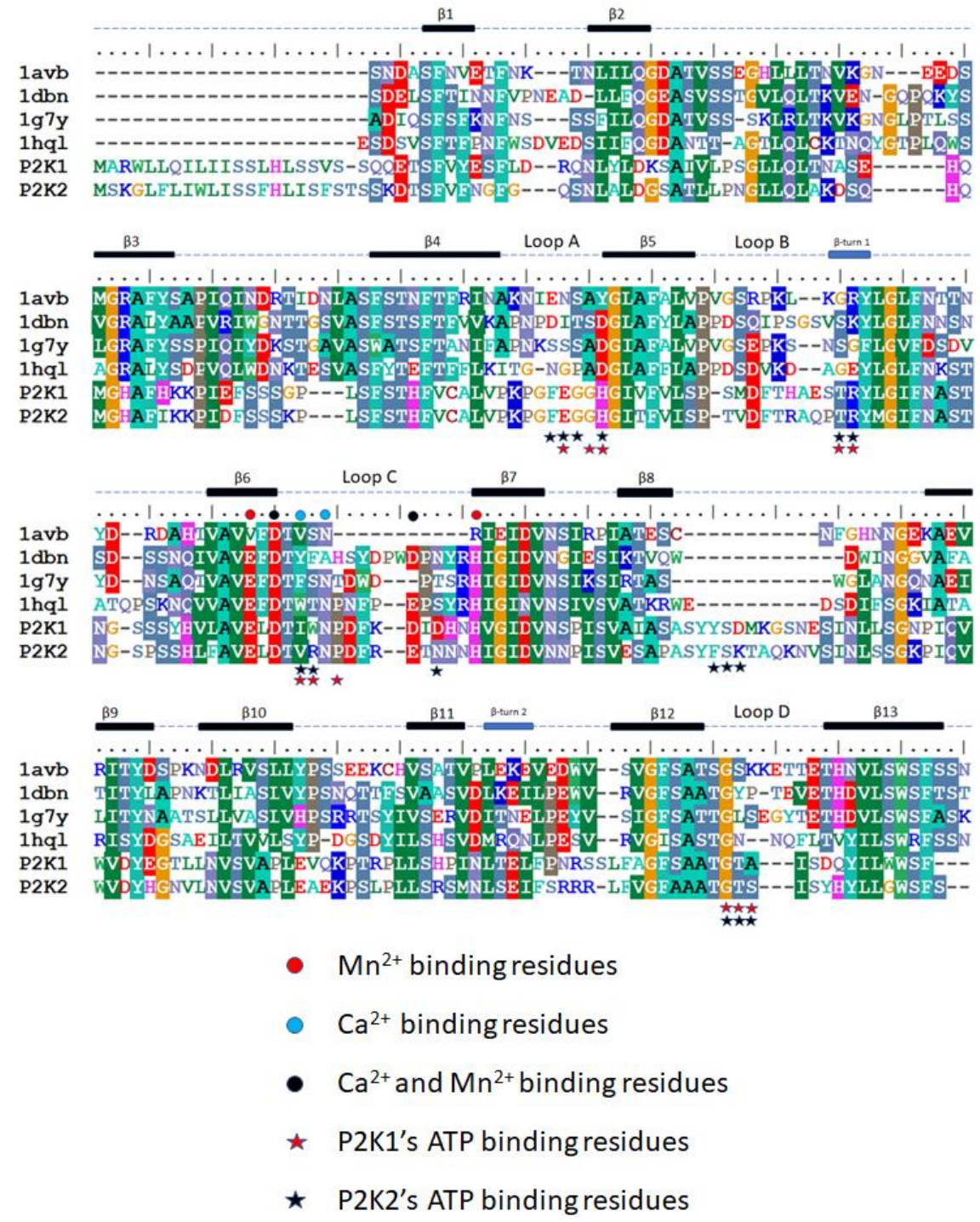

Figure IV.1: Multiple sequence alignment of the P2K2 and P2K1 extracellular domains by comparing to four crystalized lectin proteins. 1AVB (Phaseolus vulgaris), 1DBN (Maackia amurensis), 1G7Y (Dolichos biflorus) and 1HQL (Griffonia simplicifolia). The figure was generated by Bioedit. 
As expected, $\mathrm{P} 2 \mathrm{~K} 2$ showed high affinity binding for ATP in our in vitro binding assay $\left(\mathrm{K}_{\mathrm{d}}=40.76 \pm 7.331 \mathrm{nM}\right.$ and $\left.\mathrm{Bmax}=428.1 \pm 46.57 \mathrm{pmol} / \mathrm{mg}\right)$ (Figure III.7). The binding affinity of $\mathrm{P} 2 \mathrm{~K} 2$ is roughly equivalent to that measured previously for $\mathrm{P} 2 \mathrm{~K} 1$ ( $\mathrm{K}_{\mathrm{d}}$ $=45.7 \pm 3.1 \mathrm{nM}$ and $\mathrm{Bmax}=488.0 \pm 6.3 \mathrm{pmol} / \mathrm{mg}$ ) (Choi et al., 2014). Interestingly, in vitro competitive binding data indicate that $\mathrm{P} 2 \mathrm{~K} 2$ has much higher specificity for ATP and ADP than demonstrated for P2K1. ADP binds to P2K2 with lower affinity than ATP $\left(\mathrm{K}_{\mathrm{j}}\right.$ of ADP $=97.3 \mathrm{nM}$ while $\mathrm{K}_{\mathrm{j}}$ of ATP $\left.=31.7 \mathrm{nM}\right)$ where as GTP showed very low binding affinity for P2K2 $\left(\mathrm{K}_{\mathrm{j}}=2.23 \mu \mathrm{M}\right)$ and other nucleotides (ITP, CTP, TTP and UTP) showed no binding affinity (Figure III.8). Our results suggest that P2K2 specifically selects ATP and ADP as its ligand while P2K1 has a broader range of nucleotide-binding specificity (ATP > ADP $>$ ITP $>$ GTP $>$ UTP) (Choi et al., 2014). The physiological relevance of this is unknown but could be important, especially if P2K1 and $\mathrm{P} 2 \mathrm{~K} 2$ function in planta as a heteromeric complex.

Through collaborations, we identified the crystal structure of P2K1, unpublished. In parallel, we also conducted experiments to predict the structures of P2K1 and P2K2 using homology modeling. Using the computational modeling method, we visualized not only the putative 3D protein structure, but also the putative P2K2-ATP interaction model of P2K2. Compared with the previously published P2K1-ATP interaction model (Nguyen et al., 2016), $\mathrm{P} 2 \mathrm{~K} 1$ and P2K2 share 7 ATP-binding residues, including E96, H99, T117, R118, V143 (I143 in P2K1), G244 (G245 in P2K1) and T245 (T246 in P2K1) over 15 and 11 putative ATP-binding residues of P2K2 and P2K1 respectively (Figure IV.1). The larger number of ATP-interacting residues in P2K2 could explain the greater ATP specificity of P2K2 than P2K1. Nguyen et al. (2016) used site-directed mutagenesis and 
in vitro binding assays to show that $p 2 k 1$ deletions in loop B or loop C prevented ATP binding while $p 2 k 1$ deletion in loop A did not affect in ATP binding (Nguyen et al., 2016). Of those key amino acid residues predicted to interact with ATP in the P2K2 structure, we mutated three, with only mutations at histidine 99 (H99) strongly affecting ATP binding. Mutations in other ATP binding residues, although it is possible that these mutations could destabilize the protein and, hence, we could not recover the protein. While H99 is formally part of loop A, the deletion described in the Nguyen et al. 2016 paper did not delete the entire loop A (only four over nine residues of loop A were deleted), and H99 was still retained in their mutant version of the protein. The information suggested that $\mathrm{H} 99$ might be a critical conserved ATP-binding residue in both $\mathrm{P} 2 \mathrm{~K} 1$ and $\mathrm{P} 2 \mathrm{~K} 2$ proteins, consistent with the conservation of this residue in both proteins. More importantly, many carbohydrate-binding lectin proteins have conserved aspartic acid, instead of $\mathrm{H} 99$ in $\mathrm{P} 2 \mathrm{~K} 1$ and $\mathrm{P} 2 \mathrm{~K} 2$, perhaps explaining why these $\mathrm{P} 2 \mathrm{~K}$ proteins recognize nucleotides and not sugars (Adar and Sharon, 1996; Gouget et al., 2006; Sharon, 2007).

\section{Other extracellular ATP receptors in the LecRLK family}

After successfully identifying the second eATP receptor in plants as a homolog of P2K1, we expect that other LecRLK members, either within clade I or in other clades, may also serve as nucleotide receptors. Such additional receptors could have been easily missed in our screens that depend on the ability of the receptor to increase cytosolic calcium levels. In other words, if other receptors do not signal via elevated calcium levels, then we would not find them using our current methods. 
With the in vitro binding results with the extracellular domain mutant versions of P2K1 (Nguyen et al., 2016) and P2K2 (in this thesis), we proposed that the conserved H99 residue is critical for ATP binding to the ectodomain. Hence, we searched the various LecRLK protein sequences for this conserved residue. We found that all LecRLK clade I members, except for LecRLK I.8. Interestingly, LecRLK I.8 was reported to be an $\mathrm{NAD}^{+}$receptor and have low ATP binding affinity (Wang et al., 2017). Besides clade I, there are 18 additional LecRLK members having H99. However, our sequence analysis for the kinase domain (data not shown) showed that two of them (LecRLKs III.1 and III.2) do not have putative active kinases (i.e., they lack the kinase activation loop). These two proteins could still serve as eATP receptors, but would likely do so in complex with a co-receptor, such as another kinase. Therefore, there is the potential for many more (i.e., 16 or more) P2K proteins in Arabidopsis, as shown in Table IV.1. Because Nguyen et al. (2016) showed that the deletion of some P2K1-P2K2 conserved residues in loop A, extended loop and loop D do not affect ATP binding affinity, we only focused on the other conserved residues, including G98, H99, T117, R118, V144 (I144 in P2K1), P147 and F174 (Y174 in P2K1). The analysis showed that LecRLK IV.3 is the most likely candidate (with six of the seven conserved residues found in P2K1 and P2K2). However, confirmation of the presence of additional eATP receptors in Arabidopsis, as well as other plants, awaits extensive biochemical characterization. 
Table IV.1: LecRLK members, not belonging to clade I that have a conserved $\mathrm{H99}$ and a predicted active kinase domain. "_“" Indicates residues that are not conserved.

\begin{tabular}{|c|c|c|c|c|c|c|c|}
\hline & \multicolumn{2}{|c|}{ Loop A } & \multicolumn{2}{c|}{ Loop B } & \multicolumn{2}{c|}{ Loop C } & $\begin{array}{c}\text { Extended } \\
\text { loop }\end{array}$ \\
\hline Name & G98 & H99 & T117 & R118 & V/I144 & P147 & F/Y174 \\
\hline P2K1 & G & H & T & R & I & P & Y \\
\hline P2K2 & G & H & T & R & V & P & F \\
\hline LecRLK II.1 & G & H & N & - & - & - & F \\
\hline LecRLK IV.1 & G & H & S & - & I & - & W \\
\hline LecRLK IV.2 & G & H & S & - & I & - & - \\
\hline LecRLK IV.3 & G & H & S & - & I & P & W \\
\hline LecRLK IV.4 & G & H & - & - & I & - & W \\
\hline LecRLK V.3 & - & H & - & - & - & - & Y \\
\hline LecRLK V.4 & - & H & - & - & - & - & Y \\
\hline LecRLK V.5 & - & H & - & - & - & - & Y \\
\hline LecRLK V.6 & - & H & - & - & - & - & Y \\
\hline LecRLK V.7 & - & H & - & - & - & - & Y \\
\hline LecRLK V.8 & - & H & - & - & - & - & - \\
\hline LecRLK V.9 & G & H & S & - & F & - & Y \\
\hline LecRLK VII.1 & G & H & - & - & F & - & W \\
\hline LecRLK VII.2 & G & H & S & - & F & - & Y \\
\hline LecRLK IX.1 & G & H & - & - & F & P & - \\
\hline LecRLK IX.2 & G & H & - & - & F & P & - \\
\hline
\end{tabular}

\section{P2K2 may function as a co-receptor for P2K1.}

Because $\mathrm{P} 2 \mathrm{~K} 2$ can partially reverse the $\mathrm{P} 2 \mathrm{~K} 1$ phenotype in $p 2 k 1-3$ mutant line, we suggest that P2K2 might have redundant functions with P2K1. Interestingly, P2K1 and P2K2 are the results of tandem genome duplication events (Hofberger et al., 2015). The evidence can explain why P2K1 and P2K2 share high sequence identity (74\%) (data was not shown). However, P2K1 and P2K2 were identified as ohnologous genes (the paralogous genes that diverged at the same time through whole-genome duplication). 
Ohnologous genes can share similar functions, but more often diverge and develop different functions (Moreira and López-García, 2011; Hofberger et al., 2015). Our current data, although not definitive, argue that both P2K1 and P2K2 have a similar function in that they bind and respond to eATP and can, at least, partially complement one another. The expression pattern of $P 2 K 1$ and the strength of the $p 2 k 2$ mutant phenotype argue that P2K1, under the conditions in our assays, is the primary eATP receptor. However, it is intriguing that $\mathrm{P} 2 \mathrm{~K} 1$ and $\mathrm{P} 2 \mathrm{~K} 2$ interact in planta. This may only be relevant when $\mathrm{P} 2 \mathrm{~K} 2$ is induced, such as during pathogen infection. Under these conditions, it is possible, although not proven, that a heteromeric complex of $\mathrm{P} 2 \mathrm{~K} 1-\mathrm{P} 2 \mathrm{~K} 2$ is formed and plays a critical role in purinergic signaling. There are some hints as to how such a receptor complex could function in that $\mathrm{P} 2 \mathrm{~K} 1$ can trans-phosphorylate $\mathrm{P} 2 \mathrm{~K} 2$, but $\mathrm{P} 2 \mathrm{~K} 2$ cannot trans-phosphorylate P2K1 (Figures III.22 and III.23). However, additional work is required to define the physiological significance of this trans-phosphorylation and to confirm the importance of P2K1-P2K2 interaction in planta. Heteromeric purinergic receptor complexes are well documented in P2X animal system (Nicke et al., 1998; Virginio et al., 1998; Kawate et al., 2009).

Jones et al. (2014) used the split-ubiquitin yeast two-hybrid system to screen and identify more than 12,000 membrane-protein interactions. Their data predict four proteins as candidates for interaction with $\mathrm{P} 2 \mathrm{~K} 1$ and 51 proteins as candidates for interaction with P2K2 (30 of them with the highest P2K2 interaction score, are shown in Table IV.2) (Jones et al., 2014). In the table, we note some proteins that may be components in P2K2 signaling cascades. For example, an ortholog of PAP3, purple acid phosphatase 3, in common bean, was reported to function as an extracellular ATP hydrolase (Liang et al., 
2010). It is suggested that PAP3 may regulate eATP homeostasis. CNGC17 is a member of the cyclic nucleotide-gated channel family. Some CNGC members were reported to mediate calcium flux coupled to purinergic signaling (Hua et al., 2003; Ali et al., 2007; Frietsch et al., 2007). Hence, the list of genes shown in Table IV.2 may be a fruitful starting point to expand our knowledge of purinergic signaling, especially in relation to P2K2 function.

Overall, our data suggest that P2K2 is an eATP co-receptor with P2K1. Additionally, ATP can induce P2K1-P2K2 interaction. Then, P2K1 can transphosphorylate $\mathrm{P} 2 \mathrm{~K} 2$ which enables $\mathrm{P} 2 \mathrm{~K} 2$ to interact with several downstream proteins and could phosphorylate them by its kinase activity. 
Table IV.2: Candidate proteins predicted to interact with P2K2. The list is in order of high to low P2K2 interaction score. Data derived from split-ubiquitin yeast two-hybrid screening for Arabidopsis protein-protein interactions (Jones et al., 2014).

\begin{tabular}{|c|c|}
\hline AGI & Name \\
\hline At4g19030 & NLM1, NOD26-LIKE INTRINSIC PROTEIN 1;1 \\
\hline At1g14700 & PAP3, PURPLE ACID PHOSPHATASE 3 \\
\hline At5g01180 & PTR5, PEPTIDE TRANSPORTER 5 \\
\hline $\operatorname{At} \mathbf{g 0 2 0 2 0}$ & PTR4, PEPTIDE TRANSPORTER 4 \\
\hline At3g21630 & CERK1, CHITIN ELICITOR RECEPTOR KINASE 1 \\
\hline $\operatorname{At1g63120}$ & RBL2, RHOMBOID-LIKE 2 \\
\hline At5g52420 & PRCE3, PSI-INTERACTING ROOT-CELL ENRICHED 3 \\
\hline At3g13175 & PRCE1, PSI-INTERACTING ROOT-CELL ENRICHED 1 \\
\hline $\operatorname{At1g69870}$ & NRT1.7, NITRATE TRANSPORTER 1.7 \\
\hline At3g44930 & CHX10, CATION/H+ EXCHANGER 10 \\
\hline $\operatorname{At4g30360}$ & CNGC17, CYCLIC NUCLEOTIDE-GATED CHANNEL 17 \\
\hline $\operatorname{At1g12110}$ & NRT1.1, NITRATE TRANSPORTER 1.1 \\
\hline At3g25805 & UNKNOWN \\
\hline At4g21940 & CPK15, CALCIUM-DEPENDENT PROTEIN KINASE 15 \\
\hline At1g63110 & UNKNOWN \\
\hline $\operatorname{At1g11000}$ & MLO4, MILDEW RESISTANCE LOCUS O4 \\
\hline At3g54140 & PTR1, PEPTIDE TRANSPORTER 1 \\
\hline $\operatorname{At5g41800}$ & UNKNOWN \\
\hline At3g18800 & UNKNOWN \\
\hline $\operatorname{At1g50740}$ & Transmembrane protein 14C \\
\hline At3g26090 & RGS1, REGULATOR OF G PROTEIN SIGNALING 1 \\
\hline At4g04570 & CYSTEINE-RICH RLK (RECEPTOR-LIKE PROTEIN KINASE) 40 \\
\hline $\operatorname{At1g29060}$ & SFT12 \\
\hline At3g10640 & SNF7 family protein \\
\hline $\operatorname{At4g30850}$ & HHP2, HEPTAHELICAL TRANSMEMBRANE PROTEIN 2 \\
\hline At5g59650 & LRR, Leucine-rich repeat protein kinase family protein \\
\hline $\operatorname{At1g21240}$ & WAK3, WALL ASSOCIATED KINASE 3 \\
\hline $\operatorname{At1g47640}$ & UNKNOWN \\
\hline $\operatorname{At} 2 \mathrm{~g} 26180$ & IQD6, IQ-DOMAIN 6 \\
\hline At4g37680 & HHP4, HEPTAHELICAL TRANSMEMBRANE PROTEIN 4 \\
\hline
\end{tabular}




\section{Roles of P2K2 in eATP-triggered plant defense}

Plants recognize conserved molecular patterns derived from pathogens (i.e., pathogen-associated molecular patterns (PAMPs)) resulting in the activation of an innate immune response called PAMP-triggered immunity (PTI) (Jones and Dangl, 2006). These PAMPs are recognized by specific pattern recognition receptors (PRRs). In a similar manner, specific PRRs can also recognize molecules released from plants due to cellular damage, termed damage-associated molecular patterns (DAMPs) (Gust et al., 2017). The responses of plants to DAMPs are similar to PTI response (Yamaguchi and Huffaker, 2011). Consequently, plants trigger a variety of secondary intracellular events, such as increases in the concentration of cytosolic calcium and reactive oxygen species (ROS) and protein phosphorylation (e.g., MAPKs and CDPKs). As a result, various transcription factors (e.g., MYBs, MYCs and ZATs) are activated that contribute to pathogen resistance (Bigeard et al., 2015).

In both animals and plants, eATP is defined as a DAMP (Jacob et al., 2013; Choi et al., 2014; Tanaka et al., 2014; Tripathi and Tanaka, 2018). The eATP recognition by its receptors triggers very similar responses to well-characterized PAMPs (Choi et al., 2014; Chen et al., 2017). Indeed, given that PAMPs often cause the release of ATP, we have previously proposed that PTI response is, at least in plants, due to purinergic signaling (Choi et al., 2014).

It is now clear that both $\mathrm{P} 2 \mathrm{~K} 1$ and $\mathrm{P} 2 \mathrm{~K} 2$ contribute to the ability of ATP to induce plant immune responses. For example, $p 2 k 2$ T-DNA mutant plants show defects in the eATP-triggered increase in cytosolic calcium (Figures III.4 and III.5), MAPK activation 
(Figure III.27) and plant defense gene expression (Figure III.28). Our results also show that the $p 2 k 2$ mutant was more susceptible to the pathogen $P$. syringae than wild-type, while the $P 2 K 2$ overexpression line was more resistant (Figure III.24). An important role of $\mathrm{P} 2 \mathrm{~K} 2$ in the response to pathogen infection is consistent with findings that $P 2 K 2$ expression is strongly induced in response to exogenous ATP or P. syringae (via pathogen) inoculation (Figures III.25 and III.28). The induction of $P 2 K 2$ by $P$. syringae was previously reported (Balague et al., 2017). The data are consistent with a model in which P2K2, normally expressed at a low basal levels, is induced upon pathogen challenge (perhaps specifically due to eATP release) resulting in the formation and activation of heteromeric P2K1-P2K2 complex to activate downstream signaling cascades that regulate plant immunity.

\section{Open questions}

In contrast to animals, plants are rooted in the soil and, hence, immobile. Therefore, to survive, plants developed a sophisticated system to recognize and respond to environmental changes. The system provides mechanisms to both recognize a signal and translate it into the appropriate physiological response that enables the plant to grow, reproduce and survive in a changing and sometimes hostile environment. The type, duration and intensity of the signals are all critical for inducing the correct downstream responses.

While, in general, P2K1 and P2K2 display similar activities, slight differences could be physiologically relevant. For example, the P2K2 kinase domain shows consistently stronger kinase activity in our assays relative to the P2K1 kinase domain. As 
noted above, the P2K2 ectodomain shows greater specificity for ATP and ADP than P2K1 relative to other nucleotides. Jones et al. (2014) identified a much larger number of proteins predicted to interact with $\mathrm{P} 2 \mathrm{~K} 2$ than $\mathrm{P} 2 \mathrm{~K} 1$. Our unpublished work with proteins identified through interaction with $\mathrm{P} 2 \mathrm{~K} 1$ also supports the notion that these proteins interact with $\mathrm{P} 2 \mathrm{~K} 2$ more strongly than $\mathrm{P} 2 \mathrm{~K} 1$. Hence, $\mathrm{P} 2 \mathrm{~K} 1$ and $\mathrm{P} 2 \mathrm{~K} 2$ are not identical proteins, suggesting that $\mathrm{P} 2 \mathrm{~K} 2$ has the potential to have unique function or, capabilities upon P2K1-P2K2 complex fomation. However, all the data point to the fact that, under the conditions in our assays, P2K1 is the dominant eATP receptor.

There are many, still unresolved questions relevant to the mechanism of eATP signaling in plants, as well as the specific roles of $\mathrm{P} 2 \mathrm{~K} 1$ and $\mathrm{P} 2 \mathrm{~K} 2$. These include (in no order of importance):

1. What is the mechanism by which eATP recognition is coupled to an increase in cytoplasmic calcium levels? The data, although far from definitive, suggest that $\mathrm{P} 2 \mathrm{~K}$ receptors either directly or indirectly activate both plasma membrane and vacuolar calcium channels, but this remains to be identified.

2. What are the mechanisms that couple eATP recognition to the variety of downstream signaling events, including MAPK activation, NO and ROS production and induction of gene expression.

3. Are there additional eATP receptors in plants? Mammals have 15 such receptors (including P2X and P2Y) and, therefore, how can plants make do with only two?

4. To what extent does purinergic signaling explain the plant response to various biotic and abiotic stresses? In other words, does the release of ATP by stress 
completely explain how stress induces gene expression, as opposed to specialized pathways that recognize only a specific stress.

5. Clade I of the LecRLK family, which contains both P2K1 and P2K2, appears to be exclusive to the Brassicaceae. Therefore, do divergent plant species utilize receptors significantly different from P2K1 or do only a few, key amino acids found in the LecRLK ectodomains of other species define their ability to serve as purinergic receptors and, hence, make them hard to identify by sequence-based searches.

These questions make it clear that the study of purinergic signaling in plants is still in its infancy. However, the ever-expanding evidence that eATP is involved in a variety of important plant developmental and growth responses suggests that further investment in studies of purinergic signaling in plants is warranted. At present, there are relatively few laboratories worldwide exploring this interesting area of plant research. Hopefully, as more data and papers appear, other researchers will be attracted to this exciting and interesting area. 


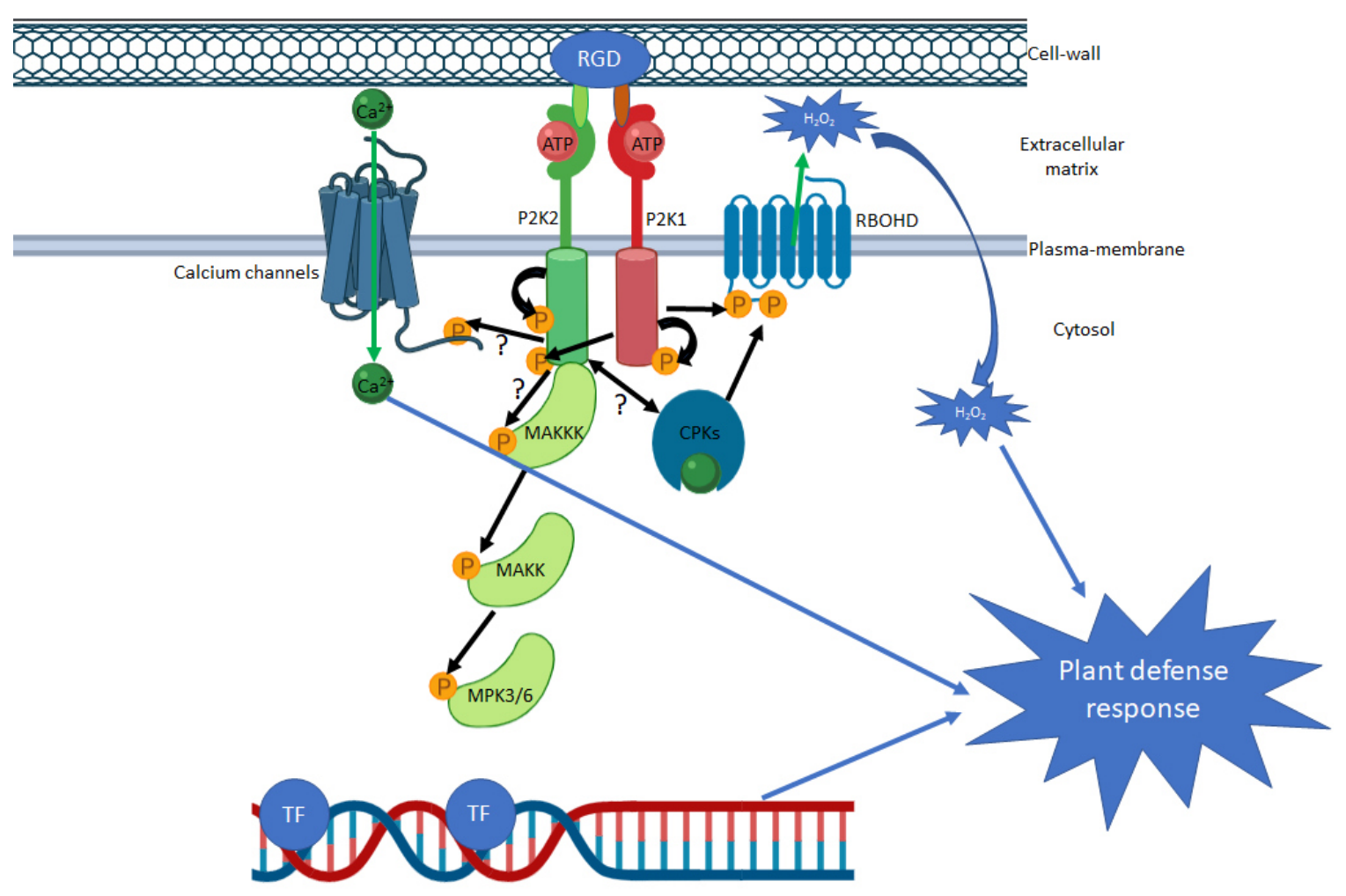

Figure IV.1: Model of P2K2 function, as a potential co-receptor of P2K1, in eATP perception and plant defense responses. In response to stress (e.g., bacterial infection), the eATP concentration increases. eATP is recognized by $\mathrm{P} 2 \mathrm{~K} 1$ and/or $\mathrm{P} 2 \mathrm{~K} 2$, which may form a heteromeric complex of $\mathrm{P} 2 \mathrm{~K} 1-\mathrm{P} 2 \mathrm{~K} 2$, a process that is enhanced by exogenous ATP. P2K1 and P2K2 can autophosphorylate, while P2K1 can trans-phosphorylate $\mathrm{P} 2 \mathrm{~K} 2$. As a result of eATP binding, RBOHD is phosphorylated and activated to generate ROS, thereby controlling the stomatal aperture, while also contributing to pathogen defense. ATP binding also activates calcium channels that raise intracellular calcium levels contributing to the cellular response. The MAPK cascade (MAKKK, MAKK and MPK3/6) and plant defense gene expression are induced by eATP through mechanisms that remain to be elucidated. The question marks indicate potential events that need further investigation. Calcium channels (potentially CNGCs) may directly interact with 
and be activated by $\mathrm{P} 2 \mathrm{~K}$ receptors upon eATP binding. P2K2 may interact with and phosphorylate downstream proteins to activate MAPK cascades or recruit cytosolic protein kinases (e.g., CPKs) to contribute to downstream signaling events. 


\section{Supplemental data}
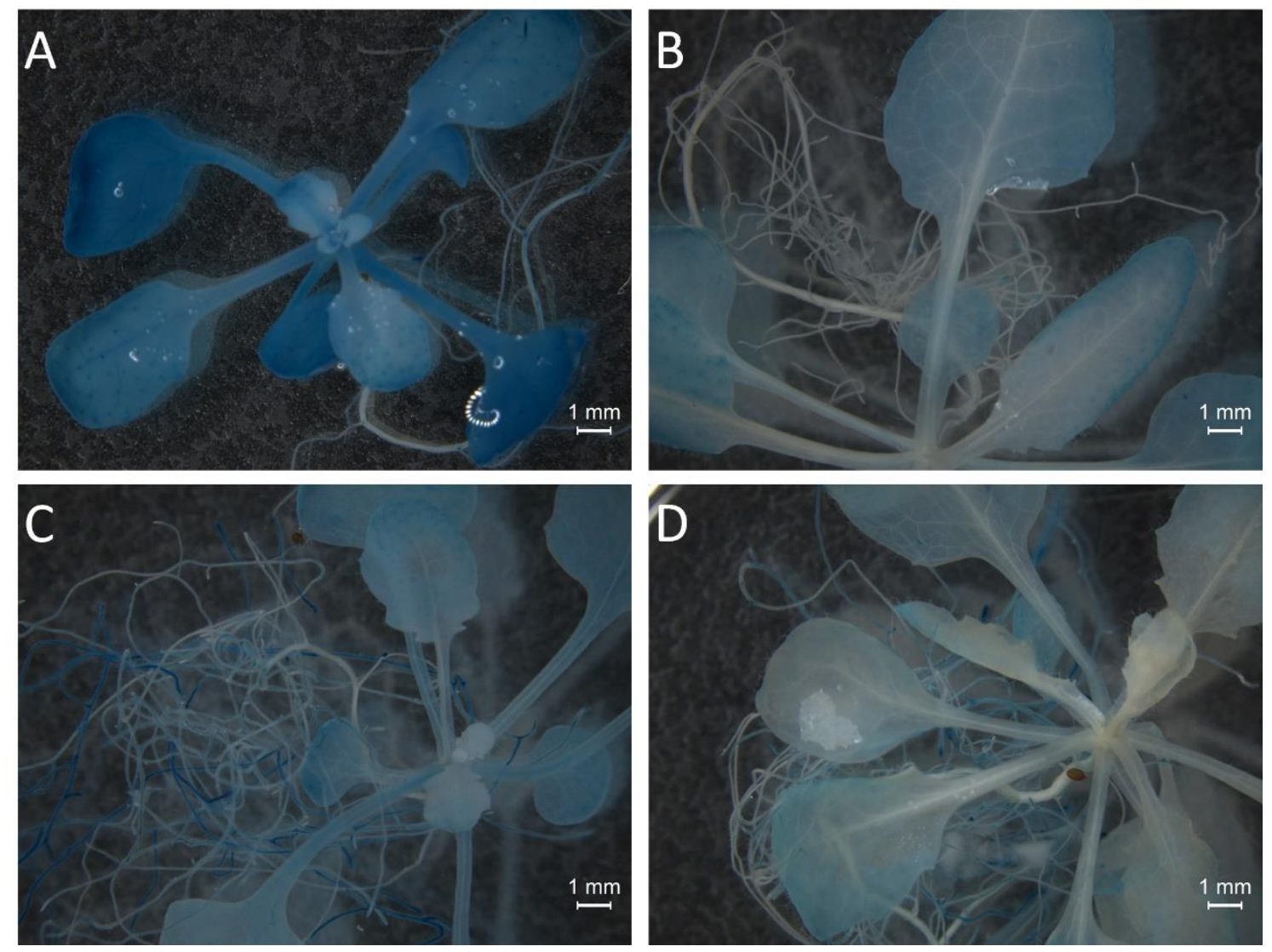

\section{Supplemental Figure S1: Gus staining assay showed $P 2 K 2$ promoter activity in}

whole plants. pP2K2:GUS transgenic plants were grown in $1 \frac{1}{2} \mathrm{MS}$ medium and collected after two weeks (A), three weeks (B), three weeks with 30-minute $200 \mu \mathrm{M}$ ATP treatment (C) or three weeks with 16-hour P. syringae DC3000 treatment (D). After overnight GUS staining, samples had been washed atleast three times with ethanol before being observed under a light microscope. Scale bar $=1 \mathrm{~mm}$. 

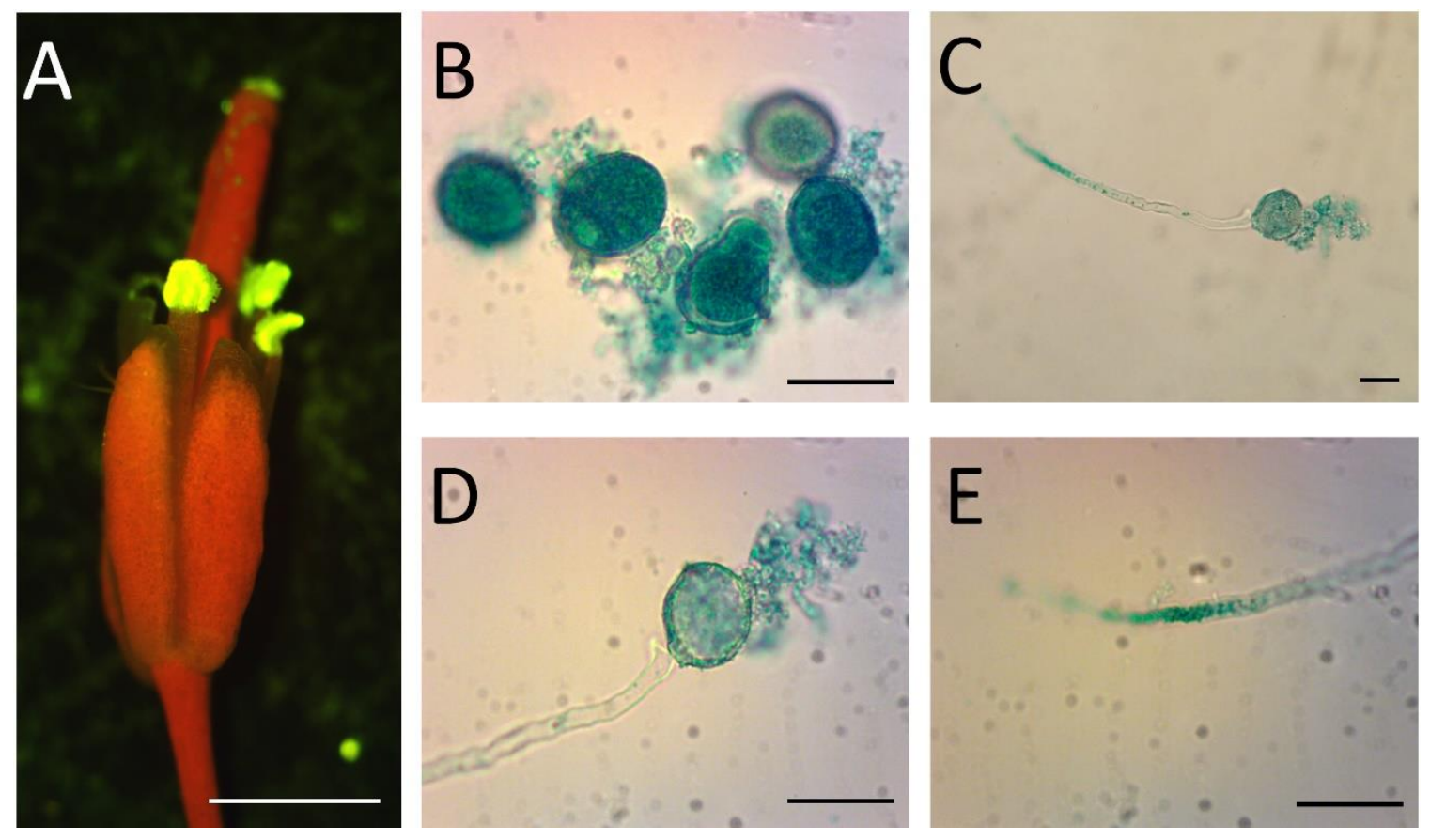

Supplemental Figure S2: P2K2 promoter activity in pollen. (A) A flower of pP2K2:GFP transgenic plant were observed under a flourescense microscope, Scale bar = $1 \mathrm{~mm}$. (B-E) Scale bar $=20 \mu \mathrm{m}$. Three to four-week-old pP2K2:GUS transgenic plants were used to collect pollen. The in vitro pollen germination method was described (Dickinson et al., 2018). (B) Ungerminated pollens. (C and D) Germinated pollen. (E) Germinated pollen tube tip. 


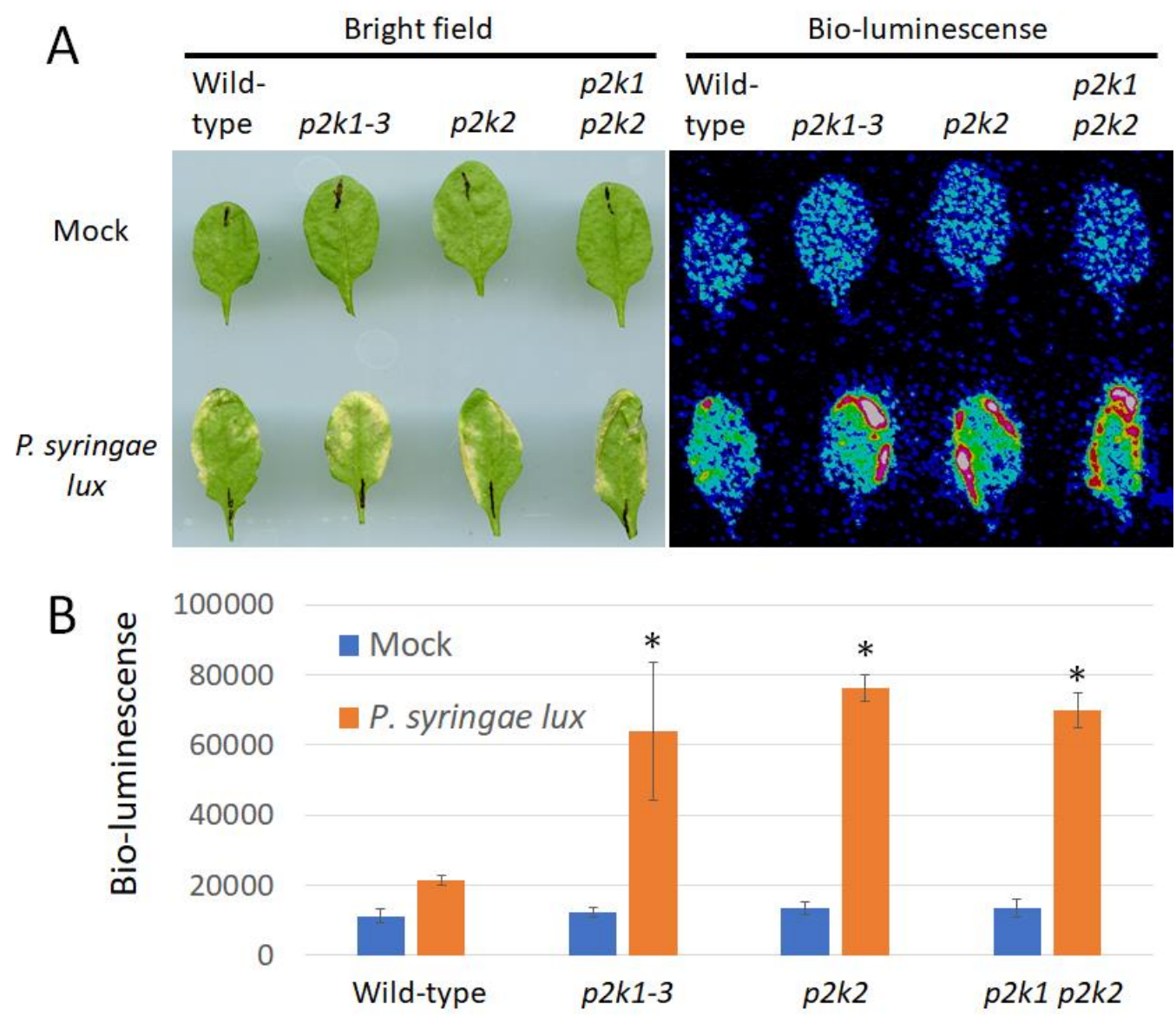

Supplemental Figure S3: Susceptibility of $p 2 k 1-3, p 2 k 2$ and $p 2 k 1 p 2 k 2$ to $P$. syringae in bacterial leaf infitration assay. Wild-type (a negative control) and $p 2 k 1-3$ (a positive control) were used to compare to $p 2 k 2$ and $p 2 k 1 p 2 k 2$. Three-week-old leaves were infiltrated P. syringae (OD $=0.0001$ in $\mathrm{MgCl}_{2} 10 \mathrm{mM}$ buffer) . (A) Bright-field photographs ware taken one day after inoculation using a normal camera while the bacteria invasion was detected using a CCD camera (the bio-luminescence panel). (B) Bacterial populations of $P$. syringae were detected and quantified by a CCD camera detecting bio-luminescense signals. The bars indicate the standard errors for 6 independent leaves. 


\section{BIBLIOGRAPHY}

Adar R, Sharon N (1996) Mutational studies of the amino acid residues in the combining site of Erythrina corallodendron lectin. European journal of biochemistry 239: 668-674

Ali R, Ma W, Lemtiri-Chlieh F, Tsaltas D, Leng Q, von Bodman S, Berkowitz GA (2007) Death don't have no mercy and neither does calcium: Arabidopsis CYCLIC NUCLEOTIDE GATED CHANNEL2 and innate immunity. The Plant cell 19: 1081-1095

Arnaud D, Desclos-Theveniau M, Zimmerli L (2012) Disease resistance to Pectobacterium carotovorum is negatively modulated by the Arabidopsis Lectin Receptor Kinase LecRK-V.5. Plant signaling \& behavior 7: 1070-1072

Balague C, Gouget A, Bouchez O, Souriac C, Haget N, Boutet-Mercey S, Govers F, Roby D, Canut H (2017) The Arabidopsis thaliana lectin receptor kinase LecRKI.9 is required for full resistance to Pseudomonas syringae and affects jasmonate signalling. Molecular plant pathology 18: 937-948

Bigeard J, Colcombet J, Hirt H (2015) Signaling mechanisms in pattern-triggered immunity (PTI). Molecular plant 8: 521-539

Bjorkgren I, Lishko PV (2016) Purinergic signaling in testes revealed. The Journal of general physiology 148: 207-211

Bouwmeester K, de Sain M, Weide R, Gouget A, Klamer S, Canut H, Govers F (2011) The lectin receptor kinase LecRK-I.9 is a novel Phytophthora resistance component and a potential host target for a RXLR effector. PLoS pathogens 7: e1001327

Bouwmeester K, Govers F (2009) Arabidopsis L-type lectin receptor kinases: phylogeny, classification, and expression profiles. Journal of experimental botany 60: $4383-4396$

Bouwmeester K, Han M, Blanco-Portales R, Song W, Weide R, Guo LY, van der Vossen EA, Govers F (2014) The Arabidopsis lectin receptor kinase LecRK-I.9 enhances resistance to Phytophthora infestans in Solanaceous plants. Plant biotechnology journal 12: 10-16

Bouwmeester K, Meijer HJ, Govers F (2011) At the Frontier; RXLR Effectors Crossing the Phytophthora-Host Interface. Frontiers in plant science 2: 75

Burkle L, Cedzich A, Dopke C, Stransky H, Okumoto S, Gillissen B, Kuhn C, Frommer WB (2003) Transport of cytokinins mediated by purine transporters of the PUP family expressed in phloem, hydathodes, and pollen of Arabidopsis. The Plant journal : for cell and molecular biology 34: 13-26

Burnstock G (1972) Purinergic nerves. Pharmacological reviews 24: 509-581 
Burnstock G (2018) Purine and purinergic receptors. Brain and Neuroscience Advances 2: 2398212818817494

Burnstock G, Dale N (2015) Purinergic signalling during development and ageing. Purinergic signalling 11: 277-305

Burnstock G, Verkhratsky A (2010) Long-term (trophic) purinergic signalling: purinoceptors control cell proliferation, differentiation and death. Cell death \& disease 1: e9

Cao Y, Li H, Pham AQ, Stacey G (2016) An Improved Transient Expression System Using Arabidopsis Protoplasts. Current protocols in plant biology 1: 285-291

Chang SJ, Tzeng CR, Lee YH, Tai CJ (2008) Extracellular ATP activates the $\mathrm{PLC} / \mathrm{PKC} / \mathrm{ERK}$ signaling pathway through the P2Y2 purinergic receptor leading to the induction of early growth response 1 expression and the inhibition of viability in human endometrial stromal cells. Cellular signalling 20: $1248-1255$

Chen D, Cao Y, Li H, Kim D, Ahsan N, Thelen J, Stacey G (2017) Extracellular ATP elicits DORN1-mediated RBOHD phosphorylation to regulate stomatal aperture. Nature communications 8: 2265

Chen H, Zou Y, Shang Y, Lin H, Wang Y, Cai R, Tang X, Zhou JM (2008) Firefly luciferase complementation imaging assay for protein-protein interactions in plants. Plant physiology 146: 368-376

Chiu TY, Christiansen K, Moreno I, Lao J, Loque D, Orellana A, Heazlewood JL, Clark G, Roux SJ (2012) AtAPY1 and AtAPY2 function as Golgi-localized nucleoside diphosphatases in Arabidopsis thaliana. Plant \& cell physiology 53: 1913-1925

Choi J, Tanaka K, Cao Y, Qi Y, Qiu J, Liang Y, Lee SY, Stacey G (2014) Identification of a plant receptor for extracellular ATP. Science 343: 290-294

Choi J, Tanaka K, Liang Y, Cao Y, Lee SY, Stacey G (2014) Extracellular ATP, a danger signal, is recognized by DORN1 in Arabidopsis. The Biochemical journal 463: $429-437$

Clark G, Wu M, Wat N, Onyirimba J, Pham T, Herz N, Ogoti J, Gomez D, Canales AA, Aranda G, Blizard M, Nyberg T, Terry A, Torres J, Wu J, Roux SJ (2010) Both the stimulation and inhibition of root hair growth induced by extracellular nucleotides in Arabidopsis are mediated by nitric oxide and reactive oxygen species. Plant molecular biology 74: 423-435

Davis AM, Hall A, Millar AJ, Darrah C, Davis SJ (2009) Protocol: Streamlined subprotocols for floral-dip transformation and selection of transformants in Arabidopsis thaliana. Plant Methods 5: 3

Demidchik V, Nichols C, Oliynyk M, Dark A, Glover BJ, Davies JM (2003) Is ATP a signaling agent in plants? Plant physiology 133: 456-461

Demidchik V, Shang Z, Shin R, Thompson E, Rubio L, Laohavisit A, Mortimer JC, Chivasa S, Slabas AR, Glover BJ, Schachtman DP, Shabala SN, Davies JM (2009) Plant extracellular ATP signalling by plasma membrane NADPH oxidase 
and $\mathrm{Ca} 2+$ channels. The Plant journal : for cell and molecular biology 58: 903913

Dennison KL, Spalding EP (2000) Glutamate-gated calcium fluxes in Arabidopsis. Plant physiology 124: 1511-1514

Desclos-Theveniau M, Arnaud D, Huang TY, Lin GJ, Chen WY, Lin YC, Zimmerli L (2012) The Arabidopsis lectin receptor kinase LecRK-V.5 represses stomatal immunity induced by Pseudomonas syringae pv. tomato DC3000. PLoS pathogens 8: e1002513

Di Virgilio F, Adinolfi E (2017) Extracellular purines, purinergic receptors and tumor growth. Oncogene 36: 293-303

Dickinson H, Rodriguez-Enriquez J, Grant-Downton R (2018) Pollen Germination and Pollen Tube Growth of Arabidopsis thaliana: In vitro and Semi in vivo Methods. Bio-protocol 8: e2977

Dietrich P, Anschütz U, Kugler A, Becker D (2010) Physiology and biophysics of plant ligand-gated ion channels. Plant Biology 12: 80-93

Dubiella U, Seybold H, Durian G, Komander E, Lassig R, Witte CP, Schulze WX, Romeis T (2013) Calcium-dependent protein kinase/NADPH oxidase activation circuit is required for rapid defense signal propagation. Proceedings of the National Academy of Sciences of the United States of America 110: 8744-8749

Eltzschig HK, Sitkovsky MV, Robson SC (2012) Purinergic signaling during inflammation. The New England journal of medicine 367: 2322-2333

Eltzschig HK, Sitkovsky MV, Robson SC (2013) Purinergic signaling during inflammation. The New England journal of medicine 368: 1260

Erb L, Weisman GA (2012) Coupling of P2Y receptors to G proteins and other signaling pathways. Wiley interdisciplinary reviews. Membrane transport and signaling 1: 789-803

Fan J, Crooks C, Lamb C (2008) High-throughput quantitative luminescence assay of the growth in planta of Pseudomonas syringae chromosomally tagged with Photorhabdus luminescens luxCDABE. The Plant journal : for cell and molecular biology 53: 393-399

Fitz JG (2007) Regulation of cellular ATP release. Transactions of the American Clinical and Climatological Association 118: 199-208

Forde BG, Roberts MR (2014) Glutamate receptor-like channels in plants: a role as amino acid sensors in plant defence? F1000prime reports 6: 37

Fountain SJ, Cao L, Young MT, North RA (2008) Permeation properties of a P2X receptor in the green algae Ostreococcus tauri. The Journal of biological chemistry 283: $15122-15126$

Fountain SJ, Parkinson K, Young MT, Cao L, Thompson CR, North RA (2007) An intracellular P2X receptor required for osmoregulation in Dictyostelium discoideum. Nature 448: 200-203 
Frietsch S, Wang YF, Sladek C, Poulsen LR, Romanowsky SM, Schroeder JI, Harper JF (2007) A cyclic nucleotide-gated channel is essential for polarized tip growth of pollen. Proceedings of the National Academy of Sciences of the United States of America 104: 14531-14536

Gillissen B, Burkle L, Andre B, Kuhn C, Rentsch D, Brandl B, Frommer WB (2000) A new family of high-affinity transporters for adenine, cytosine, and purine derivatives in Arabidopsis. The Plant cell 12: 291-300

Gouget A, Senchou V, Govers F, Sanson A, Barre A, Rouge P, Pont-Lezica R, Canut $\mathbf{H}$ (2006) Lectin receptor kinases participate in protein-protein interactions to mediate plasma membrane-cell wall adhesions in Arabidopsis. Plant physiology 140: $81-90$

Gouhier-Darimont C, Stahl E, Glauser G, Reymond P (2019) The Arabidopsis Lectin Receptor Kinase LecRK-I.8 Is Involved in Insect Egg Perception. Frontiers in plant science 10: 623

Gust AA, Pruitt R, Nurnberger T (2017) Sensing Danger: Key to Activating Plant Immunity. Trends in plant science 22: 779-791

He XJ, Zhang ZG, Yan DQ, Zhang JS, Chen SY (2004) A salt-responsive receptorlike kinase gene regulated by the ethylene signaling pathway encodes a plasma membrane serine/threonine kinase. TAG. Theoretical and applied genetics. Theoretische und angewandte Genetik 109: 377-383

Hofberger JA, Nsibo DL, Govers F, Bouwmeester K, Schranz ME (2015) A complex interplay of tandem- and whole-genome duplication drives expansion of the Ltype lectin receptor kinase gene family in the brassicaceae. Genome biology and evolution 7: 720-734

Hollmann M, Heinemann S (1994) Cloned glutamate receptors. Annual review of neuroscience 17: 31-108

Hollmann M, O'Shea-Greenfield A, Rogers SW, Heinemann S (1989) Cloning by functional expression of a member of the glutamate receptor family. Nature 342: 643-648

Hua BG, Mercier RW, Leng Q, Berkowitz GA (2003) Plants do it differently. A new basis for potassium/sodium selectivity in the pore of an ion channel. Plant physiology 132: 1353-1361

Huang P, Ju HW, Min JH, Zhang X, Kim SH, Yang KY, Kim CS (2013) Overexpression of L-type lectin-like protein kinase 1 confers pathogen resistance and regulates salinity response in Arabidopsis thaliana. Plant science : an international journal of experimental plant biology 203-204: 98-106

Huang PY, Yeh YH, Liu AC, Cheng CP, Zimmerli L (2014) The Arabidopsis LecRKVI.2 associates with the pattern-recognition receptor FLS2 and primes Nicotiana benthamiana pattern-triggered immunity. The Plant journal : for cell and molecular biology 79: 243-255 
Ishiga Y, Ishiga T, Uppalapati SR, Mysore KS (2011) Arabidopsis seedling floodinoculation technique: a rapid and reliable assay for studying plant-bacterial interactions. Plant Methods 7: 32

Jacob F, Perez Novo C, Bachert C, Van Crombruggen K (2013) Purinergic signaling in inflammatory cells: P2 receptor expression, functional effects, and modulation of inflammatory responses. Purinergic signalling 9: 285-306

Jaffe MJ (1973) The Role of ATP in Mechanically Stimulated Rapid Closure of the Venus's Flytrap. Plant physiology 51: 17-18

Jeter CR, Tang W, Henaff E, Butterfield T, Roux SJ (2004) Evidence of a novel cell signaling role for extracellular adenosine triphosphates and diphosphates in Arabidopsis. The Plant cell 16: 2652-2664

Jones AM, Xuan Y, Xu M, Wang RS, Ho CH, Lalonde S, You CH, Sardi MI, Parsa SA, Smith-Valle E, Su T, Frazer KA, Pilot G, Pratelli R, Grossmann G, Acharya BR, Hu HC, Engineer C, Villiers F, Ju C, Takeda K, Su Z, Dong Q, Assmann SM, Chen J, Kwak JM, Schroeder JI, Albert R, Rhee SY, Frommer WB (2014) Border control--a membrane-linked interactome of Arabidopsis. Science 344: 711-716

Jones JD, Dangl JL (2006) The plant immune system. Nature 444: 323-329

Jung B, Florchinger M, Kunz HH, Traub M, Wartenberg R, Jeblick W, Neuhaus HE, Mohlmann T (2009) Uridine-ribohydrolase is a key regulator in the uridine degradation pathway of Arabidopsis. The Plant cell 21: 876-891

Jung B, Hoffmann C, Mohlmann T (2011) Arabidopsis nucleoside hydrolases involved in intracellular and extracellular degradation of purines. The Plant journal : for cell and molecular biology 65: 703-711

Kadota Y, Sklenar J, Derbyshire P, Stransfeld L, Asai S, Ntoukakis V, Jones JD, Shirasu K, Menke F, Jones A, Zipfel C (2014) Direct regulation of the NADPH oxidase RBOHD by the PRR-associated kinase BIK1 during plant immunity. Molecular cell 54: 43-55

Kawate T, Michel JC, Birdsong WT, Gouaux E (2009) Crystal structure of the ATPgated P2X(4) ion channel in the closed state. Nature 460: 592-598

Khakh BS, Burnstock G (2009) The double life of ATP. Scientific American 301: 8490, 92

Kim SY, Sivaguru M, Stacey G (2006) Extracellular ATP in plants. Visualization, localization, and analysis of physiological significance in growth and signaling. Plant physiology 142: 984-992

Klusener B, Young JJ, Murata Y, Allen GJ, Mori IC, Hugouvieux V, Schroeder JI (2002) Convergence of calcium signaling pathways of pathogenic elicitors and abscisic acid in Arabidopsis guard cells. Plant physiology 130: 2152-2163

Kudla J, Batistic O, Hashimoto K (2010) Calcium signals: the lead currency of plant information processing. The Plant cell 22: 541-563 
Lacombe B, Becker D, Hedrich R, DeSalle R, Hollmann M, Kwak JM, Schroeder JI, Le Novere N, Nam HG, Spalding EP, Tester M, Turano FJ, Chiu J, Coruzzi G (2001) The identity of plant glutamate receptors. Science 292: 1486-1487

Letunic I, Doerks T, Bork P (2015) SMART: recent updates, new developments and status in 2015. Nucleic acids research 43: D257-260

Lew RR, Dearnaley JDW (2000) Extracellular nucleotide effects on the electrical properties of growing Arabidopsis thaliana root hairs. Plant Science 153: 1-6

Li X (2011) Infiltration of Nicotiana benthamiana Protocol for Transient Expression via Agrobacterium. Bio-protocol 1: e95

Li Z, Chakraborty S, Xu G (2016) X-ray crystallographic studies of the extracellular domain of the first plant ATP receptor, DORN1, and the orthologous protein from Camelina sativa. Acta crystallographica. Section F, Structural biology communications 72: 782-787

Liang C, Tian J, Lam HM, Lim BL, Yan X, Liao H (2010) Biochemical and molecular characterization of PvPAP3, a novel purple acid phosphatase isolated from common bean enhancing extracellular ATP utilization. Plant physiology 152: $854-865$

Loomis WH, Namiki S, Ostrom RS, Insel PA, Junger WG (2003) Hypertonic stress increases T cell interleukin-2 expression through a mechanism that involves ATP release, $\mathrm{P} 2$ receptor, and $\mathrm{p} 38$ MAPK activation. The Journal of biological chemistry 278: $4590-4596$

Luo X, Xu N, Huang J, Gao F, Zou H, Boudsocq M, Coaker G, Liu J (2017) A Lectin Receptor-Like Kinase Mediates Pattern-Triggered Salicylic Acid Signaling. Plant physiology 174: 2501-2514

Luttge U, Schouch EV, Ball E (1974) Can Externally Applied Atp Supply Energy to Active Ion Uptake Mechanisms of Intact Plant Cells? Functional Plant Biology 1: 211-220

Maksaev G, Haswell ES (2012) MscS-Like10 is a stretch-activated ion channel from Arabidopsis thaliana with a preference for anions. Proceedings of the National Academy of Sciences of the United States of America 109: 19015-19020

Michard E, Lima PT, Borges F, Silva AC, Portes MT, Carvalho JE, Gilliham M, Liu LH, Obermeyer G, Feijo JA (2011) Glutamate receptor-like genes form $\mathrm{Ca} 2+$ channels in pollen tubes and are regulated by pistil D-serine. Science 332: 434-437

Mithofer A, Mazars C (2002) Aequorin-based measurements of intracellular Ca2+signatures in plant cells. Biological procedures online 4: 105-118

Monshausen GB, Bibikova TN, Weisenseel MH, Gilroy S (2009) Ca2+ regulates reactive oxygen species production and $\mathrm{pH}$ during mechanosensing in Arabidopsis roots. The Plant cell 21: 2341-2356 
Moore RC, Purugganan MD (2003) The early stages of duplicate gene evolution. Proceedings of the National Academy of Sciences of the United States of America 100: $15682-15687$

Moreira D, López-García P (2011) Paralogous Gene. In M Gargaud, R Amils, JC Quintanilla, HJ Cleaves, WM Irvine, DL Pinti, M Viso, eds, Encyclopedia of Astrobiology. Springer Berlin Heidelberg, Berlin, Heidelberg, pp 1215-1215

Mori K, Renhu N, Naito M, Nakamura A, Shiba H, Yamamoto T, Suzaki T, Iida H, Miura K (2018) Ca(2+)-permeable mechanosensitive channels MCA1 and MCA2 mediate cold-induced cytosolic $\mathrm{Ca}(2+)$ increase and cold tolerance in Arabidopsis. Scientific reports 8: 550

Mou Z (2017) Extracellular pyridine nucleotides as immune elicitors in arabidopsis. Plant signaling \& behavior 12: e1388977

Nguyen CT, Tanaka K, Cao Y, Cho SH, Xu D, Stacey G (2016) Computational Analysis of the Ligand Binding Site of the Extracellular ATP Receptor, DORN1. PloS one 11: e0161894

Nicke A, Baumert HG, Rettinger J, Eichele A, Lambrecht G, Mutschler E, Schmalzing G (1998) P2X1 and P2X3 receptors form stable trimers: a novel structural motif of ligand-gated ion channels. The EMBO journal 17: 3016-3028

Pei ZM, Murata Y, Benning G, Thomine S, Klusener B, Allen GJ, Grill E, Schroeder JI (2000) Calcium channels activated by hydrogen peroxide mediate abscisic acid signalling in guard cells. Nature 406: 731-734

Peiter E, Maathuis FJM, Mills LN, Knight H, Pelloux J, Hetherington AM, Sanders D (2005) The vacuolar Ca2+-activated channel TPC1 regulates germination and stomatal movement. Nature 434: 404-408

Pubill D, Dayanithi G, Siatka C, Andres M, Dufour MN, Guillon G, Mendre C (2001) ATP induces intracellular calcium increases and actin cytoskeleton disaggregation via P2x receptors. Cell calcium 29: 299-309

Reichler SA, Torres J, Rivera AL, Cintolesi VA, Clark G, Roux SJ (2009) Intersection of two signalling pathways: extracellular nucleotides regulate pollen germination and pollen tube growth via nitric oxide. Journal of experimental botany 60: 2129-2138

Reimer RJ (2013) SLC17: a functionally diverse family of organic anion transporters. Molecular aspects of medicine 34: 350-359

Rieder B, Neuhaus HE (2011) Identification of an Arabidopsis plasma membranelocated ATP transporter important for anther development. The Plant cell 23: 1932-1944

Ries S, Savithiry S, Wert V, Widders I (1993) Rapid Induction of Ion Pulses in Tomato, Cucumber, and Maize Plants following a Foliar Application of L(+)Adenosine. Plant physiology 101: 49-55

Riewe D, Grosman L, Fernie AR, Zauber H, Wucke C, Geigenberger P (2008) A Cell Wall-Bound Adenosine Nucleosidase is Involved in the Salvage of 
Extracellular ATP in Solanum tuberosum. Plant and Cell Physiology 49: 15721579

Ruiz-Pavon L, Karlsson PM, Carlsson J, Samyn D, Persson B, Persson BL, Spetea C (2010) Functionally important amino acids in the Arabidopsis thylakoid phosphate transporter: homology modeling and site-directed mutagenesis. Biochemistry 49: 6430-6439

Sawada K, Echigo N, Juge N, Miyaji T, Otsuka M, Omote H, Yamamoto A, Moriyama Y (2008) Identification of a vesicular nucleotide transporter. Proceedings of the National Academy of Sciences of the United States of America 105: $5683-5686$

Schmid M, Davison TS, Henz SR, Pape UJ, Demar M, Vingron M, Scholkopf B, Weigel D, Lohmann JU (2005) A gene expression map of Arabidopsis thaliana development. Nature genetics 37: 501-506

Sharon N (2007) Lectins: carbohydrate-specific reagents and biological recognition molecules. The Journal of biological chemistry 282: 2753-2764

Shiu SH, Bleecker AB (2003) Expansion of the receptor-like kinase/Pelle gene family and receptor-like proteins in Arabidopsis. Plant physiology 132: 530-543

Singh P, Chien CC, Mishra S, Tsai CH, Zimmerli L (2013) The Arabidopsis LECTIN RECEPTOR KINASE-VI.2 is a functional protein kinase and is dispensable for basal resistance to Botrytis cinerea. Plant signaling \& behavior 8: e22611

Singh P, Kuo YC, Mishra S, Tsai CH, Chien CC, Chen CW, Desclos-Theveniau M, Chu PW, Schulze B, Chinchilla D, Boller T, Zimmerli L (2012) The lectin receptor kinase-VI.2 is required for priming and positively regulates Arabidopsis pattern-triggered immunity. The Plant cell 24: 1256-1270

Song CJ, Steinebrunner I, Wang X, Stout SC, Roux SJ (2006) Extracellular ATP induces the accumulation of superoxide via NADPH oxidases in Arabidopsis. Plant physiology 140: 1222-1232

Stael S, Wurzinger B, Mair A, Mehlmer N, Vothknecht UC, Teige M (2012) Plant organellar calcium signalling: an emerging field. Journal of experimental botany 63: $1525-1542$

Steinebrunner I, Wu J, Sun Y, Corbett A, Roux SJ (2003) Disruption of apyrases inhibits pollen germination in Arabidopsis. Plant physiology 131: 1638-1647

Swarbreck SM, Colaco R, Davies JM (2013) Plant calcium-permeable channels. Plant physiology 163: 514-522

Tanaka K, Choi J, Cao Y, Stacey G (2014) Extracellular ATP acts as a damageassociated molecular pattern (DAMP) signal in plants. Frontiers in plant science 5: 446

Tanaka K, Gilroy S, Jones AM, Stacey G (2010) Extracellular ATP signaling in plants. Trends in cell biology 20: 601-608 
Tanaka K, Swanson SJ, Gilroy S, Stacey G (2010) Extracellular nucleotides elicit cytosolic free calcium oscillations in Arabidopsis. Plant physiology 154: 705-719

Tang W, Brady SR, Sun Y, Muday GK, Roux SJ (2003) Extracellular ATP inhibits root gravitropism at concentrations that inhibit polar auxin transport. Plant physiology 131: 147-154

Theobald DL (2010) A formal test of the theory of universal common ancestry. Nature 465: $219-222$

Thomas C, Rajagopal A, Windsor B, Dudler R, Lloyd A, Roux SJ (2000) A role for ectophosphatase in xenobiotic resistance. The Plant cell 12: 519-533

Thomas C, Sun Y, Naus K, Lloyd A, Roux S (1999) Apyrase functions in plant phosphate nutrition and mobilizes phosphate from extracellular ATP. Plant physiology 119: 543-552

Tovell VE, Sanderson J (2008) Distinct P2Y receptor subtypes regulate calcium signaling in human retinal pigment epithelial cells. Investigative ophthalmology \& visual science 49: 350-357

Traub M, Florchinger M, Piecuch J, Kunz HH, Weise-Steinmetz A, Deitmer JW, Ekkehard Neuhaus H, Mohlmann T (2007) The fluorouridine insensitive 1 (fur1) mutant is defective in equilibrative nucleoside transporter 3 (ENT3), and thus represents an important pyrimidine nucleoside uptake system in Arabidopsis thaliana. The Plant journal : for cell and molecular biology 49: 855-864

Tripathi D, Tanaka K (2018) A crosstalk between extracellular ATP and jasmonate signaling pathways for plant defense. Plant signaling \& behavior 13: e1432229

Tripathi D, Zhang T, Koo AJ, Stacey G, Tanaka K (2018) Extracellular ATP Acts on Jasmonate Signaling to Reinforce Plant Defense. Plant physiology 176: 511-523

Udvardy J, Farkas GL (1973) ATP stimulates the formation of nucleases in excised Avena leaves. Zeitschrift für Pflanzenphysiologie 69: 394-401

Veley KM, Marshburn S, Clure CE, Haswell ES (2012) Mechanosensitive channels protect plastids from hypoosmotic stress during normal plant growth. Current biology : CB 22: 408-413

Virginio C, Robertson G, Surprenant A, North RA (1998) Trinitrophenyl-substituted nucleotides are potent antagonists selective for P2X1, P2X3, and heteromeric $\mathrm{P} 2 \mathrm{X} 2 / 3$ receptors. Molecular pharmacology 53: 969-973

Wang C, Zhou M, Zhang X, Yao J, Zhang Y, Mou Z (2017) A lectin receptor kinase as a potential sensor for extracellular nicotinamide adenine dinucleotide in Arabidopsis thaliana. eLife 6

Wang L, Wilkins KA, Davies JM (2018) Arabidopsis DORN1 extracellular ATP receptor; activation of plasma membrane $\mathrm{K}(+)$-and $\mathrm{Ca}(2+)$-permeable conductances. The New phytologist 218: 1301-1304

Wang Y, Bouwmeester K (2017) L-type lectin receptor kinases: New forces in plant immunity. PLoS pathogens 13: e1006433 
Wang Y, Bouwmeester K, Beseh P, Shan W, Govers F (2014) Phenotypic analyses of Arabidopsis T-DNA insertion lines and expression profiling reveal that multiple L-type lectin receptor kinases are involved in plant immunity. Molecular plantmicrobe interactions : MPMI 27: 1390-1402

Wang Y, Cordewener JH, America AH, Shan W, Bouwmeester K, Govers F (2015) Arabidopsis Lectin Receptor Kinases LecRK-IX.1 and LecRK-IX.2 Are Functional Analogs in Regulating Phytophthora Resistance and Plant Cell Death. Molecular plant-microbe interactions : MPMI 28: 1032-1048

Wang Y, Nsibo DL, Juhar HM, Govers F, Bouwmeester K (2016) Ectopic expression of Arabidopsis L-type lectin receptor kinase genes LecRK-I.9 and LecRK-IX.1 in Nicotiana benthamiana confers Phytophthora resistance. Plant cell reports 35: 845-855

Weerasinghe RR, Swanson SJ, Okada SF, Garrett MB, Kim SY, Stacey G, Boucher RC, Gilroy S, Jones AM (2009) Touch induces ATP release in Arabidopsis roots that is modulated by the heterotrimeric G-protein complex. FEBS letters 583: $2521-2526$

Winter D, Vinegar B, Nahal H, Ammar R, Wilson GV, Provart NJ (2007) An "Electronic Fluorescent Pictograph" browser for exploring and analyzing largescale biological data sets. PloS one 2: e718

Wu SJ, Liu YS, Wu JY (2008) The signaling role of extracellular ATP and its dependence on $\mathrm{Ca} 2+$ flux in elicitation of Salvia miltiorrhiza hairy root cultures. Plant \& cell physiology 49: 617-624

Wu SJ, Wu JY (2008) Extracellular ATP-induced NO production and its dependence on membrane $\mathrm{Ca} 2+$ flux in Salvia miltiorrhiza hairy roots. Journal of experimental botany 59: 4007-4016

Xin Z, Wang A, Yang G, Gao P, Zheng ZL (2009) The Arabidopsis A4 subfamily of lectin receptor kinases negatively regulates abscisic acid response in seed germination. Plant physiology 149: 434-444

Yamaguchi Y, Huffaker A (2011) Endogenous peptide elicitors in higher plants. Current opinion in plant biology 14: 351-357

Yekondi S, Liang FC, Okuma E, Radziejwoski A, Mai HW, Swain S, Singh P, Gauthier M, Chien HC, Murata Y, Zimmerli L (2018) Nonredundant functions of Arabidopsis LecRK-V.2 and LecRK-VII.1 in controlling stomatal immunity and jasmonate-mediated stomatal closure. The New phytologist 218: 253-268 


\section{VITA}

An Q. Pham was born October $17^{\text {th }}, 1989$, in Can Tho city, Vietnam. He received his Bachelor of Science degree in Biotechnology from the University of Sciences, Ho Chi Minh city, Vietnam. After graduation in 2011, he started to work as a research assistant in the Center for Molecular Biomedicine, University of Medicine and Pharmacy, Ho Chi Minh city, Vietnam. In 2013, An Pham received the Vietnam Education Foundation fellowships from USA goverment for Ph.D. He started his Ph.D. program in plant sciences at the University of Missouri - Columbia, USA with Dr. Gary Stacey. 